\author{
UnB - UNIVERSIDADE DE BRASÍLIA \\ FGA - FACULDADE GAMA \\ PROGRAMA DE PÓS-GRADUAÇÃO EM ENGENHARIA \\ BIOMÉDICA
}

\title{
ONTO-MAMA-NM: UM MODELO ONTOLÓGICO DE TRATAMENTO DE NEOPLASIA MAMÁRIA
}

HENDERSON MATSUURA SANCHES

ORIENTADORA: Dra. LOURDES MATTOS BRASIL COORIENTADORA: Dra. LIANA B. GOMIDE MATHEUS

DISSERTAÇÃO DE MESTRADO EM ENGENHARIA BIOMÉDICA

PUBLICAÇÃO: 065A/2017

BRASÍLIA/DF: FEVEREIRO - 2017 
UNIVERSIDADE DE BRASÍLIA

FACULDADE UNB GAMA

ENGENHARIA BIOMÉDICA

\section{ONTO-MAMA-NM: UM MODELO ONTOLÓGICO DE TRATAMENTO DE NEOPLASIA MAMÁRIA}

\section{HENDERSON MATSUURA SANCHES}

DISSERTAÇÃO DE MESTRADO SUBMETIDA À FACULDADE UNB GAMA DA UNIVERSIDADE DE BRASÍLIA, COMO PARTE DOS REQUISITOS NECESSÁRIOS PARA A OBTENÇÃO DO TÍTULO DE MESTRE EM ENGENHARIA BIOMÉDICA.

APROVADA POR:

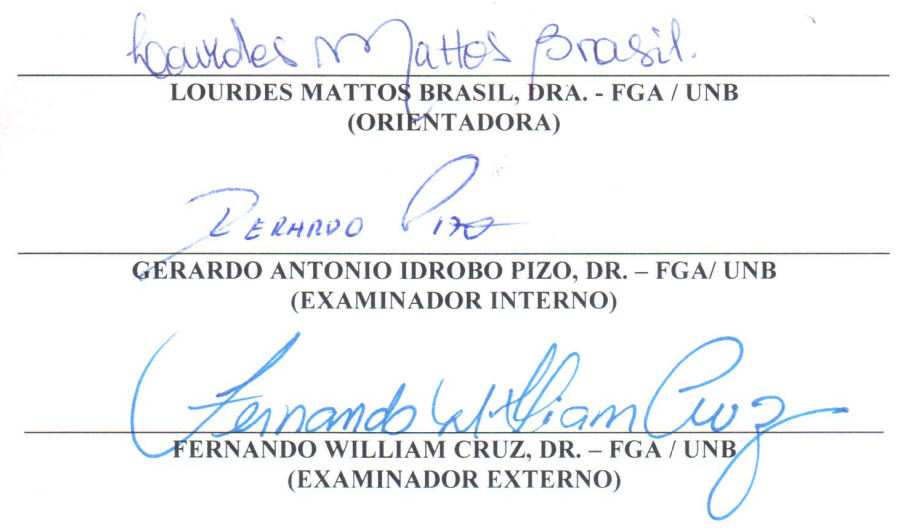

BRASÍLIA, 23 DE FEVEREIRO DE 2017 
BRASÍLIA/DF, 23 DE FEVEREIRO DE 2017.

FICHA CATALOGRÁFICA

HENDERSON MATSUURA SANCHES 
ONTO-MAMA-NM: UM MODELO ONTOLÓGICO DE TRATAMENTO DE NEOPLASIA MAMÁRIA, [Distrito Federal] 2017.

97.p., 210 x 297 mm (FGA/UnB Gama, Mestre, Engenharia Biomédica, 2017). Dissertação de Mestrado - Universidade de Brasília. Faculdade Gama. Programa de Pós-Graduação em Engenharia Biomédica.

1. Ontologia 2. Neoplasia Mamária

3. Methontology 4. OWL

I. FGA UnB Gama/ UnB. $\quad$ II. Título (série)

\section{REFERÊNCIA BIBLIOGRÁFICA}

SANCHES, H. M. (2017). ONTO-MAMA-NM: UM MODELO ONTOLÓGICO DE TRATAMENTO DE NEOPLASIA MAMÁRIA. Dissertação de Mestrado em Engenharia Biomédica, Publicação 065A/2017, Programa de Pós-Graduação em Engenharia Biomédica, Faculdade Gama, Universidade de Brasília, Brasília, DF, 97.p.

\section{CESSÃO DE DIREITOS}

AUTOR: HENDERSON MATSUURA SANCHES

TÍTULO: ONTO-MAMA-NM: UM MODELO ONTOLÓGICO DE TRATAMENTO DE NEOPLASIA MAMÁRIA

GRAU: Mestre

ANO: 2017

É concedida à Universidade de Brasília permissão para reproduzir cópias desta dissertação de mestrado e para emprestar ou vender tais cópias somente para propósitos acadêmicos e científicos. $\mathrm{O}$ autor reserva outros direitos de publicação e nenhuma parte desta dissertação de mestrado pode ser reproduzida sem a autorização por escrito do autor.

HENDERSON MATSUURA SANCHES

2017

ENDEREÇO: Q. 02, Conj. D, Casa 122, Setor Norte - Gama - DF

CEP 72430-204, Brasília, DF - Brasil. 
DEDICATÓRIA

Aos meus pais Marcus Sanches e Amelia Matsuura Sanches. 


\section{AGRADECIMENTOS}

Agradeço primeiramente a Deus pela vida, força e saúde para conclusão de mais um sonho em minha vida.

À minha família pela compreensão, principalmente meu pai e minha mãe que sempre me apoiaram, pelo carinho e cuidado comigo, e a todos que me ajudaram nessa jornada acadêmica.

Aos professores do curso, pelos estímulos nas disciplinas e desenvolvimento deste projeto, especificamente aos meus orientadores: a Profa. Dra. Lourdes Mattos Brasil e Profa. Dra. Liana Barbaresco Gomide Matheus pela exigência e explanações para aperfeiçoamento deste trabalho.

À equipe do projeto do câncer de mama, em especial aos colegas Maria Tereza e Daniel Braga.

Aos meus amigos que me auxiliaram em vários aspectos para o desenvolvimento das atividades desse projeto: Daniel Braga, Roberto Aguiar e João Paulo. E, especificamente, a Patrycia Klavidianos, pela paciência e ajuda nas inúmeras dúvidas.

Aos meus amigos das comunidades software livre de Brasília e do Brasil, como a Comunidade LibreOffice Brasil e demais comunidades pelos incentivos: Eliane Domingos, Valdir Barbosa, Klaibson Ribeiro, George Mendonça, Guilherme Razgriz. 


\title{
RESUMO
}

\section{ONTO-MAMA-NM: UM MODELO ONTOLÓGICO DE TRATAMENTO DE NEOPLASIA MAMÁRIA}

\author{
Autor: HENDERSON MATSUURA SANCHES \\ Orientador: Profa. Dra ${ }^{\text {a }}$ Lourdes Mattos Brasil \\ Coorientador: Profa. Dra . Liana B. Gomide Matheus \\ Programa de Pós-Graduação em Engenharia Biomédica \\ Brasília, Fevereiro de 2017.
}

O objetivo desse trabalho foi a construção de um modelo ontológico da Neoplasia Mamária (NM) denominado ONTO-MAMA-NM. Esse modelo é uma ferramenta importante para auxiliar especialistas e estudantes da área da saúde no tratamento do câncer de mama. O modelo ontológico foi criado na linguagem Web Ontology Language (OWL), cuja principal vantagem é a facilidade para expressar significados e semântica e aplicabilidade no processo de informações de forma automatizada. Por se tratar de um modelo aplicado à área médica, o ONTO-MANA-NM procura manter a compatibilidade com os padrões Digital Imaging and Communications in Medicine (DICOM) e Health Level Seven International (HL7), de modo a preservar a interoperabilidade das informações dos pacientes em ambientes hospitalares. Como resultado, obteve-se um detalhamento da ontologia desenvolvida e implementada no software Protégé 5.1 com o apoio da metodologia denominada de Methontology. Foi descrito todo o processo de desenvolvimento, desde a coleta de dados até a validação final do modelo junto aos especialistas. Sendo assim, foi avaliado em duas etapas, isto é, primeiramente pelos especialistas: fisioterapeutas, médicos, residentes e alunos da fisioterapia e medicina do HUB. Ao final do processo da validação do ONTO-MAMA-NM, informaram que desconheciam a ontologia e não tinham visto nada semelhante referente ao tratamento da NM, obtendo assim o primeiro modelo ontológico do tratamento da NM.

Palavras-chaves: Ontologia, Neoplasia Mamária, Câncer de Mama, Methontology, Protégé, $O W L$ 


\title{
ABSTRACT \\ ONTO-MAMA-NM: AN ONTOLOGY MODEL OF MAMMARY NEOPLASIA TREATMENT
}

\author{
Author: Henderson Matsuura Sanches \\ Supervisor: Prof. Dr. Lourdes Mattos Brasil \\ Co-supervisor: Prof. Dr. Liana B. Gomide Matheus \\ Post-Graduation Program in Biomedical Engineering
}

\section{Brasília, Month of Year.}

The aim of this work was the development of a Mammary Neoplasia (NM) ontological model called ONTO-MAMA-NM. This model is a relevant tool to assist experts and students of the health area in the treatment of breast cancer. The ontological model was implemented in the Web Ontology Language (OWL) language, whose main advantage is the facility to express meanings, semantics and applicability in the information process in an automated way. As a model applied to the medical field, ONTO-MANA-NM seeks to maintain compatibility with the Digital Imaging and Communications in Medicine (DICOM) and Health Level Seven International (HL7) standards, in order to preserve the interoperability of patients information in hospital environments. As a result, it was developed a detailed ontology and implemented in Protégé 5.1 software with the support of the methodology called as Methontology. The final development process was described since the data collection until the final validation of the model with the experts. Thus, it was evaluated in two stages, that is, firstly by the specialists: physiotherapists, physicians, residents and students of physiotherapy and HUB medicine. At the end of the ONTOMAMA-NM validation process, they reported that they did not know about the ontology and had not seen anything similar regarding NM treatment, thus obtaining the first ontological model of NM treatment.

Key-words: Ontology, Mammary Neoplasm, Breast Cancer, Methontology, Protégé, OWL. 


\section{SUMÁRIO}

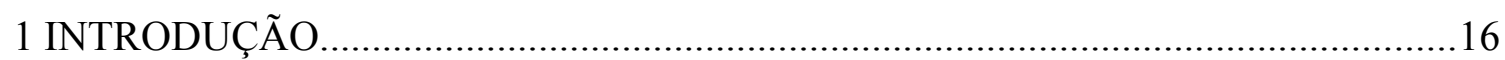

1.1 Contextualização e Formulação do Problema........................................................16

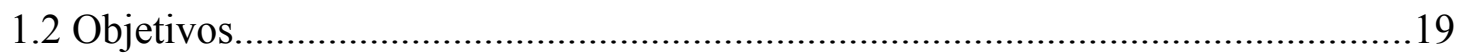

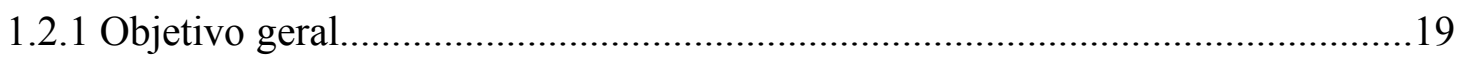

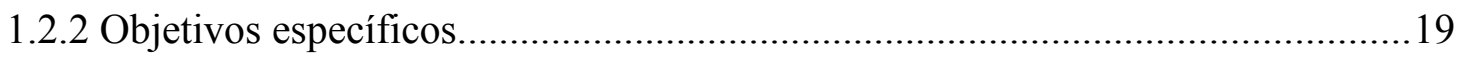

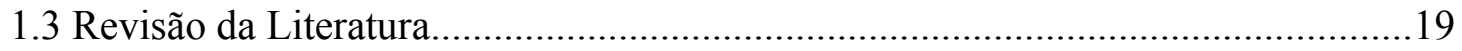

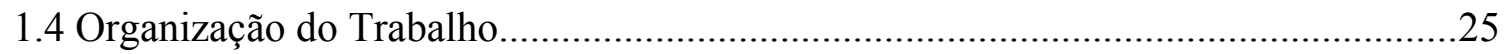

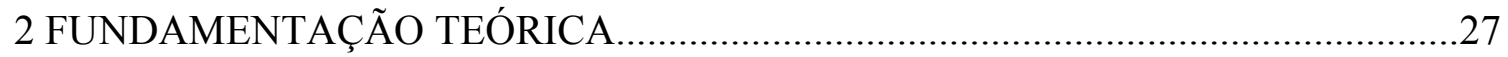

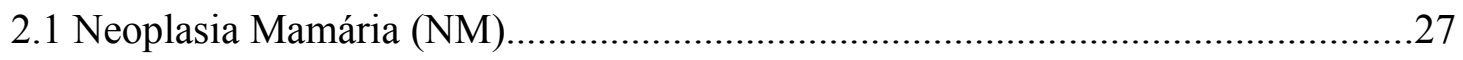

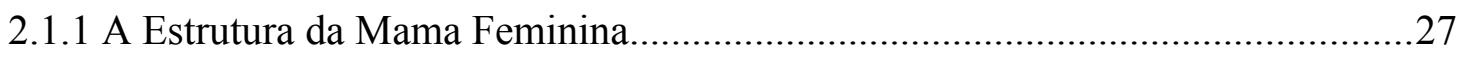

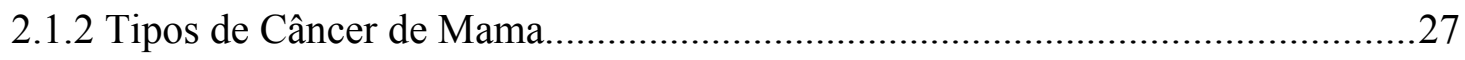

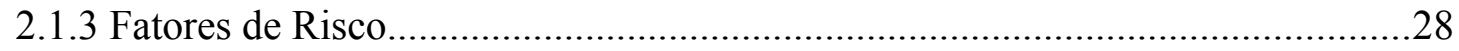

2.14 Diagnóstico do câncer de mama.........................................................................29

2.1.5 Tratamento do Câncer de Mama.....................................................................30

2.2 SISTEMAS DE INFORMAÇÕES HOSPITALARES PARA O DIAGNÓSTICO E TRATAMENTO DO CÂNCER DE MAMA.......................................................................

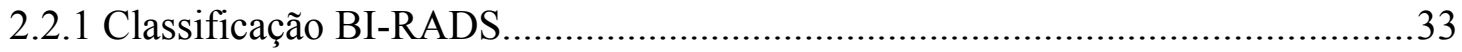

2.2.2 O padrão Digital Imaging and Communications in Medicine (DICOM).............34

2.2.3 O padrão Health Level Seven International (HL7)...............................................35

2.2.4 O Problema de Integração e Reuso de Informações Médicas.................................37

2.3 O Uso da Ontologia na Área Médica.......................................................................

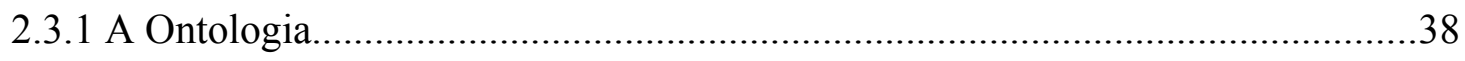

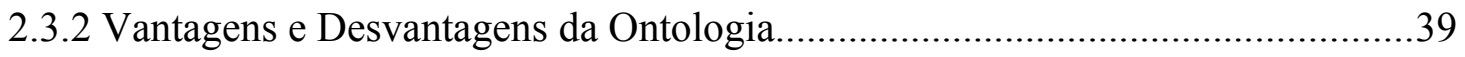

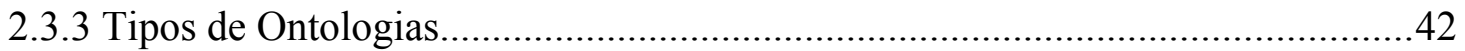

2.3.4 Ontologia no contexto da Web Semântica (OWL, RDF e outros padrões)..........44

2.3.5 Ontologia da Anatomia da Mama Feminina (ONTO-MAMA)...........................48

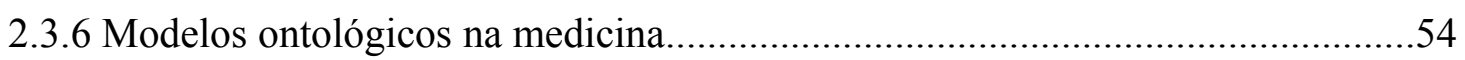

2.3.7 Ferramentas computacionais para criação e manutenção de modelos ontológicos

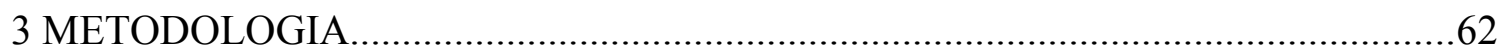

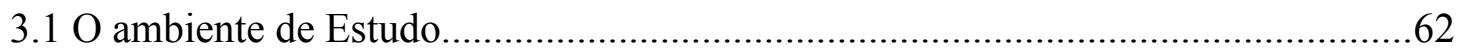

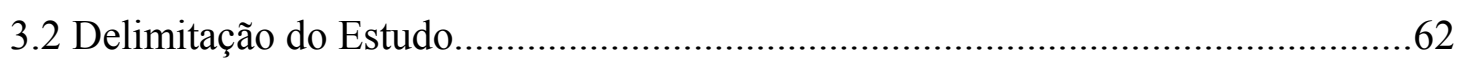




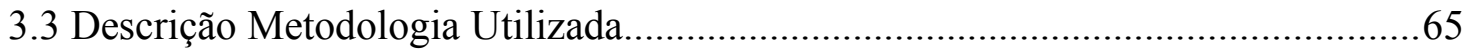

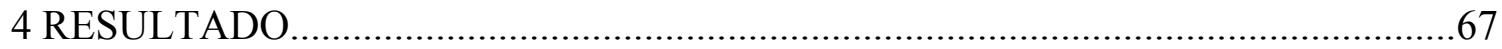

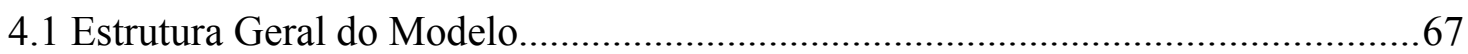

4.2 Perfil das Pacientes com Câncer de Mama............................................................

4.3 Sobre o Uso e Reuso de Informações do Modelo.......................................................76

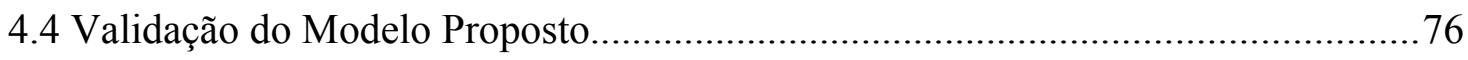

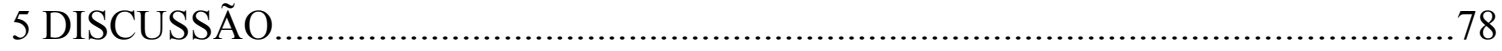

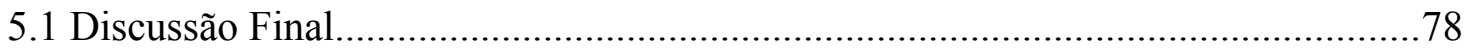

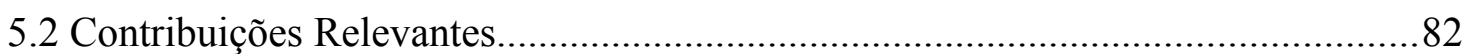

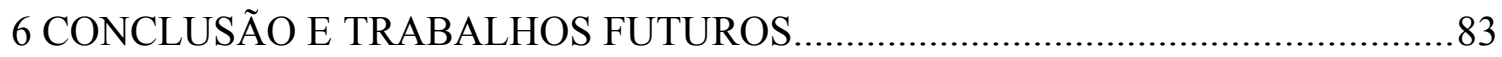

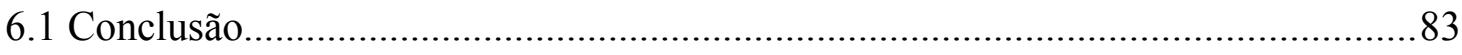

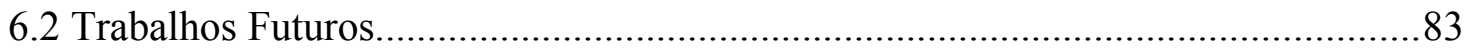

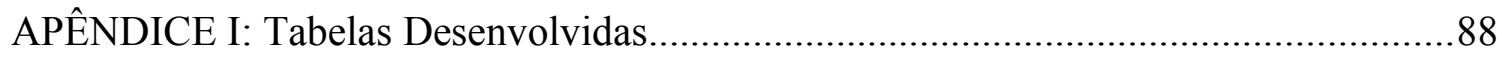

APÊNDICE 2: Figuras e Fluxogramas não Utilizados......................................................90

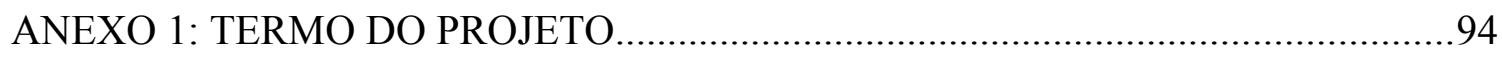

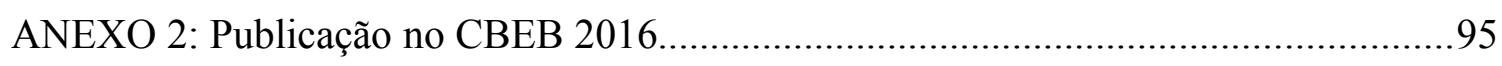

ANEXO 3: Ficha de Avaliação Fisioterapêutica - Câncer de Mama..................................96 


\section{LISTA DE TABELAS}

Tabela 1: Pesquisa por palavras-chave na língua portuguesa.........................................19

Tabela 2: Pesquisa por palavras-chave na língua inglesa..............................................20

Tabela 3: Pesquisa por palavras-chave na língua portuguesa no SWOOGLE...................21

Tabela 4: Pesquisa por palavras-chave na língua inglesa no SWOOGLE.........................22

Tabela 5: Comparativo de Linguagens para Ontologias (Adaptado de HINZ, 2006)..........46

Tabela 6: Ferramentas para Construção de Ontologias (Adaptado de HINZ, 2006)...........59

Tabela 7: Perfil das pacientes com Câncer de Mama.................................................................68

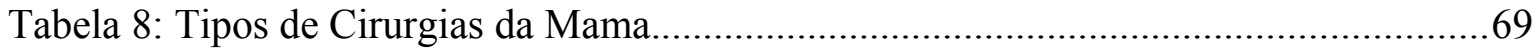

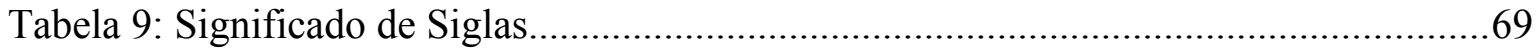

Tabela 10: Tratamentos Fisioterapêuticos......................................................................

Tabela 11: Web Services DICOM e o HL7 e XML (Adaptado de SIQUEIRA et. al, 2016).

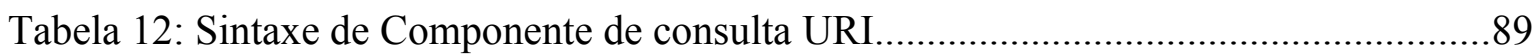

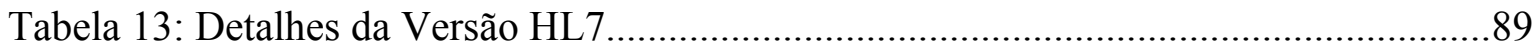

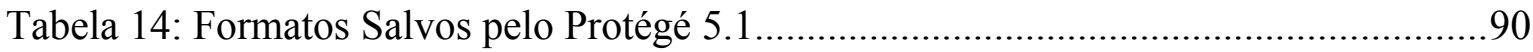

Tabela 15: Formatos com Interoperabilidade OWL - NM...........................................90 


\section{LISTA DE FIGURAS}

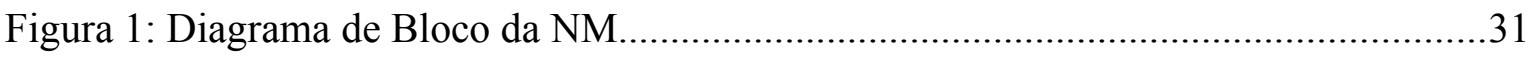

Figura 2: Ontologias de Aplicação (MORAIS; AMBRÓSIO, 2007).................................42

Figura 3: Arquitetura da Web Semântica (BERNERS-1EE, et al, 2001)..........................44

Figura 4: Modelo ONTO-MAMA (KLAVDIANOS (2011) ..........................................48

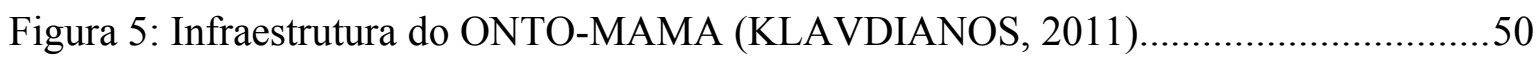

Figura 6: Estrutura do ONTO-MAMA OWL (KLAVDIANOS, 2010).............................51

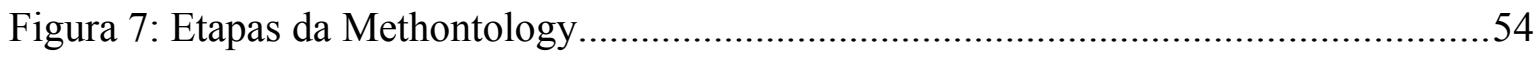

Figura 8: Metodologia Enterprise (MORAIS; AMBRÓSIO, 2007)...................................54

Figura 9: Metodologia On-To-Knowledge (MORAIS; AMBRÓSIO, 2007)......................55

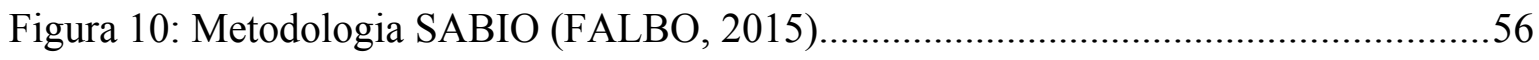

Figura 11: Protégé Versão 5.1 Instalado no Linux Mint 18...............................................58

Figura 12: Protégé 5.1 Aberto com suas Abas

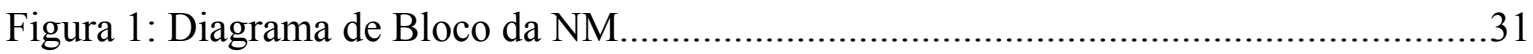

Figura 2: Ontologias de Aplicação (MORAIS; AMBRÓSIO, 2007)................................42

Figura 3: Arquitetura da Web Semântica (BERNERS-1EE, et al, 2001)...........................44

Figura 4: Modelo ONTO-MAMA (KLAVDIANOS (2011).........................................48

Figura 5: Infraestrutura do ONTO-MAMA (KLAVDIANOS, 2011) ..............................50

Figura 6: Estrutura do ONTO-MAMA OWL (KLAVDIANOS, 2010).............................51

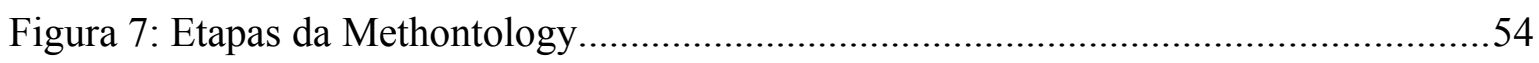

Figura 8: Metodologia Enterprise (MORAIS; AMBRÓSIO, 2007)..................................54

Figura 9: Metodologia On-To-Knowledge (MORAIS; AMBRÓSIO, 2007).....................55

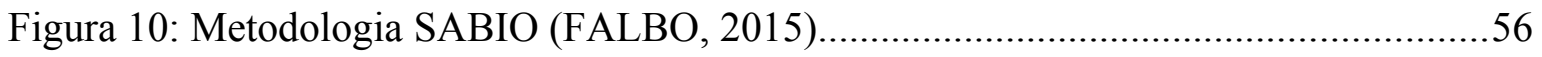

Figura 11: Protégé Versão 5.1 Instalado no Li no Linux Mint 18.....................................59

Figura 13: Diagrama de Bloco de Tratamento da Neoplasia Mamária...............................62

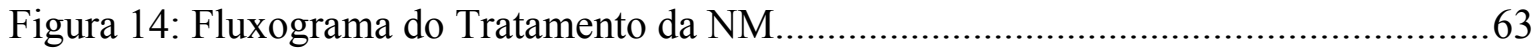


Figura 15: Fluxograma dos Tratamentos Cirúrgicos Encaminhados para Fisioterapia.......63

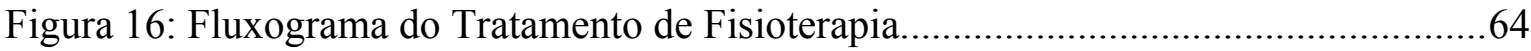

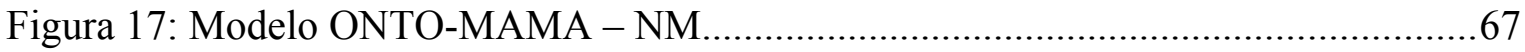

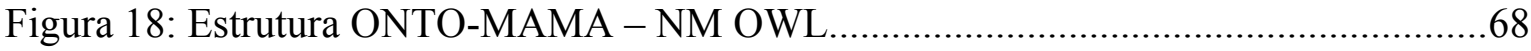

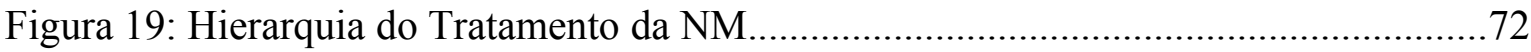

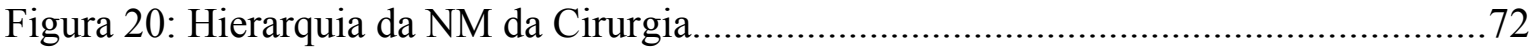

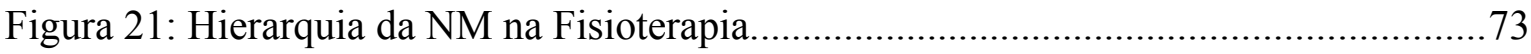

Figura 22: Ontologia da NM no Protégé 5.1 …............................................................... 73

Figura 23: Object Properties da NM no Protégé 5.1............................................................

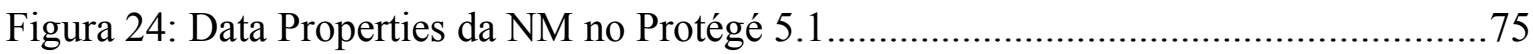

Figura 25: Validação do Tratamento da NM no Protégé 5.1 ................................................76

Figura 26: Diagrama de Bloco de Tratamento da Quimioterapia para a Cirurgia...............89

Figura 27: Fluxograma de Tratamento da Quimioterapia da Cirurgia.................................90

Figura 28: Diagrama de Bloco dos Procedimentos da Cirurgia...........................................90

Figura 29: Validação do Diagnostico da NM no Protégé 5.1 .............................................91 


\section{LISTA DE SÍMBOLOS, NOMENCLATURAS E ABREVIAÇÕES}

ABNF - Augmented Backus-Naur Form

ACM - Association for Computing Machinery

ACR - American College of Radiology

AGHU - Aplicativo de Gestão de Hospitais Universitários

ANAMAMA - Anatomia da Mama Feminina

ASM - Ambiente de Simulação Médica

CAPES - Coordenação de Aperfeiçoamento de Pessoal de Nível Superior

BI-RADS - Sistema de Laudos e Registros de Dados de Imagens da Mama

CBEB - Congresso Brasileiro de Engenharia Biomédica

DICOM - Digital Imaging and Communications in Medicine

DOAJ - Directory of Open Access Journal

FCE - Faculdade Ceilândia

FGA - Faculdade Gama

GO - Gene Ontology

HL7 - Health Level Seven International

HTTP - Hypertext Transport Protocol

HTTPS - Hypertext Transport Protocol Secure

HUB - Hospital Universitário de Brasília

IBICT - Instituto Brasileiro de Informações em Ciência e Tecnologia

IEEE - Institute of Eletrical and Eletronics Engineers

INCA - Instituto Nacional do Câncer

ISO - International Standards Organization

LNCC - Laboratório Nacional de Ciência e Tecnologia

ME - Menthor Editor 
MS - Ministério da Saúde

NM - Neoplasia Mamária

NEMO - Núcleo de Estudos em Modelagem Conceitual e Ontologias

OBO - Open Biomedical Ontologies

openGALEN - Generalized Architecture for Languages, Encyclopaedias and Nomenclatures

OpenJDK - Open Java Development Kit

OMS - Organização Mundial da Saúde

ONTOBRAS - Seminário de Pesquisa em Ontologia do Brasil

ONTO-MAMA - Ontologia da Anatomia da Mama Feminina

OSI - Open Systems Interconnection

OWL - Web Ontology Language

PubMed - Publications in Medicine

PS - Standards Publication

RDF - Resource Description Framework

SABIO - Systematic Approach for Building Ontologies

SE - Sistema Especialista

SIS - Sistemas de Informação em Saúde

Scielo - Scientific Eletronic Library Online

Scirus - Scientific Information

SGBD - Sistema de Gerenciamento de Banco de Dados

$\mathrm{SO}$ - Sistema Operacional

SOA - Service Oriented Architecture

STI - Sistema Tutor Inteligente

SWOOGLE - Swoogle Semantic Web Search Engine

UCB - Universidade Católica de Brasília 
UFES - Universidade Federal do Espírito Santo

UFG - Universidade Federal do Goias

UFO - Unified Ontology Fundamental

UML - Unified Modeling Language

UMLS - Unified Medical Language System

UnB - Universidade de Brasília

URI - Uniform Resource Identifier

W3C - World Wide Web Consortium 


\section{INTRODUÇÃ̃o}

\subsection{CONTEXTUALIZAÇÃO E FORMULAÇÃO DO PROBLEMA}

A denominada "Era da Informação" ou "Era Digital" designa os avanços tecnológicos advindos da Terceira Revolução Industrial e tem como característica principal a rápida troca de informações em um ciberespaço instrumentalizado pela informática e internet (MUNDO DA EDUCAÇÃO, 2016). Neste novo paradigma tecnológico, a mudança mais notória que se observa é a ampliação da capacidade em se processar, compartilhar e integrar informações por meio de diversos meios e envolvendo conceitos e culturas diversificadas. Logo, a demanda por compreender o conteúdo da informação de modo a aplicá-la eficientemente, tem ganho força e importância. Atualmente, o conteúdo, e não só a forma, ditam as regras para uma melhor interoperabilidade e uso inteligente dos dados. $\mathrm{E}$ quando se trata de conteúdo, é inevitável não mencionar o significado que a informação carrega consigo.

A World Wide Web (W3C), ou simplesmente Web, inaugurou um excelente ambiente para pesquisa e troca de informações, principalmente considerando-se a quantidade de dados que ela armazena. No entanto, estas informações são em sua maioria armazenadas sem qualquer critério de organização, padronização ou classificação quanto ao significado que carregam. Isso dificulta tremendamente o processamento dos dados por meio de mecanismos inteligentes e automatizados. Por esta razão, tem-se hoje a necessidade em se transformar a Web atual em uma Web Semântica na qual a informação é provida tanto para o consumo humano quanto para o processamento de máquina. No entanto, para que a Web Semântica funcione, mecanismos automatizados, como softwares de Inteligência Artificial (IA), por exemplo, devem ter acesso às informações padronizadas e também às regras de inferência e significado destes dados. Nesse sentido, a forma de se representar a informação no contexto da $W e b$ Semântica é de vital importância nos dias atuais (LIMA; CARVALHO, 2005).

Este mesmo raciocínio pode ser aplicado em relação às informações médicas. Antigamente, o histórico de saúde dos pacientes eram registrados manualmente em prontuários armazenados em grandes arquivos físicos localizados geralmente nos subsolos 
de hospitais e clínicas. Hoje em dia, a maioria das instituições de saúde mantêm alguma forma de digitalização de dados e os governos de diversos países já consideram seriamente o desenvolvimento de prontuários eletrônicos dos seus cidadãos. Com isso, dois protocolos envolvendo informações médicas foram criados como forma de padronizar os dados e garantir a melhor interoperabilidade entre os estabelecimentos de saúde: Digital Imaging and Communications in Medicine (DICOM) e o Health Level Seven International (HL7). Em nossa visão, tais padrões embora importantes, são extremamente limitados e não resolvem o problema da semântica da informação.

O DICOM, por exemplo, é composto de 20 partes e outros documentos suplementares que definem uma espécie de dicionário de dados para armazenamento de informações em dispositivos médicos, como exemplo, o mamógrafo, ou em arquivo e mídias digitais. (NEMA, 2016). No entanto, para se processar estas informações o software deve ser compatível com o DICOM, ou seja, deve ter sido programado para esta finalidade. Isto implica que as regras de formação do dado, seu significado e a relação com outras informações de relevância médica são codificados manualmente no software e, em caso de mudanças, devem ser alterados manualmente pelo programador. Outro problema com o padrão DICOM é no que diz respeito ao armazenamento de informações detalhadas e associadas às áreas dos especialistas. O DICOM propõe um dicionário de informações gerais dos pacientes, seus exames médicos e admite algumas extensões para, por exemplo, construir-se relatórios e pareceres médicos. Os fabricantes de dispositivos médicos as utilizam com frequência como forma de implementar características atrativas e únicas em seus equipamentos e softwares médicos. Entretanto, tais extensões ao DICOM são de ordem proprietária, pois não seguem nenhum padrão e são compreensíveis somente para aqueles que as desenvolveram. Portanto, as extensões ao DICOM não podem ser classificadas como interoperáveis (ANDERSON, OLIVEIRA, SERGIPE, 2016).

O HL7, por sua vez, tem como objetivo principal definir um protocolo de transmissão de dados entre sistemas informatizados e dispositivos médicos, dentro e fora das fronteiras dos hospitais e clínicas médicas. Logo, ele se concentra mais na entrega da informação do que em seu significado ou uso propriamente dito. Pode-se entender o HL7 como um protocolo de comunicação tal como o TCP/IP, mas que também abrange o fluxo de informações entre equipamentos, pessoas e sistemas informatizados. Deste modo, existe 
uma grande lacuna entre a padronização das informações médicas e sua transmissão/processamento (ANDERSON, OLIVEIRA, SERGIPE, 2016).

Um dos temas de maior relevância atual na área da saúde é a Neoplasia Mamária (NM). Segundo o Instituto Nacional do Câncer (INCA), são esperados 57.960 novos casos de câncer de mama no Brasil em 2016. O risco estimado é de 58 a cada 100.000 mulheres. Não considerando os tumores de pele não melanoma, esse tipo de câncer o mais frequente nas mulheres das regiões Sudeste, Sul, Centro-Oeste e Nordeste. Na região Norte, é o segundo mais incidente (INCA, 2016).

Logo, a proposta deste trabalho é realizar um estudo de caso real para a análise de informações médicas e, ao mesmo tempo, propor um modelo semântico de dados que seja interoperável, facilmente adaptável e de uso abrangente. 


\subsection{OBJETIVOS}

\section{I.2.1 Objetivo geral}

O objetivo desse estudo foi construir e descrever um modelo ontológico do tratamento da neoplasia mamária na linguagem Web Ontology Language (OWL).

\section{I.2.2 Objetivos específicos}

Os objetivos específicos desse estudo podem ser detalhados segundos dois aspectos ou áreas de interesse: engenharia clínica e tecnologia da informação.

Para alcançar o objetivo geral, foram propostos os seguintes tópicos específicos:

1. Estuda a NM objetivando o tratamento do paciente e compreender o escopo da NM enquanto área de conceito para que seja decidido o que será especificado;

2. Estudar a técnica de representação de informações por meio da ontologia, bem como metodologias para o desenvolvimento de modelos ontológicos;

3. Estudar e analisar os padrões DICOM e HL7;

4. Escolher uma ferramenta computacional para criar o desenvolvimento do modelo ontológico;

5. Desenvolver e Validar o modelo ontológico com o auxílio de especialistas.

\subsection{REVISÃO DA LITERATURA}

A pesquisa da base bibliográfica utilizada neste trabalho considerou a busca por livros, teses, monografias e artigos nas seguintes fontes especializadas: Publications in Medicine (PubMed), Institute of Electrical and Electronics Engineers (IEEE), Universidade Federal do Espírito Santo (UFES), Instituto Brasileiro de Informações em Ciência e Tecnologia (IBICT), Directory of Open Access Journal (DOAJ), Scientific Eletronic Library Online (Scielo), Scientific Information (Scirus), Science Direct, Routledge (Talor and Francis Group), Journal of Education Psychologist, Advances in Computer-Human Interactions (ACHI), International Journal of Education and Development using Information and Communication Technology (IJEDICT), periódicos da Coordenação de Aperfeiçoamento de Pessoal de Nível Superior (CAPES), Seminário de Pesquisa em Ontologia do Brasil 
(ONTOBRAS), Swoogle Semantic Web Search Engine (SWOOGLE) e na Meta Data Management Software. As pesquisas realizadas com algumas palavras-chave, nas bases de dados já mencionadas, em língua portuguesa, sendo a busca feita na área de engenharias e em ciências da saúde, estão distribuídas na Tabela 1 indicando a busca por palavras-chaves do tema em estudo.

Tabela 1: Pesquisa por palavras-chave na língua portuguesa ${ }^{1}$

\begin{tabular}{|c|c|c|c|c|c|}
\hline Palavras-chave & CAPES & PUBMED & $\mathbf{A C M}$ & IEEE & Total \\
\hline ONTO & 0 & 0 & 0 & 0 & 0 \\
\hline ONTO + CM & 0 & 0 & 0 & 0 & 0 \\
\hline ONTO + NM & 0 & 0 & 0 & 0 & 0 \\
\hline ONTO + STI & 0 & 0 & 0 & 0 & 0 \\
\hline $\begin{array}{c}\text { ONTO + STI + } \\
\text { CM } \\
\end{array}$ & 0 & 0 & 0 & 0 & 0 \\
\hline $\begin{array}{c}\text { ONTO + STI + } \\
\text { NM } \\
\end{array}$ & 0 & 0 & 0 & 0 & 0 \\
\hline ONTO + IA & 0 & 0 & 0 & 0 & 0 \\
\hline $\begin{array}{c}\text { ONTO + STI+ } \\
\text { IA+ CM } \\
\end{array}$ & 0 & 0 & 0 & 0 & 0 \\
\hline $\begin{array}{c}\text { ONTO + STI + } \\
\text { IA + NM } \\
\end{array}$ & 0 & 0 & 0 & 0 & 0 \\
\hline $\begin{array}{c}\text { ONTO + } \\
\text { MENTHO }\end{array}$ & 0 & 0 & 0 & 0 & 0 \\
\hline $\begin{array}{c}\text { ONTO + } \\
\text { MENTHO + STI } \\
\end{array}$ & 0 & 0 & 0 & 0 & 0 \\
\hline $\begin{array}{c}\text { ONTO + } \\
\text { MENTHO + STI } \\
+ \text { IA } \\
\end{array}$ & 0 & 0 & 0 & 0 & 0 \\
\hline $\begin{array}{c}\text { ONTO + } \\
\text { MENTHO + CM } \\
\text { +STI + IA } \\
\end{array}$ & 0 & 0 & 0 & 0 & 0 \\
\hline $\begin{array}{c}\text { ONTO + } \\
\text { MENTHO + NM } \\
+ \text { STI + IA } \\
\end{array}$ & 0 & 0 & 0 & 0 & 0 \\
\hline
\end{tabular}

(Legenda: $O N T O=$ Ontologia $; C M=$ Câncer de Mama; $N M=$ Neoplasia Mamaria, $S T I=$ Sistema Tutor Inteligente, $I A=$ Inteligencia Artificial; $M E N T H O=$ Methontology).

1

As combinações de palavras-chaves que tiveram valores iguais a zero foram desconsideradas nas apresentações das distribuições numéricas. 
Para a pesquisa em língua inglesa, a distribuição numérica na Tabela 2 mostra a busca feita na área de engenharias e em ciências da saúde com as palavras-chaves em função do tema em estudo.

Tabela 2: Pesquisa por palavras-chave na língua inglesa.

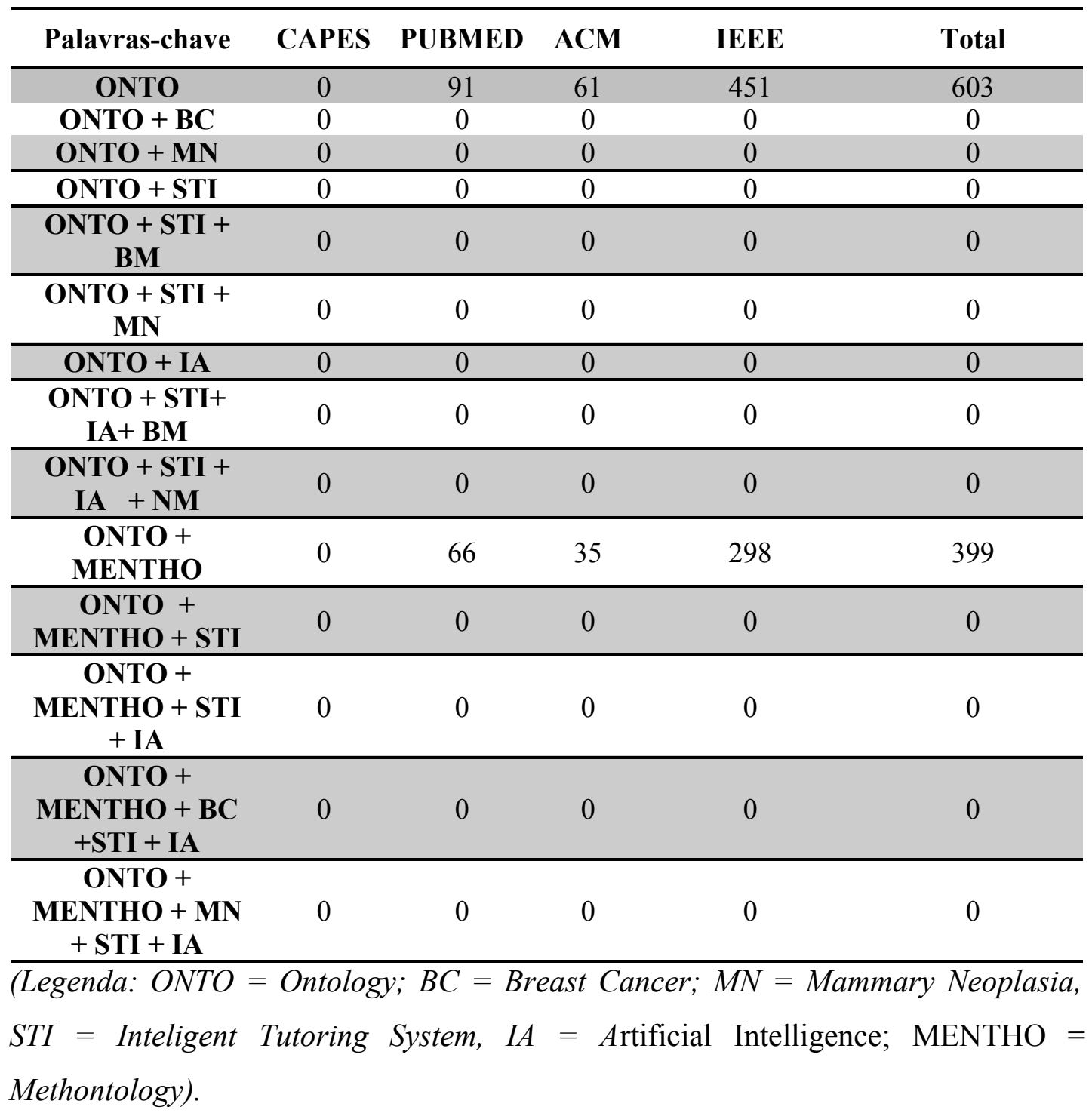

No site Semantic Web Search (SWOOGLE, 2016), foram encontrados cinco exemplos de ontologia do câncer de mama desenvolvido em $O W L$. Percebeu-se que as ontologias são muito básicas, isto é, somente com algumas implementações de classes e subclasses do câncer de mama em que os membros de uma das subclasses indicam tumores de um a três ou sem nenhuma informação. Foi encontrada também uma ontologia voltado ao suporte de desição câncer de mama, sendo impossível estudá-lo pois o mesmo apresenta 
erro 404 ao tentar baixar o arquivo. O SWOOGLE é um site de busca para a Web Semântica, documentos, termos e dados encontrados na Web e, segundo informações do próprio site, pode ser encontrado mais de 10.000 ontologias. Nas Tabelas 3 e 4, é mostrada a pesquisa realizada no site do SWOOGLE.

Tabela 3: Pesquisa por palavras-chave na língua portuguesa no SWOOGLE.

\begin{tabular}{|c|c|c|}
\hline Palavras-chave & SWOOGLE & Total \\
\hline ONTO & 22 & 22 \\
\hline ONTO + CM & 0 & 0 \\
\hline ONTO + NM & 0 & 0 \\
\hline ONTO + STI & 0 & 0 \\
\hline $\begin{array}{c}\text { ONTO + STI + } \\
\text { CM } \\
\end{array}$ & 0 & 0 \\
\hline $\begin{array}{c}\text { ONTO + STI + } \\
\text { NM } \\
\end{array}$ & 0 & 0 \\
\hline ONTO + IA & 0 & 0 \\
\hline $\begin{array}{c}\text { ONTO + STI+ } \\
\text { IA+ CM }\end{array}$ & 0 & 0 \\
\hline $\begin{array}{c}\text { ONTO + } \\
\text { MENTHO } \\
\end{array}$ & 0 & 0 \\
\hline $\begin{array}{c}\text { ONTO + STI + } \\
\text { IA + NM } \\
\end{array}$ & 0 & 0 \\
\hline $\begin{array}{c}\text { ONTO + } \\
\text { MENTHO + STI } \\
\end{array}$ & 0 & 0 \\
\hline $\begin{array}{l}\text { ONTO + } \\
\text { MENTHO + STI } \\
\quad+\text { IA } \\
\end{array}$ & 0 & 0 \\
\hline $\begin{array}{l}\text { ONTO + } \\
\text { MENTHO + CM } \\
+ \text { STI + IA } \\
\end{array}$ & 0 & 0 \\
\hline $\begin{array}{c}\text { ONTO + } \\
\text { MENTHO + NM } \\
+ \text { STI + IA } \\
\end{array}$ & 0 & 0 \\
\hline $\begin{array}{c}\text { ONTO + } \\
\text { SNOMED } \\
\end{array}$ & 0 & 0 \\
\hline ONTO + OBO & 0 & 0 \\
\hline \multicolumn{3}{|c|}{$\begin{array}{l}\text { (Legenda: } \text { ONTO }=\text { Ontologia; } C M=\text { Câncer de Mama; } N M=\text { Neoplasia Mamaria, } \\
\text { STI = Sistema Tutor Inteligente, } I A=\text { Inteligência Artificial, MENTO = }\end{array}$} \\
\hline
\end{tabular}


Tabela 4: Pesquisa por palavras-chave na língua inglesa no SWOOGLE.

\begin{tabular}{|c|c|c|}
\hline Palavras-chave & SWOOGLE & Total \\
\hline ONTO & 12.208 & 12.208 \\
\hline $\mathrm{ONTO}+\mathrm{BC}$ & 5 & 5 \\
\hline ONTO + MN & 0 & 0 \\
\hline ONTO + STI & 0 & 0 \\
\hline $\begin{array}{c}\text { ONTO + STI + } \\
\text { BC } \\
\end{array}$ & 0 & 0 \\
\hline $\begin{array}{c}\text { ONTO + STI + } \\
\text { NM } \\
\end{array}$ & 0 & 0 \\
\hline ONTO + IA & 3 & 3 \\
\hline $\begin{array}{c}\text { ONTO + STI+ } \\
\text { IA + BC } \\
\end{array}$ & 0 & 0 \\
\hline $\begin{array}{c}\text { ONTO + STI + } \\
\text { IA + NM } \\
\end{array}$ & 0 & 0 \\
\hline $\begin{array}{c}\text { ONTO + } \\
\text { MENTHO } \\
\end{array}$ & 0 & 0 \\
\hline $\begin{array}{c}\text { ONTO + STI + } \\
\text { IA + NM } \\
\end{array}$ & 0 & 0 \\
\hline $\begin{array}{c}\text { ONTO + } \\
\text { MENTHO + STI } \\
\end{array}$ & 1 & 1 \\
\hline $\begin{array}{c}\text { ONTO + } \\
\text { MENTHO + STI } \\
\text { + IA }\end{array}$ & 0 & 0 \\
\hline $\begin{array}{c}\text { ONTO + } \\
\text { MENTHO + BC } \\
+ \text { STI + IA } \\
\end{array}$ & 0 & 0 \\
\hline $\begin{array}{r}\text { ONTO + } \\
\text { SNOMED } \\
\end{array}$ & 2 & 2 \\
\hline ONTO + OBO & 85 & 85 \\
\hline
\end{tabular}

(Legenda: ONTO = Ontology; $B C=$ Breast Cancer; $M N=$ Mammary Neoplasia, $S T I=$ Inteligent Tutoring System, IA = Artificial Intelligence; MENTHO = Methontology, $S N O M E D=S N O M E D-C T ;$ OBO = Open Biomedical Ontologies $).$

Analisando os trabalhos nas bases de dados/pesquisa, dentre os que mais se relacionam ao tema resultante da pesquisa, destacam-se os trabalhos a seguir: 
Sabino e Heinzle (2015) desenvolveram uma ferramenta para construção de ontologia a partir de dados não estruturados, em que o trabalho utiliza a especificação de tags $O W L$ da ferramenta Protégé para criar uma ontologia adaptado de Curilem (2002). A ontologia criada foi editada na ferramenta Protégé, demonstrando assim que ela é compatível com o padrão de tags $O W L$ utilizado pela mesma.

Elisa, Pickler, Ferneda (2014) desenvolveram um método para a utilização de ontologias na indexação automática. O trabalho apresenta diretrizes técnicas para a construção e utilização de ontologias no processo de indexação automática por meio de exemplos. Conclui-se que a utilização de ontologias no processo de indexação permitindo não só agregar novos recursos ao processo de indexação, mas também permite pensar em novas e avançadas funcionalidades em um sistema de recuperação de informação.

Souza, Falbo, Vijaykumar (2012) desenvolveram o uso de ontologias na garantia da qualidade e melhoria de processos. $O$ trabalho apresenta uma visão geral do estudo da arte das ontolgias e seu uso na garantia da qualidade e na melhoria de processos de software.

Isac e Conci (2011) desenvolveram o uso de ontologias para a manipulação de imagens relacionadas ao câncer de mama. $\mathrm{O}$ trabalho apresenta um estudo sistemático de aplicações que utilizam ontologias como ferramenta para a manipulação em imagens médicas relacionadas ao câncer de mama, descrevendo as principais características de sistemas que as utilizam.

Klavdianos et al. (2011) desenvolveram uma ontologia da anatomia da mama feminina (ONTO-MAMA). Os autores criaram uma ontologia da anatomia da mama em que a primeira etapa do projeto foi a elaboração de ontologia para a descrição do procedimento médico da punção da mama por agulha fina e a construção do ambiente de realidade virtual.

Guizzardi et al. (2009) desenvolveram ontologias de fundamentação e modelagem conceitual, onde o trabalho tem objetivo de apresentar o grupo NEMO (Núcleo de Estudos em Modelagem Conceitual e Ontologias), organizado como parte do programa de difusão internacional de pesquisas e educação em ontologias da International Association on Ontologies and Applications (IAOA), através do seu International Outreach Subcommite. 
Freitas, Schulz, Moraes (2009) fizeram uma pesquisa de terminologias e ontologias atuais em biologia e medicina, no qual o trabalho apresenta uma estrutura descritiva, compara os sistemas em termos de seus elementos de arquitetura, expressividade e cobertura, além de analisar a natureza das entidades que eles denotam. Em especial, examina a Classificação Internacional de Doenças (CID), Medical Subject Headings (MeSH) Cabeçalhos Médicos, Gene Ontology (GO) Ontologia Genética, Systematized Nomenclature of Medicine - Clinical Terms (SNOMED - CT) Nomenclatura Sistematizada de Medicina - Termos Clínicos, Generalized Architecture for Languages, Encyclopaedias and Nomenclatures (openGALEN), Arquitetura Generalizada de Linguagens, Enciclopédias e Nomenclaturas, Foundational Model of Anatomy (FMA), Unified Medical Language System (UMLS) Sistema Unificado de Linguagem Médica e Open Biomedical Ontologies (OBO) Foundry Oficina de Ontologias Biomédicas Abertas.

Lichtenstein, Sigulem, D. Md (2008) criaram uma ontologia em saúde com a ferramenta Protégé no padrão $O W L$ e descreveram conceitos importantes sobre a ferramenta de edição e administração de ontologias Protégé e o padrão OWL (linguagem e ontologia para web), que foi o primeiro padrão semântico "completo" adotado pelo Consórcio $W W W$ e as comunidades de IA e Informática em Saúde.

Morais, Ambrósio (2007) realizaram o estudo de Ontologias: conceitos, usos, tipos, metodologias, ferramentas e linguagens, com o objetivo de descrever os conceitos de ontologia, seus principais usos, tipos, metodologias de desenvolvimento, ferramentas de especificação e linguagens de representação.

Portanto, observou-se escassos resultados por meio da busca utilizando as referidas palavra-chaves. Dessa forma, esse trabalho torna-se relevante, pois é a primeira pesquisa a construir e utilizar a ontologia para descrever o tratamento da neoplasia mamária.

\subsection{ORGANIZAÇÃO DO TRABALHO}

Este trabalho está organizado em seis capítulos, incluindo este capítulo.

No capítulo dois, é apresentada uma visão geral do referencial teórico, objetivando a compreensão das tecnologias, conceitos, e padrões utilizados na indústria para a promoção 
da interoperabilidade ${ }^{2}$ na área médica. Logo, são abordados os seguintes temas: (i) Neoplasia Mamaria; (ii) Sistemas de Informações Hospitalares para o Diagnóstico e Tratamento do Câncer de Mama; (iii) Classificação BI-RADS; (iv) Padrão DICOM e (iv) Padrão HL7.

O capítulo três detalha a metodologia utilizada no estudo.

O capítulo quatro descreve os resultados obtidos e a estrutura do processo de trabalho para o desenvolvimento da ontologia da NM.

O capítulo cinco discute os pontos de maior importância envolvendo o tema deste estudo e apresenta as conclusões finais do trabalho.

Por fim, o capítulo seis apresenta os trabalhos futuros que podem ser desenvolvidos a partir das ideias apresentadas neste documento.

2 É a capacidade de um sistema (informatizado ou não) de se comunicar de forma transparente (ou o mais próximo disso) com outro sistema (semelhante ou não). 


\section{FUNDAMENTAÇÃO TEÓRICA}

\subsection{NEOPLASIA MAMÁRIA (NM)}

\subsubsection{A Estrutura da Mama Feminina}

Uma das características dos mamíferos é a presença de glândulas mamárias, ou simplesmente da mama. Esses órgãos fazem parte da produção de leite, fornecendo alimento aos filhotes que nascem de certa forma, imaturos e dependentes. Entre as diversas espécies de mamíferos, o número de glândulas emparelhadas varia muito e está relacionada com o número de jovens em cada ninhada. Na maioria dos seres humanos e outros primatas, apenas uma glândula desenvolve em cada lado na região peitoral (PAULSEN \& WASCHKE, 2012). No indivíduo do sexo feminino, ocorre extenso desenvolvimento da mama, após o nascimento. Essas mudanças possuem relação direta com a idade e hormônios que influenciam na função reprodutiva. Aos 20 anos de idade, a mulher possui a mama em seu maior desenvolvimento e a partir de 40 anos inicia-se as alterações atróficas na mama (BLAND \& COPELAND III, 2014). As mamas podem ser acometidas por doenças benignas como a mastalgia, os cistos, a doença fibrocística da mama, o fibroadenoma, a secreção através do mamilo e a infecção da mama, bem como por doença maligna, como o câncer de mama.

\subsubsection{Tipos de Câncer de Mama}

O câncer de mama é o segundo tipo mais frequente no mundo e o principal entre as mulheres. É a segunda doença que mais mata mulheres no Brasil, segundo informação da Organização Mundial da Saúde (OMS), do Ministério da Saúde (MS) e do Instituto Nacional de Câncer (INCA, 2016). A estimativa é de cerca de 57.960 novos casos de câncer de mama para 2016 (INCA, 2016).

O diagnóstico do câncer de mama envolve procedimentos para diferenciar lesões benignas de lesões malignas. Para a realização do diagnóstico é utilizada, principalmente, a mamografia, ultrassonografia, ressonância magnética e biópsia mamária. Recentemente foi divulgado um estudo na Biosensors and Bioelectronics que utiliza biossensores para 
detectar geneticamente, 18 tipos de câncer, sendo um deles o câncer de mama (OLHAR DIGITAL, G1, TECMUNDO, 2016).

\subsubsection{Fatores de Risco}

Apesar de amplamente estudado, ainda não é possível estabelecer a causa e os fatores desencadeadores do câncer de mama, no entanto, diversos fatores de risco têm sido implicados tais como a idade avançada, a presença de familiares em primeiro grau portadoras de câncer de mama, a menarca precoce (antes dos 11 anos), a nuliparidade, a menopausa tardia (após 52 anos), o sedentarismo e a alimentação inadequada (FERREIRA, 2011).

- Idade: Com o avançar da idade, a incidência do câncer de mama aumenta significa mente, atingindo pico entre 55 e 64 anos de idade. Desta forma, a chance de uma mulher desenvolver o câncer de mama aos 30 anos de idade é de 1:2.212, enquanto para a mulher de 50 anos é 1:54. Uma explicação para esse fato pode ser o envolvimento dos esteroides ovarianos no processo (FERREIRA, 2011).

- Histórico Familiar: Mulheres com familiares em primeiro grau portadoras de câncer de mama têm risco relativo aproximado duas vezes maior que mulheres sem histórico familiar de câncer de mama. O risco é maior quanto maior o número de parentes afetados, se o familiar apresentou tumor bilateral e também se a doença incidiu antes dos 50 anos. O câncer de mama hereditário é responsável por cerca de 9\% dos tumores mamários. Parentes em segundo grau acometidos pela doença determinam menor risco (FERREIRA, 2011).

- Fatores Reprodutivos: Várias evidências apontam que os níveis dos esteroides ovarianos, principalmente os estrogênios, estejam fortemente implicados na transformação maligna do tecido mamário. Assim, fatores como a menarca precoce, antes dos 11 anos, a nuliparidade e a menopausa tardia, após 52 anos, estão associadas ao aumento da incidência do tumor de mama, pois provocam uma exposição mais longa aos estímulos dos esteroides ovarianos. A menarca precoce parece triplicar o risco, enquanto a menopausa tardia duplica o risco para o desenvolvimento do câncer de mama (FERREIRA, 2011). 
- Contraceptivos Orais: O uso de anticoncepcionais orais (ACO) é um motivo controverso, porém tem relevância, pois é o método contrecptivo mais utilizado no mundo atualmente. Por outro lado, o ACO não parece influenciar a presença de receptores estrogênios e progesterônicos em tumores de mulheres que fizeram uso deste método contraceptivo (FERREIRA, 2011).

- Atividade Física: É considerado como fator protetor contra o câncer de mama e também contra outros tipos de tumores. Quando se comparam estudantes que desenvolveram atividades esportistas durante o período escolar com estudantes não atletas observou-se um menor risco para o desenvolvimento do câncer de mama entra as atletas que nas não atletas (FERREIRA, 2011).

- Alimentação: A dieta é um assunto frequentemente pesquisado como um possível fator de risco para o desenvolvimento da doença. População com alto rendimento apresenta maior incidência de câncer de mama podendo ser reflexo da alimentação altamente calórico, sendo a exceção o Japão que apresenta hábito alimentares totalmente diferentes e tem baixo índice incidência da doença. Diferentes estudos mostram a relação entre a alta ingestão de alimentos com alto teor de gordura, principalmente gorduras insaturadas. A ingestão de álcool e o risco de câncer de mama parece bem estabelecida, estudos demonstram para cada $10 \mathrm{~g}$ de álcool consumido por dia há um aumento no risco em cerca de $9 \%$. Também é aventada a hipótese que o álcool induz a expressão de receptores estrogênicos em células mamárias, e desta forma levaria à proliferação destas células, ou ainda atuaria como facilitador ou indutor, visto que um de seus metabólicos, o acetaldeído, é carcinogênico (FERREIRA, 2011).

\subsection{Diagnóstico do câncer de mama}

O diagnóstico do câncer de mama envolve procedimentos e meios para diferenciar lesões benignas de malignas, permitindo, ainda, no caso de malignas, determinar sua localização e extensão local, como o uso de métodos complementares, bem como avaliar a extensão tumoral à distância (ABRÃO, 1995). O diagnóstico do câncer de mama é realizado por meio de exames clínicos como mamografia, ultrassonografia, biópsia mamária e ressonância (ABRÃO, 1995). 
- Mamografia: Representa a forma mais comum para o rastreamento do câncer de mama, o qual deve ser realizado por radiologista familiarizado com a patologia mamária e o exame clínico. Equipamentos com tubo de molibdênio, operados com alta amperagem e baixa quilovoltagem, em torno de 26 a $27 \mathrm{Kv}$, a fim de maximizar o efeito fotoelétrico.

- Ultrassonografia: É utilizada no diagnostico de prováveis lesões mamárias, como complemento da mamografia, para maior acuidade diagnóstica, evitando-se falsos resultados e biópsias desnecessárias. As ultrassonografia tem sido com maior poder de resolução com transdutores lineares ou setoriais de 7,5 MHZ com tradução de imagem em filmes aproximados e maior nível de resultante diagnóstica.

- Ressonância: Não tem demostrado vantagem sobre a mamografia e a ultrassonografia, que são exames de menor custo, menor risco e maior poder resolutivo.

- Biópsia Mamária: O material do parênquima mamário poderá ser obtido através de punção com agulha (core biopsy) ou de biópsia a céu aberto, iscisional ou excisional, para estudo histológico. O material obtido na agulha é de dimensões de 0,2 a $1 \mathrm{~cm}$, suficiente para o estudo histológico da lesão e determinação dos receptores hormonais, onde são necessários cerca de $100 \mathrm{mg}$ de tecido (FERREIRA, 2011).

\subsubsection{Tratamento do Câncer de Mama}

O tratamento é geralmente realizado por meio da cirurgia, radioterapia, quimioterapia, hormoterapia e imunoterapia.

- Cirurgia: Pode ser realizada de forma conservadora ou radical (mastectomia). As cirurgias conservadoras são denominadas tumorectomia/setorectomia (extirpação do tumor e margem de segurança) e quadrantectomia (extirpação do tumor e $1 / 4$ da mama). Já as radicais (mastectomia) podem ocorrer com a retirada da glândula mamária (Madden), da glândula mamária e músculo peitoral menor (Patey) e, ainda, da glândula mamária, músculos peitoral maior e menor (Halsted). Essas cirurgias podem ser acompanhadas ou não de retirada de linfonodos (lindonodectomia). 
- Radioterapia: Utiliza radiação (raios-X, raios gamas, elétrons, nêutrons, etc.) para eliminar células tumorais. A colisão destas partículas com moléculas celulares leva à formação de radicais livres e também promove danos genéticos que levam à morte celular. Sua indicação depende do tipo do estágio do tumor. É administrada por período e dosagem variados. A dose sobre a mama varia entre 45 a 50 Gy $($ Gray, 1 Gy $=100 \mathrm{cGy}($ centigray $)=1 \mathrm{rad})$.

- Quimioterapia: É o tratamento por meio de medicamentos normalmente injetados por via intravenosa. É utilizada de acordo com o estadiamento da doença, momento do diagnostico, ou ainda na recorrência do câncer, de forma paliativa.

- Hormonioterapia: O tratamento hormonal pode ser realizado de forma neoadjuvante, adjuvante e paliativa. Está indicado quado as células tumorais expressam os receptores de estrógeno e progesterona. É realizado por meio do Tamoxifeno e Inibidores da Aromatase.

- Terapia Biológica/Imunoterapia: tratamento também denominado de terapiaalvo, com o uso de anticorpo monoclonal para pacientes cujos tumores expressam o fator de crescimento C-erb-B2.

- Reabilitação Biopsicossocial: Possibilita ao paciente a convivência e o entendimento da sua nova situação de vida a partir do diagnostico e dos diferentes tipos de tratamento a que é submetida, e também procura preparar os familiares para esta nova realidade. O acompanhamento da paciente por uma equipe interdisciplinar é fundamental para a melhora da qualidade de vida do paciente. A participação de um fisioterapeuta, antes e após a cirurgia, é imprescindível na preservação e na recuperação da funcionalidade da paciente (FERREIRA, 2011).

A Figura 1 apresenta o diagrama de bloco da NM, desde o recolhimento das informações do paciente, epidemiologia, os fatores de risco, o tipo do câncer, a realização do diagnóstico, o estadiamento ${ }^{3}$, a escolha do tratamento clínico ou do tratamento paliativo e, ainda a reabilitação dos pacientes, com intuito/expectativa da cura ou a sobrevida do paciente.

3 O estadiamento descreve aspectos do câncer, como tamanho do tumor, comprometimento de linfonodos, presença de metástase. Conhecer o estágio do tumor auxilia na definição do tipo de tratamento e, quando realizado precocemente, favorece o prognóstico da paciente. 


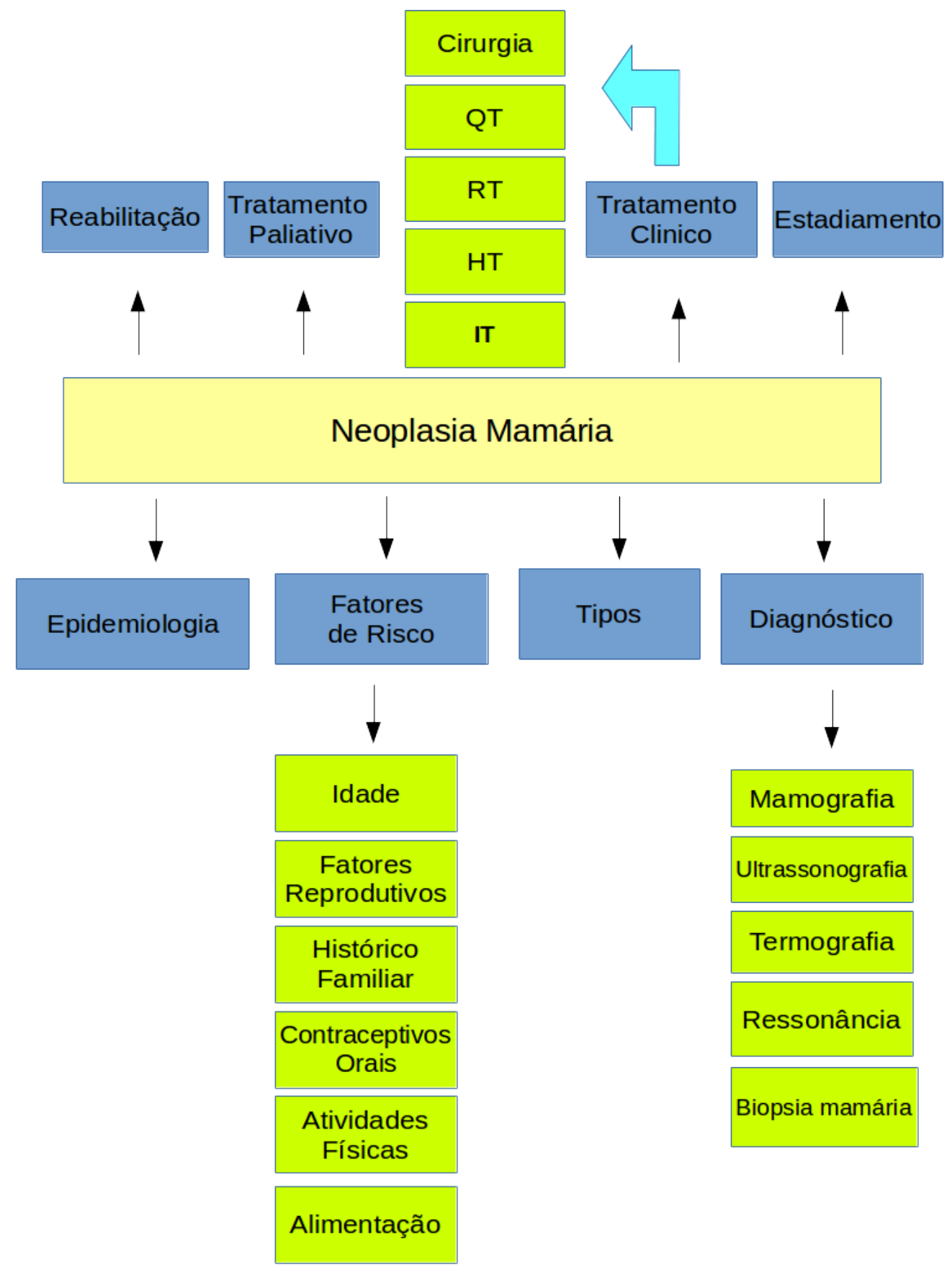

Figura 1: Diagrama de Bloco da NM. 


\subsection{SISTEMAS DE INFORMAÇÕES HOSPITALARES PARA O DIAGNÓSTICO E TRATAMENTO DO CÂNCER DE MAMA}

\subsubsection{Classificação BI-RADS}

Os resultados mamográficos sempre foram uma preocupação muito grande dos médicos radiologistas que realizam mamografias. $\mathrm{O}$ atraso da comunicação de resultados pode levar ao retardo do diagnóstico e, consequentemente, impedindo o tratamento imediato de alguma possivel anomalia (MARTINS, 2016).

$\mathrm{Na}$ busca de um consenso para uma padronização de resultados mamográficos, o Colégio Americano de Radiologia (American College of Radiology - ACR) elaborou uma classificação da sistemática dos achados mamográficos. A este padrão foi dado o nome de Relatório de Imagenologia Mamária e Sistemas de Dados (BI-RADS) (ACR, 2005). A classificação do BI-RADS segundo (MARTINS, 2016) é feita de 6 categorias conforme o grau de risco para câncer de mama. Essa classificação são:

- Categoria 0: Nesta categoria estão inclusos os achados que necessitam de avaliação adicional. É indicada a comparação com exames anteriores ou realização de exame de imagem adicional.

- Categoria 1: Nesta categoria não há nada a se comentar, não há nódulos, distorção arquitetural, calcificações suspeitas de malignidade ou assimétricas.

- Categoria 2: Achados benignos. Estão inclusos nesta categoria fibroadenomas, calcificados involuídos, múltiplas calcificações secretórias, lesões com conteúdo de gordura, tais como cistos oleosos, lipomas, galactoceles e hamartomas de densidades mistas. Todos têm aparência caracteristicamente benigna e podem ser classificados com segurança.

- Categoria 3: Achado provavelmente benigno, com menos de 2\% de possibilidade de malignidade. É sugerido ao especialista um seguimento mamográfico da mama com o achado em um intervalo de tempo de 6 meses. 
- Categoria 4: Nessa categoria se encaixam achados com anormalidade suspeita. Tais achados não têm uma aparência clássica de malignidade, possuem probabilidade de malignidade de 2\% a 95\%. Biópsia deve ser considerada.

- Categoria 5: Achados altamente sugestivos de malignidade. Lesões nessa categoria têm uma probabilidade maior que $95 \%$ de chance de ser câncer. Biópsia para comparação deve ser realizada.

- Categoria 6: Aqui se encaixam achados com malignidade comprovada. A malignidade é comprovada através de biópsia do achado. Nessa categoria é indicada a conduta terapêutica adequada.

\subsubsection{O padrão Digital Imaging and Communications in Medicine (DICOM)}

DICOM ou Comunicação de Imagens Digitais em Medicina, é um padrão internacional para imagens médicas e informações relacionadas (ISO 12052). Ele define os formatos de imagens médicas que podem ser trocados com os dados e qualidade necessárias para o uso clínico. Há literalmente milhares de milhões de imagens DICOM atualmente em uso para cuidados clínicos. Desde sua primeira publicação em 1993, DICOM revolucionou a prática da radiologia, permitindo a substituição do filme de raios-X com um fluxo de trabalho totalmente digital (DICOM, 2016).

O DICOM especifica um protocolo proprietário para a troca de dados médicos, formatação de imagens digitais e estruturação de arquivos de informações biomédicas divididos em 20 partes (NEMA, 2016).

Abaixo, pode-se ver alguns pontos de funcionamento do DICOM, sendo:

- Exemplos de dados existentes no cabeçalho alho da imagem: (0010,0010) Patients Name (0010,0020) Patients ID (0010,0030) Patients Birth Date $(0008,0050)$ Accession Number $(0008,0090)$ Referring Physicians Name;

- Composto de 20 partes mais os suplementos; Partes mais importantes sendo os Standards Publication (PS) são: PS 3.3: O Modelo do DICOM; PS 3.5: Como se codifica o DICOM; PS 3.7: Como se transmite o DICOM; PS 3.10: Como se armazenam os arquivos DICOM: PS 3.16 Controlled Terminology, em que descreve o controle de termologias e a Classificação Internacional de Doenças 
(CID), e o CID 6081 que descreve o câncer de mama e os fatores de risco; PS 3.18 Web Services que mostra as transformações dos formatos DICOM;

- A comunicação DICOM é feita Ponto a Ponto; Cada entidade assume papel de cliente ou servidor; Cliente: Service Class User (SCU); Servidor: Service Class Provider (SCP); Cada entidade envolvida na comunicação é identificada pela tripla: AE Title: Nome da entidade. Ex.: ANGIO1 Host: IP ou nome de rede;

- Comunicação DICOM Serviços para imagens: C-ECHO: Equivalente ao ping; CFIND: Pesquisa por imagens; C-STORE: Armazenamento de imagem; C-GET: Recuperação de imagem; C-MOVE: Transferência de imagens entre duas entidades;

- Comunicação DICOM Outros serviços: N-GET: recupera alguma informação; NSET: modifica uma informação; N-ACTION: Solicita realização de uma ação; NCREATE: cria uma instância de uma SOP Class; N-DELETE: apaga uma instância de uma SOP Class.

Na Tabela 12, conforme Apêndice 1, tem-se a sintaxe de componente de consulta Uniform Resource Identifier (URI), Generic Syntax, em que o componente de consulta e definida utilizando o RFC5234 conforme Augmented Backus-Naur Form (ABNF), (NEMA, 2016).

\subsubsection{O padrão Health Level Seven International (HL7)}

Fundada em 1987, Health Level Seven International (HL7) ou Nível de Saúde Sete Internacional, é uma entidade sem fins lucrativos, sendo um conjunto de padrões e práticas para a interoperabilidade em informática em saúde que se refere ao mais alto nível do modelo de comunicação do International Standards Organization (ISO) para o Open Systems Interconnection (OSI). O HL7 é apoiado por mais de 1.600 membros em mais de 50 países, incluindo mais de 500 membros corporativos que representam os profissionais de saúde, partes interessadas do governo, os contribuintes, empresas farmacêuticas, vendedores/fornecedores e empresas de consultoria integrando informações de natureza clínica e administrativa (HL7, 2016).

Segundo o site do HL7 Brasil, o Instituto HL7 Brasil é o representante oficial da HL7 Internacional, uma fundação dedicada ao desenvolvimento deste padrão, e tem por 
objetivo impulsionar o seu aprendizado e uso no Brasil. É uma instituição sem fins lucrativos, fundada em 2007, e sediada em São Paulo, Brasil. Esta iniciativa vem de encontro com a crescente preocupação, na área da Saúde e da Tecnologia da Informação, em buscar soluções que possam integrar diversos sistemas de informações em Saúde de forma transparente e flexível. Entre os diversos tipos de padrões disponíveis (conteúdo, estrutura, representação, segurança, comunicação, etc), o HL7 tem assumido um papel importante na troca, no gerenciamento e na integração entre sistemas de informações em saúde (HL7 Brasil, 2016).

No site oficial do HL7 Brasil, assim como no site do HL7 Internacional, existem comunidades onde encontra informações para ajudar quem quiser saber mais sobre o padrão HL7. Existe, também, o site do HL7 Brasil que apresenta os seguintes grupos de trabalho no Brasil, sendo eles:

- Grupo de Trabalho de Educação e Capacitação Profissional;

- Grupo de Trabalho de Interoperabilidade;

- Grupo de Trabalho de Imagens Médicas e DICOM;

- Grupo de Trabalho de Terminologia;

- Grupo de Trabalho de Comunicação;

- Grupo de Trabalho de Relações Institucionais;

- Grupo de Trabalho de HL7 V2, V3 e CDA;

- Grupo de Trabalho de HL7 FHIR.

O HL7 Brasil tem discutido a importância e a necessidade dos padrões de Interoperabilidade em Sistemas de Informação em Saúde sendo eles:

- Promover o uso dos padrões dentro dos domínios da área de saúde;

- Promover a educação e treinamento de padrões de Interoperabilidade;

- Promover a compreensão dos padrões e seus usos comuns no acesso a publicações dos padrões e na análise de necessidades para sua utilização; 
- Provê metodologias para a criação de extensões a partir das bases dos padrões de Interoperabilidade;

- Encorajar a aceitação e uso do HL7 no Brasil e nas Américas;

- Colabora com desenvolvedores da área da saúde e da informática no desenvolvimento de suas habilidades e conhecimento dos padrões.

O publico alvo do HL7 Brasil são:

- Empresas de Tecnologia em Saúde;

- Gestores de TI em Hospitais, Clínicas e Instituições de Saúde;

- Desenvolvedores de Soluções de Informática em Saúde;

- Instituições Acadêmicas de Saúde e Informática em Saúde.

Os detalhes entre as versões do HL7 V2.x e V3 pode-se vista no Apêndice 1 na Tabela 13.

\subsubsection{O Problema de Integração e Reuso de Informações Médicas}

Integrar aplicações é um dos problemas mais difíceis enfrentados pelo desenvolvimento de aplicações para empresas. Para atender aos objetivos da integração, muitos métodos, técnicas, padrões e tecnologias têm surgido ao longo dos anos (JURIC et al., 2008). Dentre essas sugestões, o Service Oriented Architecture (SOA) tem sido recomendado para resolver alguns dos desafios centrais de interoperabilidade de Sistemas de Informação em Saúde (SIS) heterogêneos (MYKKANEN et al., 2007). A utilização do SOA apresenta-se como uma saída, devido à necessidade da troca de informações entre SIS e com o aumento de organizações, evidenciando a carência gerada pela falta de interoperabilidade (Anderson et al., 2016). Interoperabilidade consiste na habilidade de um sistema ou produto de interagir com outro sistema ou produto sem um esforço especial por parte do usuário (IEEE - Standards Glossary, 2015). Para promover a interoperabilidade, o SOA tem sido utilizado alguns anos, já que permite a integração de sistemas legados e facilmente acomoda necessidades em constante evolução (TRINUGROHO et al., 2011). 


\title{
2.3 O USO DA ONTOLOGIA NA ÁREA MÉDICA
}

\subsubsection{A Ontologia}

Ontologia (do grego ontos "ente" e logoi, "ciência do ser") é a parte da metafísica que trata da natureza, realidade e existência dos entes. A Ontologia trata do ser enquanto ser, isto é, do ser concebido como tendo uma natureza comum que é inerente a todos e a cada um dos seres (ELISA; PICKLER; FERNEDA, 2014).

O termo "ontologia" tornou-se muito popular desde os meados dos anos 1990, mas, infelizmente, não havia definições universalmente aceitas (KUZNIERSKY, 2006). Desde o século XVII, o termo tem sido utilizado para denominar a disciplina de metafísica geral, dentro da tradição da "primeira Filosofia" de Aristóteles, como sendo a ciência do ser no papel de ser. É, muitas vezes, encarada como um complemento à ideia de epistemologia (ciência do conhecimento) (FREITAS; SCHULZ; MORAES, 2009).

No site do Seminário de Pesquisa em Ontologia do Brasil (ONTOBRAS, 2016), tem-se a seguinte definição:

\begin{abstract}
"Ontologia é um campo interdisciplinar preocupado com o estudo de conceitos e teorias que dão embasamento para a construção de conceitualizações compartilhadas de domínios específicos. Em anos recentes, nota-se um crescimento no interesse na aplicação de ontologias para a solução de problemas de modelagem e classificação em diversas áreas como: Ciência da Computação, Ciência da Informação, Filosofia, Inteligência Artificial, Linguística, Gerência de Conhecimento, entre outras."
\end{abstract}

Segundo a W3C (2016), a ontologia é composta pela definição dos termos utilizados na descrição e na representação de uma área do conhecimento, bem como devem prover descrições para os seguintes tipos de conceitos:

- Classes - nos vários domínios de interesse;

- Relacionamentos entre essas classes; 
- Propriedades (atributos) que essas classes devem possuir.

Outros componentes de uma ontologia, destacam-se:

- Indivíduos: Instâncias ou objetos; Classes: conjuntos (ou coleções), tipos de objetos ou tipos de coisas;

- Atributos: Aspectos, propriedades, características ou parâmetros que objetos e classes podem assumir;

- Relações: Relacionamentos que podem ser estabelecidos entre objetos ou classes;

- Regras: Implicações que descrevem as inferências lógicas que podem ser calculadas a partir de determinada asserção;

- Axiomas: Ideias que a ontologia descreve no seu domínio de aplicação;

- Eventos: Alterações em atributos ou relações ser estabelecidos entre objetos ou classes.

\subsubsection{Vantagens e Desvantagens da Ontologia}

As vantagens para o uso da ontologia são: Compartilhamento, descrição formal e exata do conhecimento; Possibilidade de expressão em várias línguas; Condição de passar de genérica à específica; Usadas por pessoas e um Sistema de Gerenciamento de Banco de Dados (SGBD); Definições de relacionamento entre conceitos; Integração de diferentes fontes; Conceitualização completa de termos; Redução da possibilidade de mal entendido (ELISA; PICKLER; FERNEDA, 2014).

As desvantagens para o uso da ontologia são: Falta de profissionais especializados; na seleção e relacionamento dos termos; falta de metodologia; de divisão; de validação (ELISA; PICKLER; FERNEDA, 2014).

Para descrever uma ontologia com conceitos ou procedimentos pode-se; tabular, criar um banco de dados, protocolos próprios como DICOM, porém não tem-se acesso aos metadados, já com a ontologia além de criar conceitos, procedimentos, classes, atributos, relacionamentos, avalização, biblioteca de caso concreto com o acesso aos meta dados 
como grande vantagem e quando cria-se uma ontologia em um SGBD não tem-se acesso aos meta dados, sendo essa uma desvantagem.

No trabalho Ontologias: conceitos, usos, tipos, metodologias, ferramentas e linguagens de (MORAIS; AMBRÓSIO, 2007), apresentam mais algumas vantagens do uso da ontologia sendo elas:

- Recuperação de informações na Internet: Projetos relacionados à recuperação de informação na Internet, dentre eles, OntoSeek, que recupera informações de catálogos de produtos on-line utilizando um sistema de agentes inteligentes, o Ontoweb (http://www.ontoweb.com.br), que é um sistema de análise de informações na Internet, que possibilita uma pesquisa contextualizada nas fontes acessadas, o SEAL (Semantic Portal), que permite o desenvolvimento de portais semânticos baseados em ontologia, ou o OntoSearch, que permite a reutilização de ontologias na Web-Semântica provendo estruturas de busca em um grande banco de dados de ontologias e outros documentos semânticos na Internet.

- Processamento de Linguagem Natural: Projetos de processamento de linguagem natural, como o Oncoterm, por exemplo, que facilita a tradução de textos médicos sobre oncologia mediante uma ontologia baseada em textos especializados e dicionários médicos.

- Gestão do Conhecimento: Projetos de representação (gestão) do conhecimento, como o Corporate Memory Management through Agents (CoMMA), por exemplo, que propõe o armazenamento da memória corporativa da empresa através do uso de ontologias.

- Web-Semântica: A Web-Semântica onde a informação é dada com significado explícito, tornando mais fácil para máquinas processarem e integrarem informações disponíveis na rede automaticamente.

- Educação: Existem alguns projetos na área de educação em ambiente de Internet, por exemplo, RichODL, que é um ambiente de aprendizado desenvolvido para treinar estudantes na modelagem e simulação de ambientes dinâmicos. Neste 
exemplo, as ontologias são utilizadas para descrever o domínio físico dos sistemas modelados.

Além de serem utilizadas em diversas áreas, o uso de ontologias traz diversas vantagens. De acordo com (GUIZZARDI, 2000), os principais benefícios relacionados à utilização de ontologias são:

- Comunicação: As ontologias possibilitam a comunicação entre pessoas acerca de determinado conhecimento, pois permitem raciocínio e entendimento sobre um domínio. Essa relação auxilia na obtenção de consenso, principalmente sobre termos técnicos, entre comunidades profissionais, de pesquisa, etc.

- Formalização: A formalização está relacionada à especificação da ontologia, que permite eliminar contradições e inconsistências na representação de conhecimento, além de não ser ambígua. Além disso, essa especificação pode ser testada, validada e verificada.

- Representação de Conhecimento e Reutilização: As ontologias formam um vocabulário de consenso que permite representar conhecimento de um domínio em seu nível mais alto de abstração, possuindo, desta forma, potencial de reutilização.

Mesmo com inúmeros benefícios (GUIZZARDI, 2000), apresenta alguns problemas, sendo eles:

- Escolha das Ontologias: A escolha de uma ontologia pode se tornar um processo político, uma vez que uma ontologia pode não ser totalmente adequada a todos os indivíduos ou grupos relacionados a algum domínio específico.

- Criação e Evolução das Ontologias: Ontologias precisam ser criadas e evoluir. Poucos trabalhos, entretanto, têm enfocado este aspecto, principalmente na língua portuguesa.

- Bibliotecas de Ontologias: A noção de biblioteca de ontologias está relacionada à independência entre elas. Desta forma, a interface entre estas ontologias se constitui em um problema, uma vez que cada uma delas pode ter sido desenvolvida em um contexto diferente. 
- Metodologia de Desenvolvimento: Este é considerado o principal problema relacionado às ontologias, principalmente pela falta de trabalhos descrevendo metodologias para seu desenvolvimento. Existe uma ausência de atividades padronizadas, ciclos de vida e métodos sistemáticos de desenvolvimento, assim como um conjunto de critérios de qualidade, técnicas e ferramentas. Isso faz com que o processo de criação de ontologias seja uma atividade quase "artística".

Apesar de apresentar inúmeras vantagens e desvantagens, uma grande vantagem do uso da ontologia para um banco de dados não dito em nenhuma das revisões da literatura é o acesso aos Metadados ${ }^{4}$, pois no Banco de Bados, somento o Adminstrador do Banco de Dados (DBA - Database Administrator) tem acesso aos Metadados e na ontologia quando disponibiliza-se o arquivo vai junto os Metadados da ontologia desenvolvida, enriquecendo a semântica do dado produzido, agregando seu significado real, e dando suporte à atividade de Administração dos Dados executados pelo especialista que irá utilizar a ontologia.

\subsubsection{Tipos de Ontologias}

Ontologias podem ser classificadas quanto ao seu grau de formalismo, aplicação, conteúdo ou função (estrutura). Quanto ao grau de formalismo, as ontologias podem ser categorizadas em altamente informais, quando expressas em linguagem natural; semiinformais, quando expressas em linguagem natural de forma restrita e estruturada; semiformais, expressas em linguagem artificial definida formalmente; e rigorosamente formais, onde os termos são definidos com semântica formal, teoremas e provas (MORAIS; AMBRÓSIO, 2007).

Segundo Morais; Ambrósio (2007), a ontologia pode ser classificada em 5 categorias, sendo eles:

- Ontologias Genéricas: São consideradas ontologias "gerais". Descrevem conceitos mais amplos, como elementos da natureza, espaço, tempo, coisas, estados, eventos, processos ou ações, independente de um problema específico ou domínio particular.

4 Pode-se dizer que metadados são "dados sobre dados". Neste contexto, metadados referem-se a estrutura descritiva da informação sobre outro dado, o qual é usado para ajudar na identificação, descrição, localização e gerenciamento de recursos da $W e b$. 
- Ontologias de Domínio: Descrevem conceitos e vocabulários relacionados a domínios particulares, tais como medicina ou computação, por exemplo. Este é o tipo de ontologia mais comum, geralmente construída para representar um "micromundo".

- Ontologias de Tarefas: Descrevem tarefas ou atividades genéricas, que podem contribuir na resolução de problemas, independente do domínio que ocorrem, por exemplo, processos de vendas ou diagnóstico. Sua principal motivação é facilitar a integração dos conhecimentos de tarefa e domínio em uma abordagem mais uniforme e consistente, tendo por base o uso de ontologias.

- Ontologias de Aplicação: Descrevem conceitos que dependem tanto de um domínio particular quanto de uma tarefa específica. Devem ser especializações dos termos das ontologias de domínio e de tarefa correspondentes (Figura 2). Estes conceitos normalmente correspondem a regras aplicadas a entidades de domínio enquanto executam determinada tarefa.

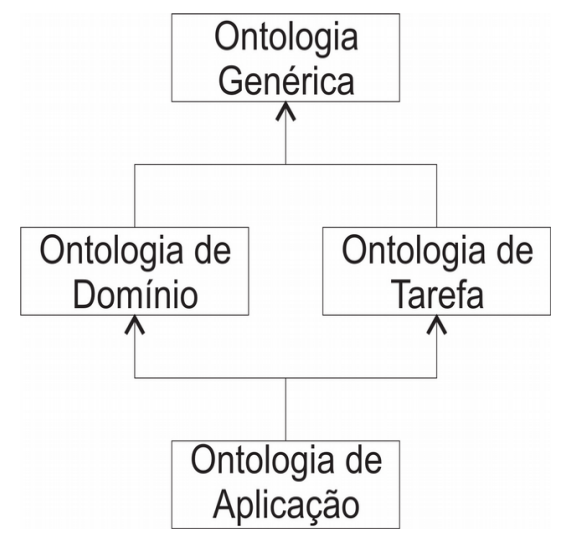

Figura 2: Ontologias de Aplicação (MORAIS; AMBRÓSIO, 2007).

- Ontologias de Representação: Explicam as conceituações que fundamentam os formalismos de representação de conhecimento, procurando tornar claros os compromissos ontológicos embutidos nestes formalismos. 


\subsubsection{Ontologia no contexto da Web Semântica (OWL, RDF e outros padrões)}

\section{A Web Semântica}

A Web Semântica surge como uma possível solução para a estruturação semântica dos dados na $W e b$, viabilizando o processamento da informação por parte das máquinas. Berners-Lee (2001), idealizador da nova $W e b$, cita um exemplo do que a Web Semântica será capaz de fazer (DZIEKANIAK; KIRINUS, 2004).

A $W e b$ Semântica representa a evolução da $W e b$ atual. Enquanto a $W e b$ tradicional foi desenvolvida para ser entendida apenas pelos usuários, a Web Semântica está sendo projetada para ser compreendida pelas máquinas, na forma de agentes computacionais, que são capazes de operar eficientemente sobre as informações, podendo entender seus significados. Desta maneira, elas irão auxiliar os usuários em operações na $W e b$.

O objetivo da Web Semântica é estruturar o conteúdo que está solto na Internet. Para isto é necessário que agentes percorram a rede, página a página para executar tarefas consideradas sofisticadas para o usuário. Esses agentes serão capazes de identificar o significado exato de uma palavra e as relações lógicas entre várias palavras (DZIEKANIAK; KIRINUS, 2004).

Na Figura 3a é apresentado a arquitetura da Web Semântica segundo Hendler, Berners-Lee e Lassila (2001), sendo dividida em três grandes camadas. A camada de estrutura, é responsável por estruturar os dados e definir seu significado. Ela é implementada utilizando as tecnologias eXtensible Markup Language (XML), Resource Description Framework (RDF). A camada de esquema, é composta pelas ontologias que possibilitam a representação de conceitos através de uma taxonomia e um conjunto de regras de inferência. A taxonomia define as classes de objetos e as relações que se estabelecem entre elas. A camada lógica, é responsável por definir mecanismos para se fazer inferência sobre os dados. Tim Berners-Lee (2002), Figura 3b, apresenta uma arquitetura da Web Semântica dividida em sete camadas: 1) Unicode e URI; 2) eXtensible Markup Language (XML); 3) Resource Description Framework (RDF) e 4) Vocabulário ontologia; 5) Lógica; 6) Prova e 7) Validação. 

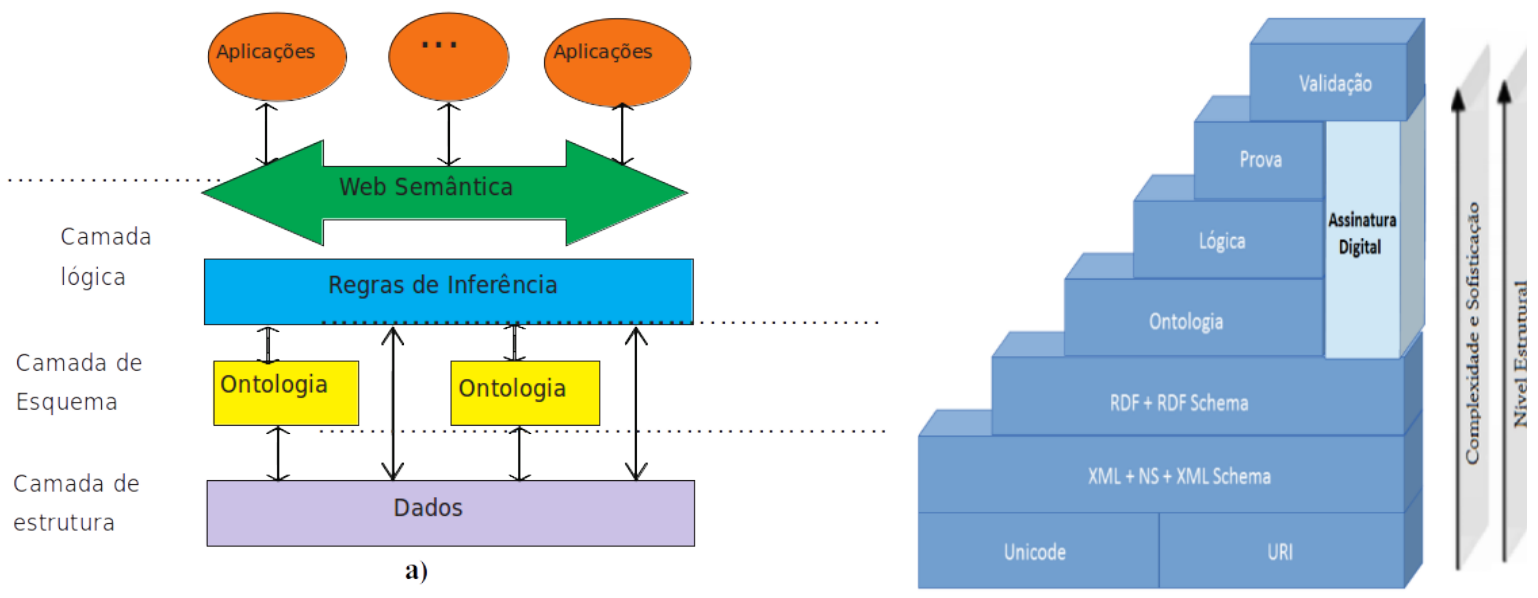

b)

Figura 3: Arquitetura da $W e b$ Semântica (HENDLER, BERNERS-LEE e LASSILA, 2001; BERNERS-LEE, 2002).

Diversas linguagens foram desenvolvidas para representação de ontologias. Alguns exemplos são: RDF/RDF(S), OIL e OWL.

\section{A Linguagem Web Ontology Language (OWL)}

A OWL é recomendada pelo consórcio $\mathrm{W} 3 \mathrm{C}$ como a principal linguagem para a construção de ontologias. Essa linguagem tem como objetivo principal atender às necessidades de aplicação da Web Semântica e ser efetivamente utilizada por aplicações que necessitem processar o conteúdo de informações, e não somente apresentar a visualização de informações (SANTAREM SEGUNDO, 2010, p.127).

A linguagem OWL foi e é projetada para prover uma linguagem de Ontologia que possa ser usada para descrever, de uma forma natural, classes e relacionamentos em documentos e aplicações $W e b$. Os elementos básicos para a construção de uma ontologia OWL são as classes, as instâncias das classes (indivíduos), propriedades e relacionamentos entre classes e instâncias (LIMA; CARVALHO, 2005). 
De acordo com Harmelen e McGuinness (2016), a OWL possui três sublinguagens incrementais projetadas para serem usadas por diferentes comunidades de implementadores e usuários:

- OWL Lite: é uma sub-linguagen da OWL DL (description logics) que usa somente algumas características da linguagem OWL e possui mais limitações do que OWL DL ou OWL Full;

- OWL DL: é usada por usuários que queiram o máximo de expressividade, com completude (todas as conclusões são garantidas serem computáveis) e decidibilidade (todas as computações terminarão em um tempo finito) computacional. Ela inclui todas as construções da linguagem OWL, mas estas construções somente podem ser usadas sob certas restrições. A sigla DL possui correspondência com a lógica descritiva, uma área de pesquisa que estuda um fragmento particular da lógica de primeira ordem;

- OWL Full: é usada por usuários que queiram o máximo de expressividade e independência sintática de Resource Description Framework (RDF), sem nenhuma garantia computacional. A OWL Full e a OWL DL suportam o mesmo conjunto de construções da linguagem OWL, embora com restrições um pouco diferentes. Enquanto a OWL DL impõe restrições sobre o uso de RDF e requer disjunção de classes, propriedades, indivíduos e valores de dados, a OWL Full permite misturar OWL com RDF Schema e não requer a disjunção de classes, propriedades, indivíduos e valores de dados. Isto é, uma classe pode ser ao mesmo tempo uma classe e um indivíduo.

Para Harmelen e McGuinness (2016), a escolha de qual sub-linguagem OWL o desenvolvedor de ontologia deve utilizar é segundo a sua necessidade da Ontologia. A escolha entre OWL Lite e OWL DL dependerá da necessidade das propriedades computacionais da Ontologia.

\section{Resource Description Framework (RDF)}

O RDF tem por objetivo definir um mecanismo de representação de metadados para descrever recursos não vinculados a um domínio específico de aplicação. Resultado do trabalho em conjunto desenvolvido por várias comunidades. O RDF recebeu a influência 
de várias fontes diferentes. As principais influências vieram das comunidades de padronização da Web (HTML, XML e SGML) da Biblioteconomia (metadados de catalogação), da representação do conhecimento (ontologias), da programação orientada a objetos, da linguagem de modelagem, entre outra (DZIEKANIAK; KIRINUS, 2004).

Para (DZIEKANIAK; KIRINUS, 2004), a estrutura de descrição da RDF é composta por três tipos de objetos: recursos, propriedades e triplas. Um recurso é o que será descrito por uma expressão RDF. Todo recurso é identificado por um URI (Uniform Resource Identifier, incluindo aí o Uniform Resource Locator - URL). Uma propriedade é qualquer característica utilizada para descrever um recurso.

\section{Extensible Markup Language (XML)}

O XML nada mais é do que uma linguagem de marcação de dados (metadados) que oferece aos seus usuários a descrição de dados estruturados, facilitando declarações precisas do conteúdo de documentos e mais ainda, facilitando a recuperação destes documentos via Web. A linguagem XML supre as deficiências da HTML, permitindo a criação de marcações definidas pelo próprio usuário e, desta forma, proporcionando uma maior descrição dos recursos em termos de metadados (DZIEKANIAK; KIRINUS, 2004).

Na Tabela 5, pode-se observar uma comparação entre as principais linguagens para ontologias (Adaptado de HINZ, 2006).

Tabela 5: Comparativo de Linguagens para Ontologias (Adaptado de HINZ, 2006).

\begin{tabular}{|c|c|c|c|}
\hline & RDF & OIL & OWL \\
\hline Objetivo & $\begin{array}{lrr}\text { Tornar possível } & \text { a } \\
\text { especificação } & \text { de } \\
\text { regras } & \text { semânticas para } \\
\text { dados } & \text { baseados } & \text { em } \\
\text { XML } & \text { de } & \text { maneira } \\
\text { padronizável } & \text { e } \\
\text { interoperável. } & \text { Definir } \\
\text { um } & \text { mecanismo } \\
\text { independente } & \text { de } \\
\text { domínio. Definir } & \text { um } \\
\text { mecanismo } & \text { para } \\
\text { descrever } & \text { recursos. }\end{array}$ & $\begin{array}{l}\text { Representação de uma } \\
\text { semântica de } \\
\text { informação acessível } \\
\text { para a máquina } W e b .\end{array}$ & $\begin{array}{l}\text { É um documento XML, } \\
\text { RDF, RDFS Originado } \\
\text { devários projetos: } \\
\text { DARPA (DAML) + EU } \\
\text { Project (OIL) }\end{array}$ \\
\hline
\end{tabular}




\begin{tabular}{|c|c|c|c|}
\hline & \begin{tabular}{lr}
\multicolumn{3}{l}{ interoperável Definir } \\
um mecanismo \\
independente r de \\
domínio Definir um \\
mecanismo para \\
descrever recursos.
\end{tabular} & & \\
\hline $\begin{array}{l}\text { Primitivas de } \\
\text { Representação }\end{array}$ & $\begin{array}{l}\text { Especificação } \\
\text { composta por rdfms e } \\
r d f \text { Representação por } \\
\text { conjunto de triplas: } \\
\text { recurso propriedade } \\
\text { valor } r \text { Objetos } \\
\text { identificados por URI } \\
\text { Elemento base é a } \\
\text { sentença representada } \\
\text { por grafos dirigidos. } \\
\text { Usa namespaces para } \\
\text { associar propriedades, } \\
\text { containers, statements } \\
\text { sobre statements. }\end{array}$ & & 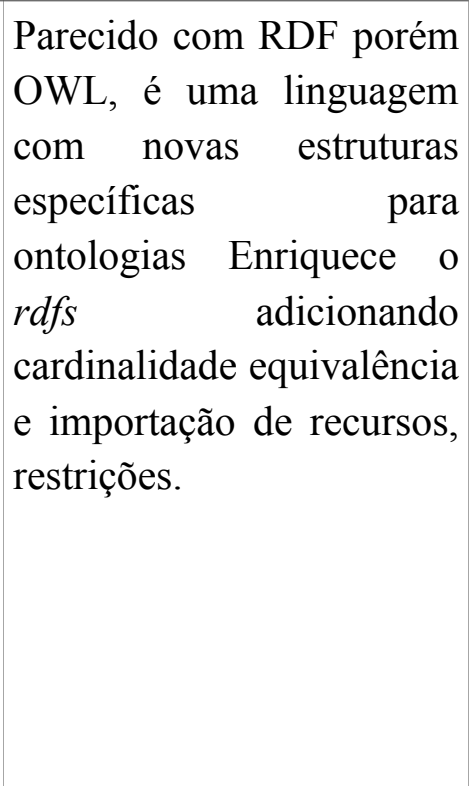 \\
\hline $\begin{array}{l}\text { Propriedades } \\
\text { lógicas }\end{array}$ & & & $\begin{array}{l}\text { Baseado em classes e tudo } \\
\text { é derivado de OWL: thing }\end{array}$ \\
\hline Vantagens & $\begin{array}{l}\text { RDFs define o } \\
\text { significado } \\
\text { estrutura usando os } \\
\text { tags estabelecidos em } \\
\text { seu modelo Provê tags } \\
\text { para definir classes, } \\
\text { subclasses } \\
\text { propriedades Permite } \\
\text { restrições de domínio } \\
\text { e de valores (range) e, } \\
\text { propriedades. }\end{array}$ & 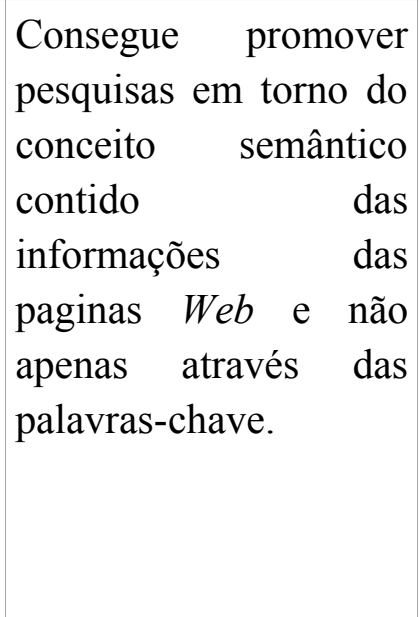 & $\begin{array}{l}\text { Subdividido em } 3 \\
\text { sublinguagens: Lite, DL e } \\
\text { FULL. }\end{array}$ \\
\hline
\end{tabular}

\subsubsection{Ontologia da Anatomia da Mama Feminina (ONTO-MAMA)}

No projeto “Atlas Anatômico 3D Aplicado a Mama”, registrado no Laboratório Nacional de Computação Científica (LNCC), Instituto Nacional de Ciência e Tecnologia em Medicina Assistida por Computação Científica (INCT-MACC), desde 2008. Ele possui 
diversos colaboradores em que cada um destes realizam tarefas diversificadas objetivando o sucesso do projeto. O campus da Universidade de Brasília (UnB) da Faculdade Gama (FGA) e a Universidade Católica de Brasília (UCB) são parceiras deste projeto nacional, sendo criado um modelo ontológico que representa a descrição da Ontologia da Anatomia da Mama Feminina (ONTO-MAMA), em uma linguagem formal denominada Web Ontology Language (OWL), capaz de prover o acesso facilitado e automatizado do conhecimento, como visto o modelo ONTO-MAMA na Figura 4.

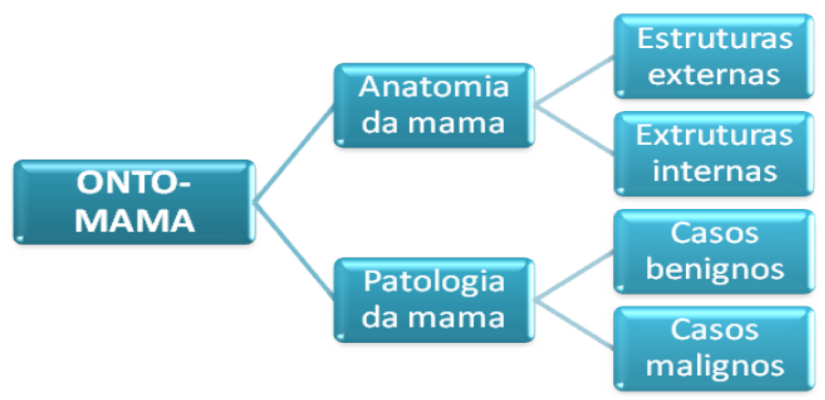

Figura 4: Modelo ONTO-MAMA (KLAVDIANOS (2011).

O ONTO-MAMA é parte do projeto científico mais amplo chamado "Atlas Anatômico 3D Anatomical Atlas aplicados na mama". O projeto começou em julho de 2008, e seu objetivo é a busca de novas propostas para a formação de alunos em áreas relacionadas com a anatomia da mama humano, em oposição ao ensino da anatomia clássica usando a dissecação de cadáveres (KLAVDIANOS, 2011).

A descrição do ONTO-MAMA pode ser realizada sobre diversos pontos de vistas e com maior ou menor grau de detalhamento. Assim sendo, para o projeto "Atlas Anatômico 3D Aplicado a Mama", o modelo ontológico procurou abranger as seguintes visões e detalhamentos:

- Anatomia da mama: O modelo ontológico definirá os conceitos para o estudo da anatomia da mama feminina de acordo com diversos perfis de profissionais atuantes na área médica. O estudo das estruturas anatômicas da mama (morfologia 
mamária) levará em consideração tanto as estruturas externas quanto as internas, incluindo neste último caso, algumas estruturas de origem molecular.

- Patologia da mama: O modelo ontológico definirá conceitos e procedimentos para diagnóstico, acompanhamento de grupo de risco, prevenção e tratamento das principais doenças (benignas ou malignas) associadas à mama feminina.

As duas partes do modelo se inter-relacionam de modo a prover maior detalhamento do domínio de conhecimento. Os conceitos ou elementos da ontologia são formalizados em OWL através da descrição de classes, propriedades, regras formais e relacionamentos. Além disso, diversas instâncias da mama feminina foram criadas de modo a descrever conceitos mais completos e complexos. Essas instâncias poderão conter, além das descrições textuais comumente encontradas nos modelos ontológicos, informações provenientes de diversas mídias, em especial: radiologias em formato DICOM, imagens em 2D ou 3D, vídeos e links externos (artigos ou outras informações de fontes externas).

Inicialmente pretendia prover a descrição da mama considerando os diversos níveis de profissionais atuantes na área médica. Esses níveis de profissionais assim como as informações interessantes para cada perfil foram objetos de estudo dos profissionais envolvidos com a construção do ONTO-MAMA.

A construção do modelo ontológico envolveu as etapas de especificação, conceitualização, formalização do conhecimento, implementação e manutenção. Neste aspecto, alguns resultados parciais de cada uma dessas etapas já foram obtidos, na Figura 5 tem-se a Infraestrutura da do ONTO-MAMA desenvolvida pela (KLAVDIANOS, 2011). 


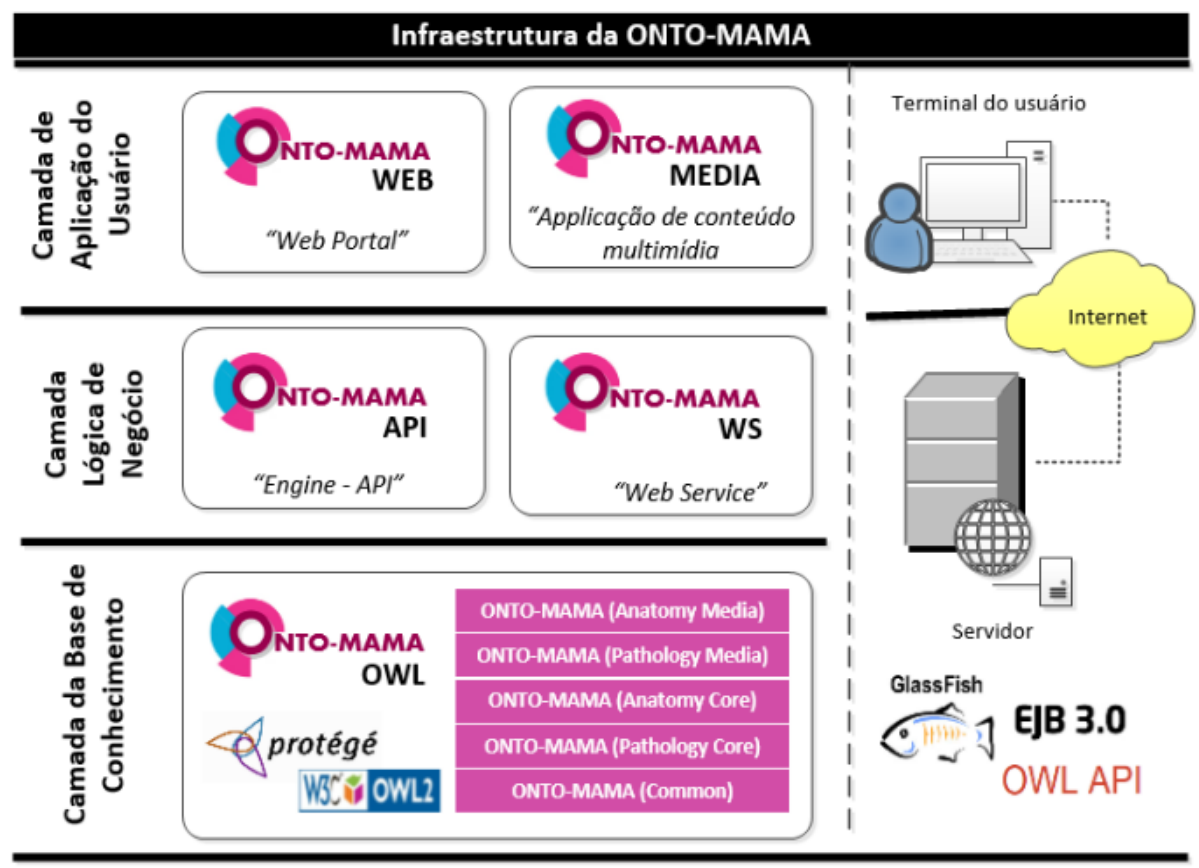

Figura 5: Infraestrutura do ONTO-MAMA (KLAVDIANOS, 2011).

- ONTO-MAMA OWL: arquivo em formato OWL que formaliza a ontologia de acordo com a perspectiva da anatomia e patologia da mama feminina. Tal modelo será construído conforme a especificação OWL 2.0 e utilizando-se o editor de ontologias Protégé mantido pela Universidade de Stanford. O modelo OWL final será construído a partir da versão existente do ONTO-MAMA que compreende, atualmente, a descrição anatômica das estruturas externas e internas da mama. Tal modelo será revisto e complementado para incluir também informações sobre a patologia da mama feminina. Além disso, a ontologia irá prover a representação das diversas instâncias da mama utilizando-se de recursos multimídia como, por exemplo, imagens, animações e vídeo. Na Figura 6 apresenta estrutura do ONTOMAMA OWL desenvolvida por (KLAVDIANOS, 2010). 


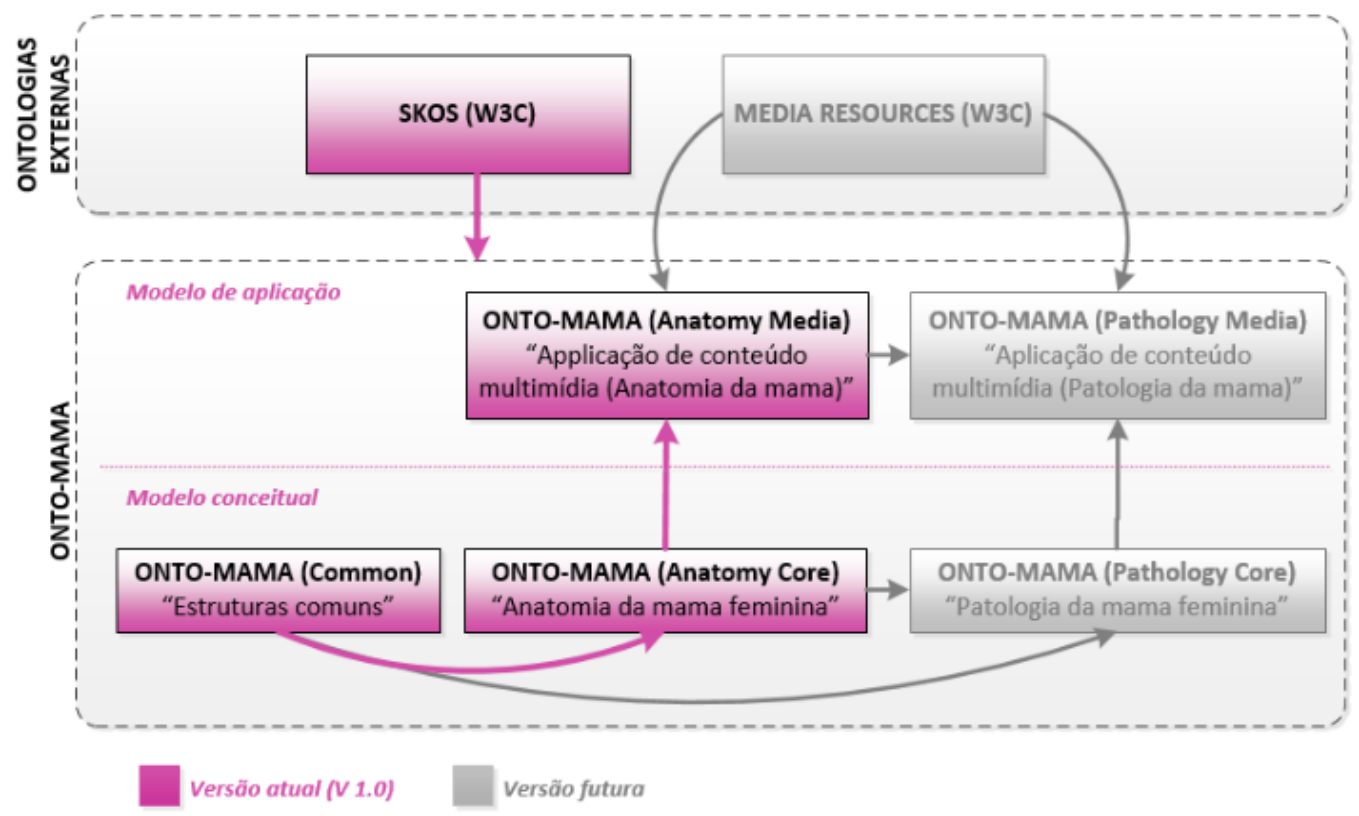

Figura 6: Estrutura do ONTO-MAMA OWL (KLAVDIANOS, 2010).

- ONTO-MAMA Engine: biblioteca de software desenvolvida para consulta e recuperação de informações descritas pelo modelo ontológico. A ONTO-MAMA Engine pode ser entendida como sendo o mecanismo inteligente de recuperação e processamento das informações contidas no modelo ontológico. Sob o ponto de vista tecnológico, este protótipo será construído em Java com o apoio da OWL API. A OWL API é uma biblioteca opensource inicialmente desenvolvida pela Universidade de Manchester. A equipe do projeto pretende, adicionalmente, realizar testes com a framework denominada Jena do grupo Apache. Os estudos destas duas soluções tecnológicas nos fornecerão uma visão mais realista sobre o desenvolvimento de aplicações envolvendo Web Semântica no domínio da saúde. Sob o ponto de vista da pesquisa científica a ONTO-MAMA Engine será desenvolvida com base nas pesquisas mais atuais da área de IA. Assim, conterá mecanismos inteligentes para inferência de estruturas, relacionamentos e regras que não foram explicitamente descritas no modelo de ontologia.

- ONTO-MAMA WS: Web Services (WS) desenvolvido em Java para consulta e recuperação de informações descritas pelo modelo ontológico. O ONTO-MAMA WS permitirá que outros aplicativos utilizem o modelo ontológico através de uma 
simples invocação do WS. A produção de serviços Web semântico será o foco principal deste protótipo que terá como base de desenvolvimento o OWL-based Web Service Ontology (OWL-S) do grupo DAML Services mantido pelo W3C Consortium. Como este é um tópico novo para a comunidade que trata de Web semântica, parte do trabalho da equipe do ONTO-MAMA será analisar as potencialidades e limitações envolvidas na produção de Web Services a partir de modelos de ontologia. Como resultado final, pretende-se publicar os serviços provenientes da ONTO-MAMA Engine a serem consumidos por clientes devidamente autorizados.

- ONTO-MAMA Portal: portal na $W e b$ para a divulgação do ONTO-MAMA e recebimento da opinião da comunidade científica. Este protótipo tem como objetivo dar publicidade ao trabalho da equipe do ONTO-MAMA, além de fornecer um canal de comunicação constante com a comunidade científica. Através do ONTOMAMA Portal, os interessados poderão fazer o download das ferramentas e fornecer opinião sobre o trabalho desenvolvido. Além disso, pretende-se publicar uma versão web do modelo ontológico que deve ser analisado especialmente por profissionais da área da saúde. Deste modo, poderemos colher online a opinião de especialistas da área da saúde, o que garantirá a contínua evolução do modelo. A base tecnológica para a construção do Portal será a linguagem Java. Adicionalmente, utilizar-se-á Web Protégé que é um editor de ontologias Web e que deverá ser modificado para contemplar requisitos de segurança e desempenho;

- Media Resources (W3C): é um vocabulário básico. O Ontology for Media Resources 1.0 é um vocabulário central (um conjunto de propriedades que descrevem recursos de mídia) e seu mapeamento para um conjunto de formatos de metadados que atualmente descrevem recursos de mídia publicados na Web. O objetivo dos mapeamentos é fornecer um conjunto interoperável de metadados, permitindo que diferentes aplicativos compartilhem e reutilizem esses metadados. O conjunto de propriedades do Ontology for Media Resources 1.0 foi selecionado com respeito ao conjunto de elementos mais adotado a partir de formatos de metadados atualmente em uso para descrever recursos de mídia, sendo alguns o RDF, Turtle (TTL), OWL 2, (Media Resources, 2016); 
- Simple Knowledge Organization System (SKOS): o SKOS é uma área de trabalho que desenvolve especificações e padrões para apoiar o uso de sistemas de organização do conhecimento, tais como thesauri, esquemas de classificação, sistemas de cabeçalho e taxonomias no âmbito da Web Semântica. Fornece uma forma padrão de representar sistemas de organização do conhecimento usando o RDF. A codificação dessas informações no RDF permite que ele seja passado entre aplicativos de computador de uma forma interoperável. Também permite que os sistemas de organização do conhecimento sejam usados em aplicativos distribuídos e descentralizados de metadados (SKOS, 2016).

\subsubsection{Modelos ontológicos na medicina}

Existem muitas metodologias para a criação de ontologias. Elas tem o intuito de sistematizar a construção e a manipulação. No entanto, algumas das metodologias descritas a seguir são aquelas que hoje são as mais utilizadas tecnicamente pela comunidade científica, sendo elas:

- Methontology: Ela é baseada na construção de ontologia a partir do conhecimento de um domínio. Suas atividades principais são especificação de requisitos, conceitualização do domínio do conhecimento, formalização do modelo conceitual em uma linguagem formal, implementação de um modelo formal e manutenção de ontologias implementadas. Esta metodologia possui ainda atividades de suporte desempenhadas durante o processo de construção da ontologia, isto é, aquisição do conhecimento, integração, avaliação, documentação e gerenciamento de configuração. Na Figura 7 é ilustrada essas etapas da Methontology (MARAFFI, 2004). 


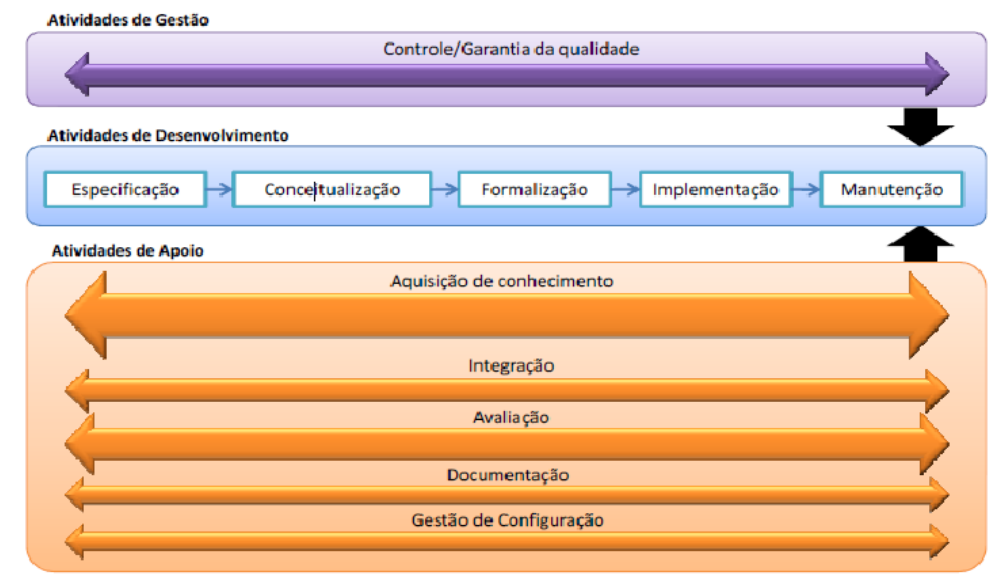

Figura 7: Etapas da Methontology.

- Enterprise: É baseada em quatro fases vista na Figura 8, isto é, identificação do propósito, identificação do escopo, formalização e documentação formal. A identificação do propósito determina o nível de formalidade que a ontologia deve ser descrita; Na identificação do escopo uma especificação é produzida de acordo com o domínio que a ontologia precisa representar; A formalização é a criação do código, definições formais e axiomas relacionados à ontologia; A documentação formal é a fase onde a ontologia será documentada e as fases de identificação do escopo e formalização podem ser revistas (MORAIS; AMBRÓSIO, 2007).

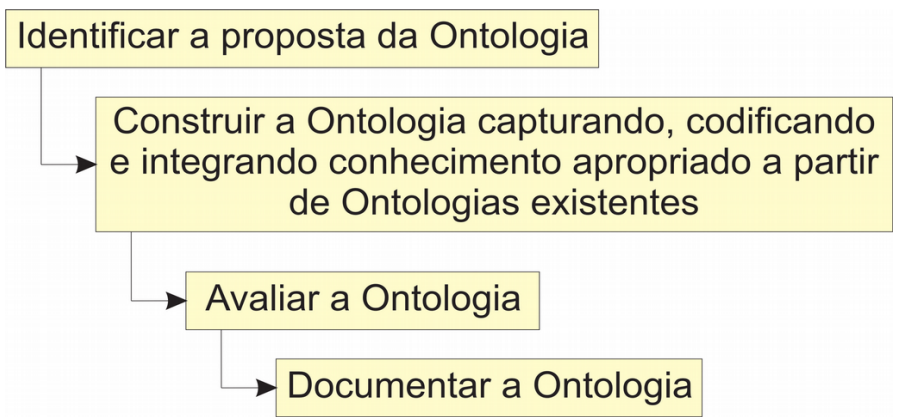

Figura 8: Metodologia Enterprise (MORAIS; AMBRÓSIO, 2007).

- On-To-Knowledge: Está metodologia é baseada em quatro fases como vista na Figura 9 sendo: kick-off, refinamento, avaliação e manutenção. No kick-off os requisitos para construção da ontologia são capturados e especificados, questões de 
competência são identificadas, ontologias potencialmente reutilizáveis são estudadas e uma primeira versão da ontologia é construída (MORAIS; AMBRÓSIO, 2007).

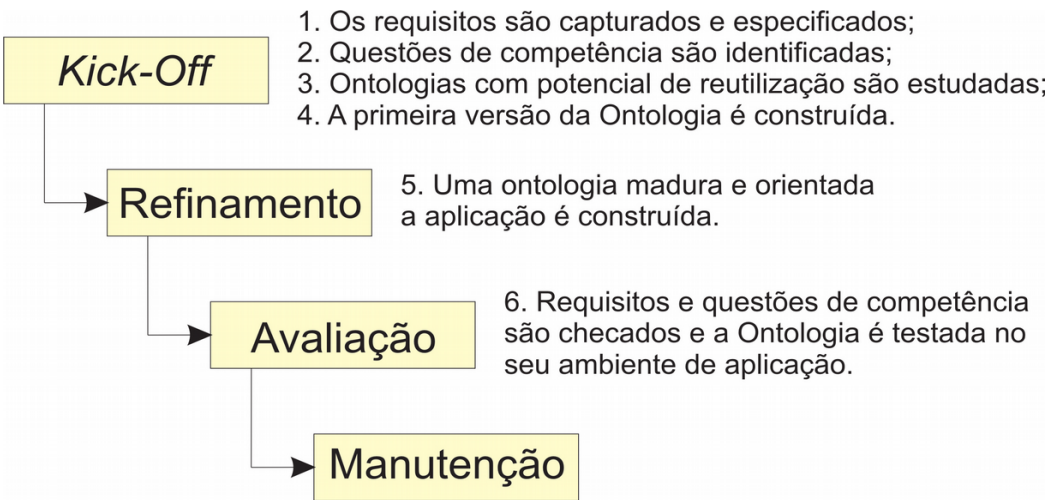

Figura 9: Metodologia On-To-Knowledge (MORAIS; AMBRÓSIO, 2007).

- Systematic Approach for Building Ontologies (SABIO): É baseada na Methontology, utilizado pela Universidade Federal do Espírito Santo (UFES). Esta metodologia tem foco no desenvolvimento de ontologias de domínio, assim como distinção entre Ontologias de Referência e Ontologias Operacionais, ainda que o processo de desenvolvimento proposto sugira uma sequência na realização de suas atividades. SABIO não prescreve um modelo de ciclo de vida específico. Ao contrário, quaisquer modelos de ciclo de vida podem ser usados, mas sugere fortemente o uso de modelos de ciclo de vida incrementais e iterativos, como pode ser visto na Figura 10. Na ilustração percebe-se que a identificação e a captura sempre volta para uma melhor identificação e os demais processos seguem todos em uma única direção (FALBO, 2015). 


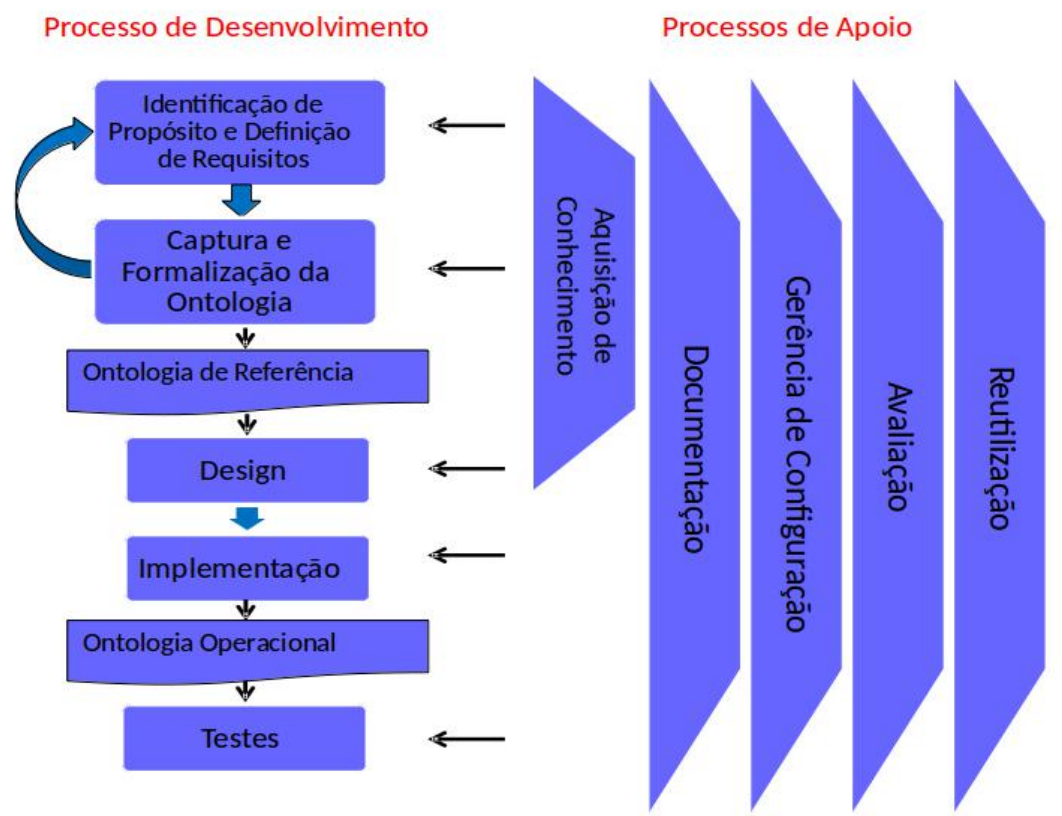

Figura 10: Metodologia SABIO (FALBO, 2015).

Existem outras metodologias voltadas a ontologia. Contudo, devido a estar fora do escopo desse trabalho, algumas delas são apenas citadas: Metodologia Gruninger e Fox; Método Uschold e King; Método Kactus; Método 101; Ontologia SENSUS; Ontobio; Medical Subject Headingns (MeSH); Gene Ontology (GO); Open Biomedical Ontologies (OBO); Foundational Model of Anatomy (FMA), SNOMED Clinical Terms (SNOMED CT) (FREITAS; SCHULZ; MORAES, 2009).

\subsubsection{Ferramentas computacionais para criação e manutenção de modelos ontológicos}

Existem várias ferramentas para a criação de ontologia, como; WebODE, OntoEdit, Menthor Editor, falara-se apenas uma delas, do Protégé por ser a mais utilizada dentro da revisão da literatura, todas essas ferramentas utilizam uma das metodologias mencionadas. 


\section{Protégé}

O Protégé uma ferramenta opensource multiplataforma podendo ser instalado no Windows, MacOSX e GNUILinux para a construção da ontologia e para a construção de modelos de domínio e aplicações baseados no conhecimento de ontologias. É um ambiente de desenvolvimento de ontologias para a Web que torna mais fácil criar, carregar, modificar e compartilhar ontologias para visualização e edição colaborativa.

Atualmente, a versão estável do Protégé utilizada pela comunidade técnica científica se encontra na versão 5.1 lançado este ano, corrigido alguns erros e versão 5.0 foi implementado um plugin para importação de planilhas. Desde a versão 4.0, possui a interoperabilidade, que nas versões anteriores não possuía, tendo a necessidade de refazer a ontologia criada, a qual utiliza inicialmente apenas os recursos padrão do aplicativo e a sua representação OWL, utilizada somente como um editor de ontologia. Vale ressaltar que o Protégé é mais que um editor, ele é uma ferramenta de recursos "ilimitado" uma vez que permite instalar qualquer plugin.

Para SABINO e HEINZLE (2015), a estrutura padrão de uma ontologia $O W L$, escrita com a ferramenta Protégé, é composta por duas tags: $<$ Ontology $>$ e $</$ Ontology $>$. A primeira tag indica o início da ontologia, enquanto a segunda a finaliza. Após isso, a ontologia é descrita como um conjunto de declarações, cada qual indicando um ferramental utilizado para representar o conhecimento (classe ou relacionamento). As declarações são representadas através de blocos contidos entre as tags: <Declaration $>$ e $</$ Declaration $>$ (Protégé, 2016), é composta por duas tags: $<$ Ontology $>$ e $</$ Ontology $>$. Para se definir uma classe dentro de um arquivo $O W L$ utiliza-se a tag <Class IRI="\#nome DaClasse"/> onde nomeDaClasse é definida como uma Internationalized Resource Identifier (IRI) é definida como nome que se deseja denominar a classe. Uma Object Property denota a relação entre classes. Para descrevê-la faz-se uso da tag <ObjectProperty $I R I=" \#$ nomeDaPropriedade"/>, onde o nomeDaPropriedade é denotado através de uma IRI. A Object Property contém um domínio e um escopo. A definição do domínio ocorre colocando uma Object Property e uma classe entre as tags $<$ ObjectPropertyDomain $>$ e $</$ ObjectPropertyDomain $>$. A definição de um escopo é envolta pelas tags $<$ ObjectPropertyRange $>$ e $<$ /ObjectPropertyRange $>$. 
Para baixar e instalar o Protégé, assim como ver a documentação, basta acessar o site do Protégé. O Protégé tem uma versão web, que pode ser utilizado mediante a criação de um login. Existe uma comunidade forte onde é possível retirar dúvidas e fazer perguntas no Twitter e no Facebook. No site Stack Overflow é possível realizar pesquisas e perguntas sobre OWL. Na Figura 11 é mostrada a versão 5.1 do Protégé 2016 instalado no Linux Mint 18 (PROTÉGÉ, 2016).

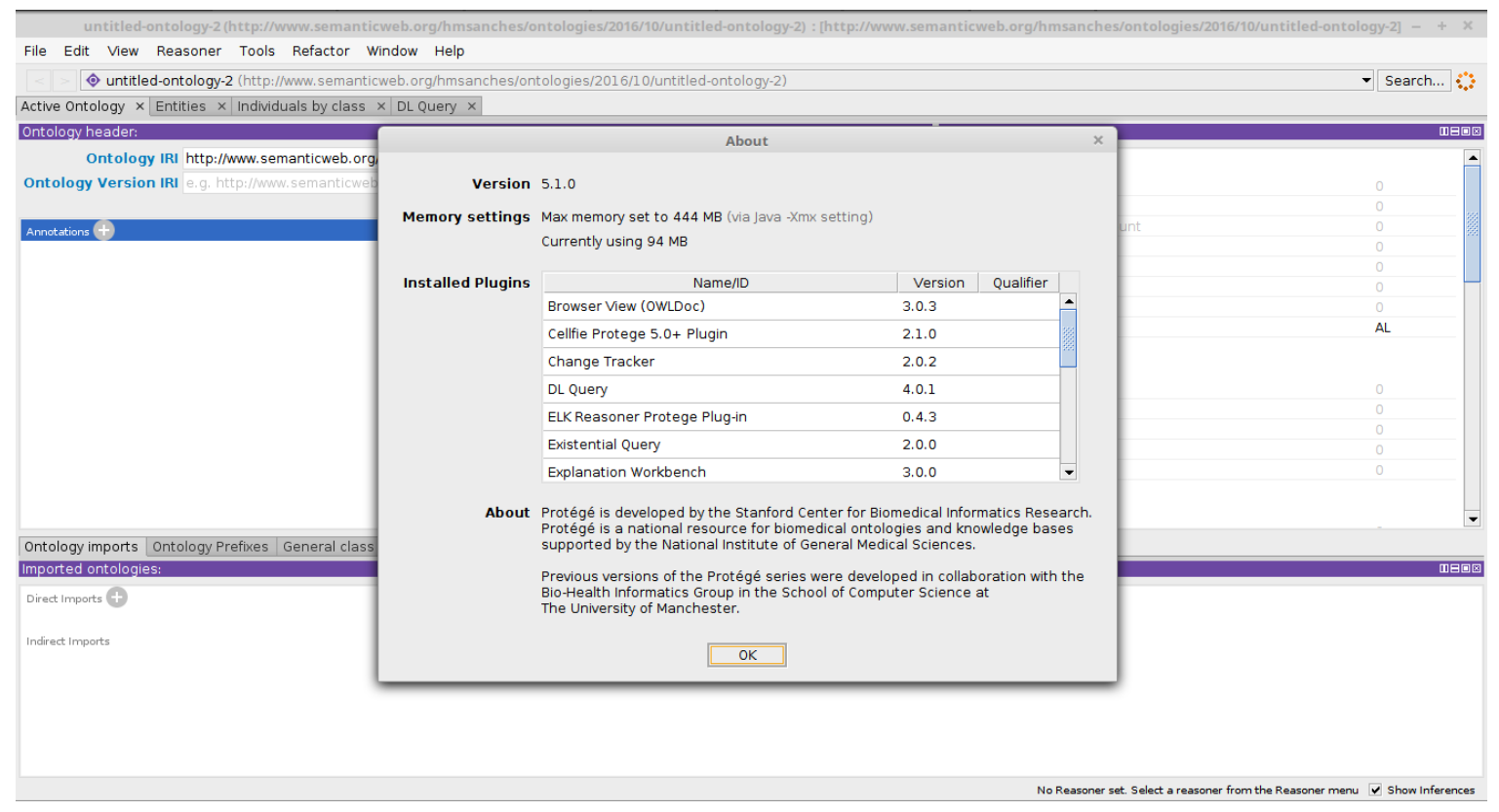

Figura 11: Protégé Versão 5.1 Instalado no Linux Mint 18.

O Protégé 5.1 está rápido ao abrir sem a necessidade de instalar o Java, compativél com o Open Java Development Kit (OpenJDK), sendo uma versão baseada no Java totalmente em software livre e de código aberto vindo instalado por padrão em inúmeras distribuições GNU/Linux e no Linux Mint 18.

Ao abrir o Protégé e maximizar, observa-se como são divididas as abas com as funcionalidades da ferramenta e quais as funcionalidades utilizadas para criar a ontologia da mama feminina, bem como utilizada para criar a neoplasia mamária, como é mostrada na Figura 12. 


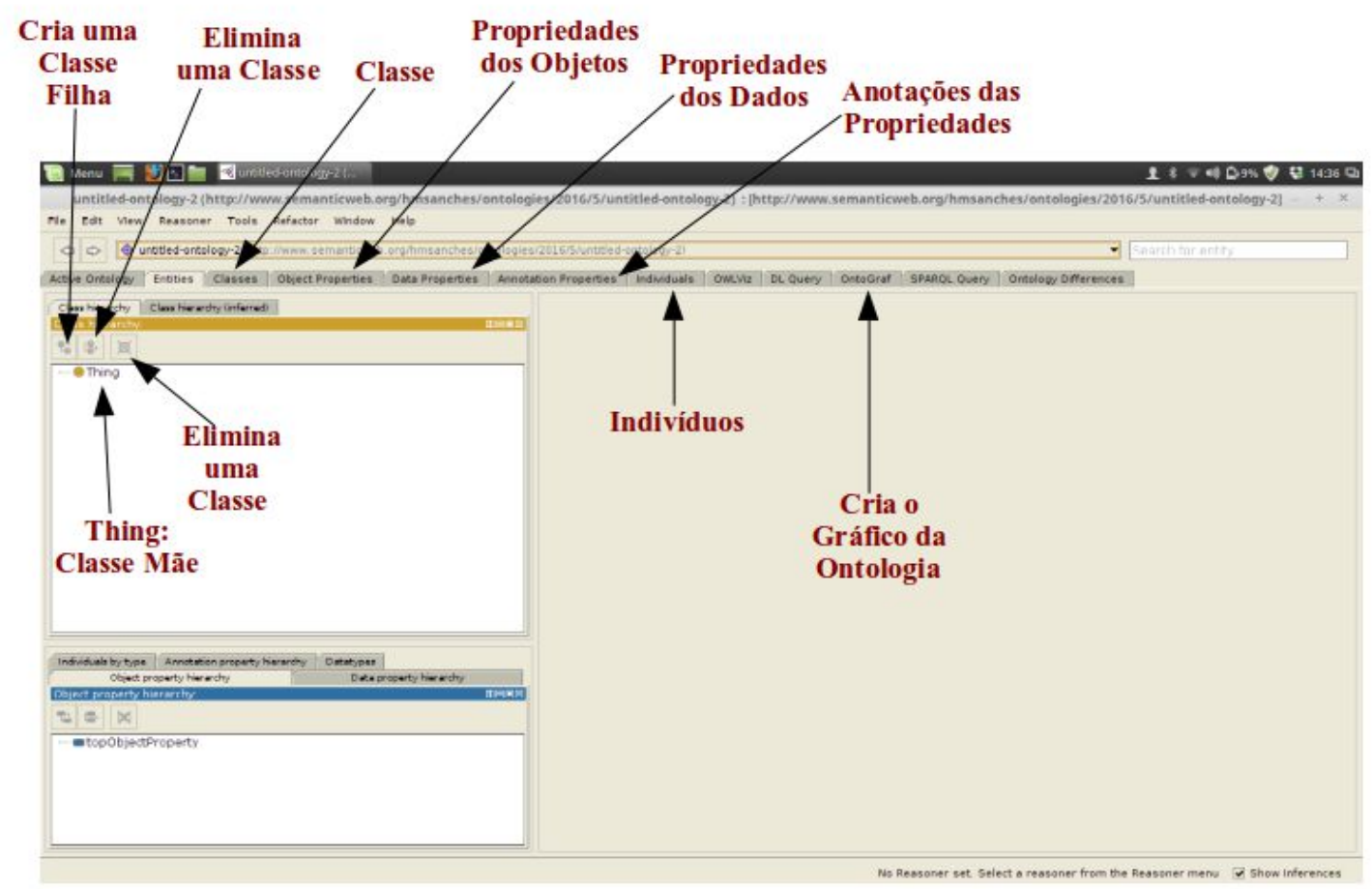

Figura 12: Protégé 5.1 Aberto com suas Abas no Linux Mint 18.

Para obter informações sobre ferramentas de criação de ontologia pode ser encontrado no site da W3C, mas, por se tratar de uma tarefa dispendiosa, qualquer apoio na construção de ontologias pode representar ganhos significativos. Na Tabela 6 apresenta algumas ferramentas para a construção de ontologias (Adaptado de HINZ, 2006).

$\mathrm{Na}$ Tabela 14, segundo o Apêndice 1, apresenta-se os formatos que podem ser salvos no Protégé 5.1. 
Tabela 6: Ferramentas para Construção de Ontologias (Adaptado de HINZ, 2006).

\begin{tabular}{|c|c|}
\hline Ferramenta & Descriçãa \\
\hline OntoEdit & $\begin{array}{l}\text { É um ambiente gráfico para edição de ontologias que permite } \\
\text { inspeção, navegação, codificação e alteração de ontologias. O modelo } \\
\text { conceitual é armazenado usando um modelo de ontologia que pode ser } \\
\text { mapeado em diferentes linguagens de representação. As ontologias } \\
\text { são armazenadas em bancos relacionais e podem ser implementadas } \\
\text { em XML, FLogic, RDF(S) e DAML+OIL (MAEDCHE; VOLZ, } \\
\text { 2001). }\end{array}$ \\
\hline WebODE & $\begin{array}{l}\text { É um ambiente para engenharia ontológica que dá suporte à maioria } \\
\text { das atividades de desenvolvimento de ontologias. A integração com } \\
\text { outros sistemas é possível, importando e exportando ontologias de } \\
\text { linguagens de marcação. Integrado serviço de importação e exportação } \\
\text { em XML, RDF(S), DAML + OIL, OWL, CARIN, FLogic, Jess, } \\
\text { Prolog (WebODE, 2016). }\end{array}$ \\
\hline $\begin{array}{c}\text { Menthor Editor } \\
\text { (ME) }\end{array}$ & $\begin{array}{l}\text { O ME é uma ferramenta de modelagem multiplataforma que roda no } \\
\text { Windows, GNULLinux e MacOSX, sendo um software livre que } \\
\text { constrói, valida e implementa as ontologias criadas utilizando a } \\
\text { especificação OntoUML sendo baseada nos padrões da Unified } \\
\text { Modeling Language (UML). Em conformidade com as distinções } \\
\text { ontológicas de uma teoria bem fundamentada, com o nome de Unified } \\
\text { Ontology Fundamental (UFO) (MENTHOR, 2016). }\end{array}$ \\
\hline Protégé & $\begin{array}{l}\text { É um ambiente interativo para projeto de ontologias de código aberto, } \\
\text { que oferece uma interface gráfica para edição de ontologias e uma } \\
\text { arquitetura para criação de ferramentas baseadas em conhecimento. A } \\
\text { arquitetura é modulada e permite a inserção de novos recursos } \\
\text { (PROTÉGÉ, 2016). }\end{array}$ \\
\hline
\end{tabular}




\section{METODOLOGIA}

\subsection{O Ambiente de Estudo}

Este estudo foi uma parceria do curso de Pós-Graduação em Engenharia Biomédica (PPGEB), da UnB/FGA e o Ambulatório de fisioterapia oncológica do UnB/HUB. Os profissionais do Ambulatório cederam uma planilha eletrônica no formado “.xls”, com 186 pacientes, contendo as iniciais dos pacientes, idade, ano de cada tratamento, o lado da mama no qual foi realizado o tratamento, o tipo de tratamento e a fisioterapia realizada. $\mathrm{O}$ estudo teve apoio da equipe de fisioterapeutas do ambulatório de oncologia do Hospital Universitário de Brasília (HUB), incluindo a fisioterapeuta Luísa Costa e a Profa. Dra. Liana B. Gomide Matheus, e foi aprovado pelo comitê de ética em pesquisa $n^{\circ}$ 031/2012 conforme documento no Anexo 1. Com os dados foi possível a criação de um diagrama de blocos e de fluxogramas para descrever o tratamento da neoplasia mamária.

\subsection{Delimitação do Estudo}

Este estudo considerou apenas a ontologia no tratamento da neoplasia mamária, tendo como foco o conceito e o fluxo/procedimento adotado. A metodologia de trabalho adotada não procurou analisar as atividades associadas à gestão e a manutenção das tecnologias estudadas, nem tão pouco descrever o processo de implantação dessas tecnologias. Segue a Figura 13, que demonstra o diagrama de bloco de tratamento da NM. Nesta figura é apresentado o processo de coleta de informações por meio do atendimento clínico e exames, bem como a classificação do BI-RADS e, em seguida, o tratamento da neoplasia mamária. 


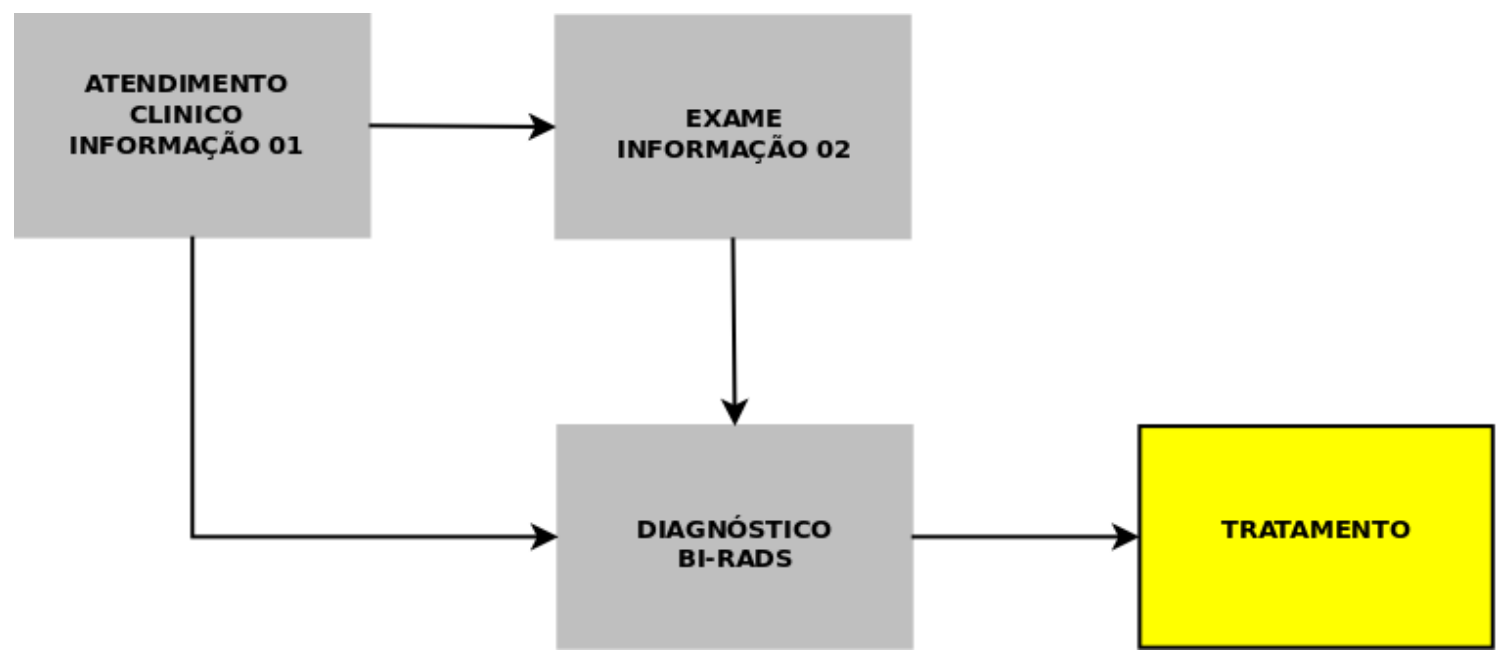

Figura 13: Diagrama de Bloco de Tratamento da Neoplasia Mamária.

$\mathrm{Na}$ Figura 14 é ilustrado o fluxograma do tratamento da NM, em que as cores em cinza representam o diagnóstico do paciente e o encaminhamento deles para o tratamento paliativo, o qual não foi foco desse estudo. Quanto a cor laranja, ela indica o processo de tratamento estudado. Após o tratamento clínico da neoplasia mamária, o paciente é encaminhado para o tratamento das sequelas.

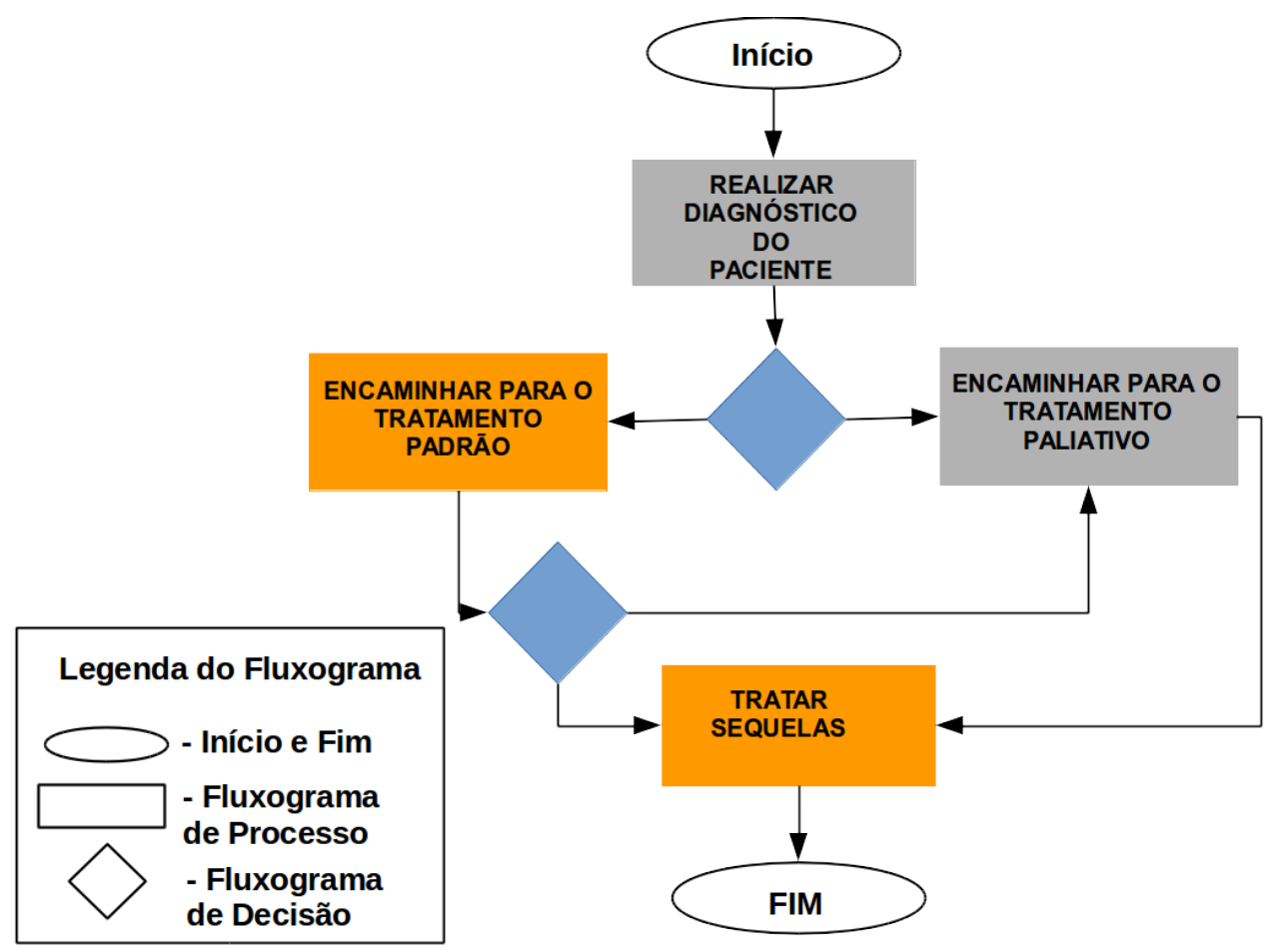

Figura 14: Fluxograma do Tratamento da NM. 
Na Figura 15 é ilustrado o fluxograma do tratamento cirúrgico, em que o processo é iniciado com o diagnóstico do paciente com a classificação BI-RADS, a escolha do tratamento cirúrgico, a tomada de decisão com o tipo de cirurgia que será realizada e, posteriormente, encaminhado para a fisioterapia para o tratamento das sequelas.

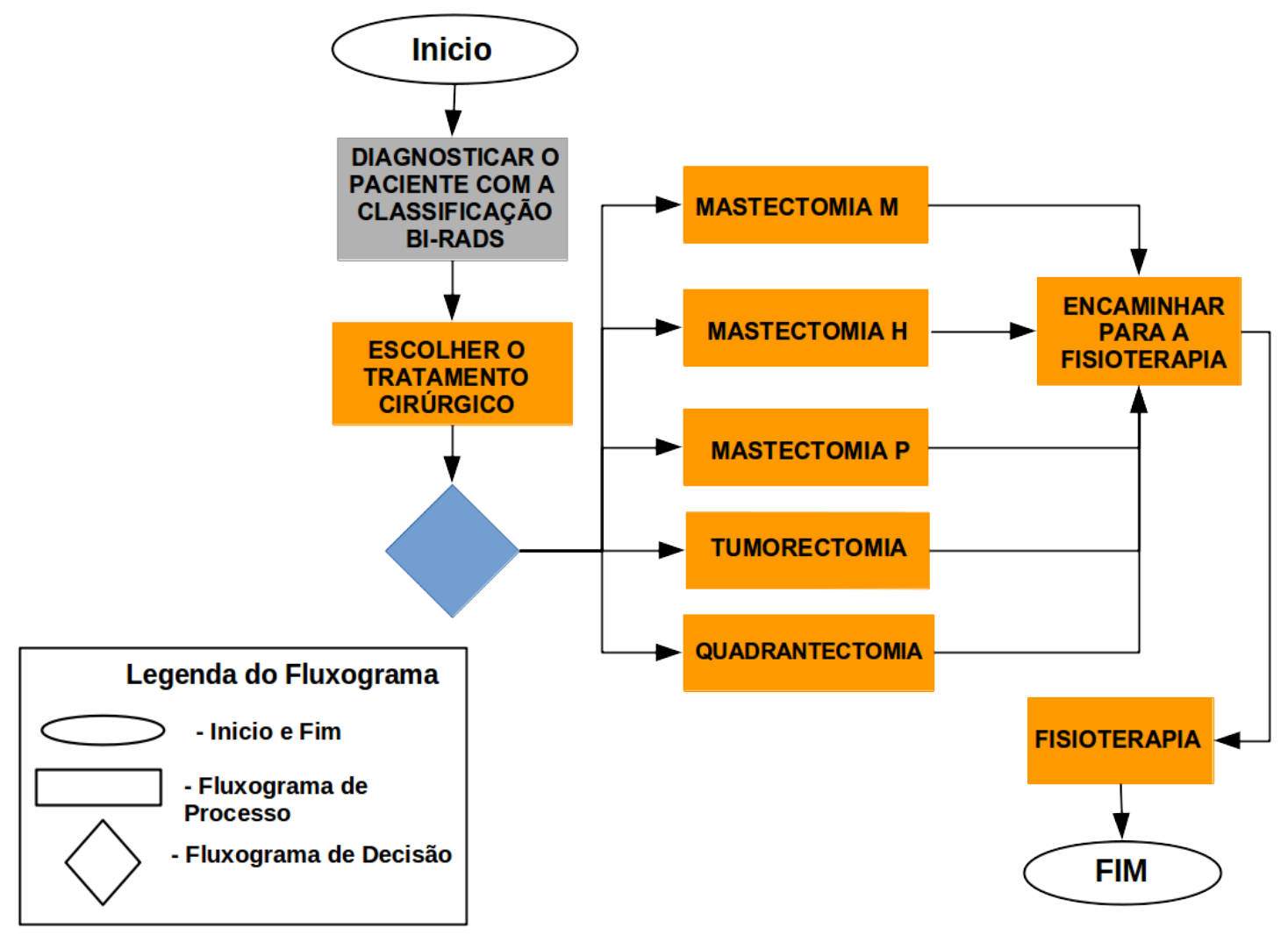

Figura 15: Fluxograma dos Tratamentos Cirúrgicos Encaminhados para Fisioterapia.

Na Figura 16 é apresentado o fluxograma do tratamento da fisioterapia, em que o especialista toma a decisão com a escolha de um ou mais recursos terapêuticos, avalia e toma a decisão de continuar ou não com o tratamento fisioterapêutico. 


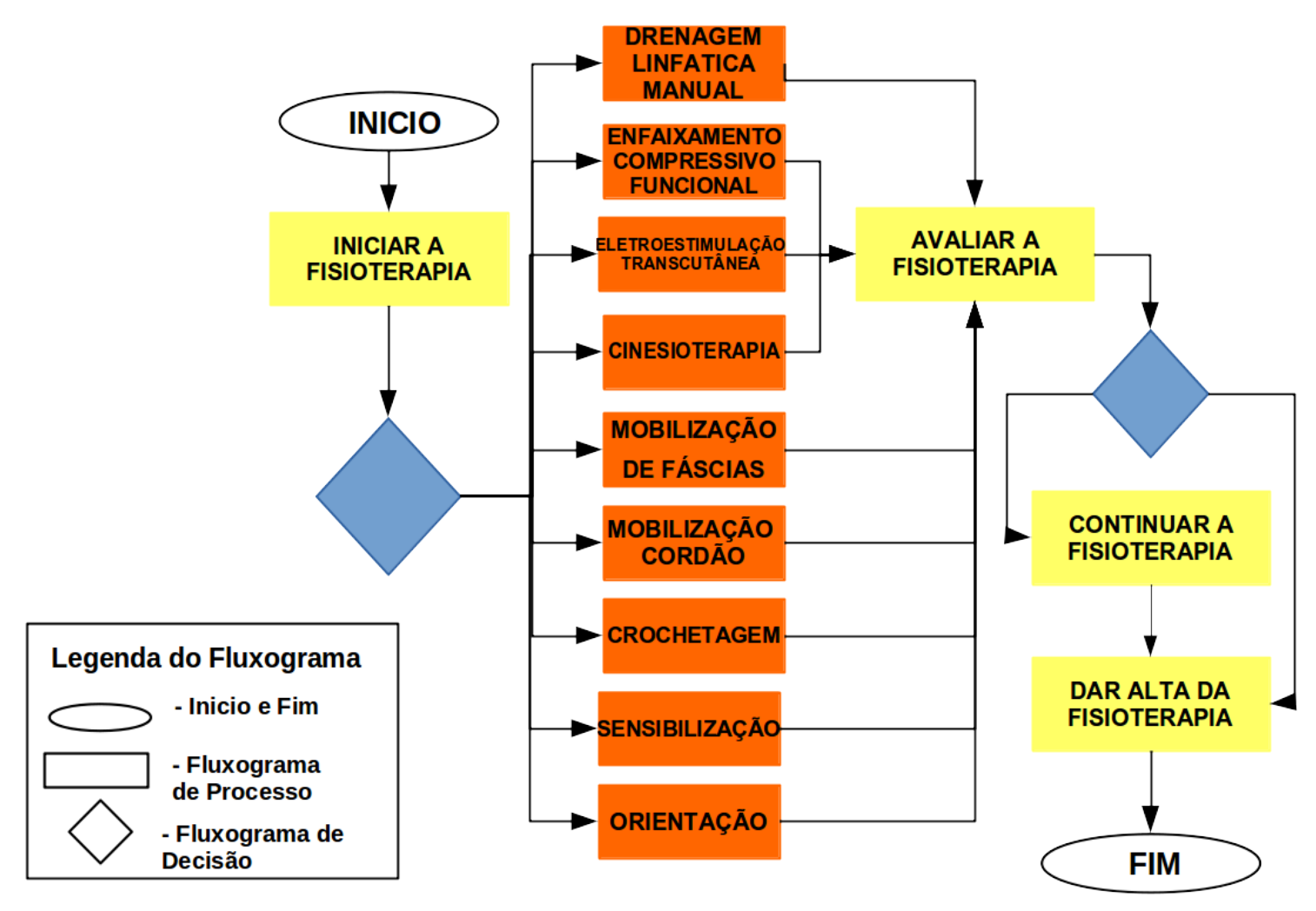

Figura 16: Fluxograma do Tratamento de Fisioterapia.

\subsection{Descrição Metodologia Utilizada}

A metodologia utilizada foi a Methontology, conforme descrita no Capítulo 2.3.6, direcionada à criação de ontologia e explicitada nas seguintes fases:

1) Especificação: Foram realizadas reuniões semanais com a Profa. Dra. Liana B. Gomide Matheus, docente do curso de fisioterapia da UnB, com experiência em Avaliação e Intervenção Fisioterapêutica em Oncologia. Foram realizadas 20 reuniões, com duração de $1 \mathrm{~h}$ a $3 \mathrm{~h}$ por encontro, no HUB, para a definição do escopo do trabalho e o nível de detalhamento do paciente que realizou o tratamento do câncer de mama. Nesse sentido, devido à abrangência muito grande do tema foi definido como escopo do trabalho a descrição das modalidades cirúrgicas e da atuação fisioterapêutica na neoplasia mamária;

2) Aquisição de Conhecimento: Para a aplicação da Methontology foram coletados dados por meio de entrevistas estruturadas, preenchimento de questionários e formulários próprios utilizados no ambulatório de fisioterapia oncológica do HUB. 
Após a definição do escopo, as reuniões foram direcionadas para a verificação dos dados coletados na planilha eletrônica. Assim, foi disponibilizado uma planilha eletrônica com dados clínicos de 186 pacientes em tratamento para o câncer de mama, atendidos no ambulatório de fisioterapia no ano de 2014. O estudo foi aprovado pelo comitê de ética $n^{0} 031 / 2012$. Na etapa seguinte, foi realizado um filtro com a utilização da suíte de escritório LibreOffice com o Calc, localizado na janela dados, autofiltro para selecionar os dados da planilha;

3) Conceitualização: Foi criado junto a especialista e com o auxílio da literatura médica vigente um vocabulário de termos, sendo cada termo composto pela descrição e fonte;

4) Formalização: O modelo conceitual criado nos estágios anteriores foi transformado em um modelo formal, ou seja, representado por meio de uma linguagem formal utilizando o software Protégé;

5) Integração: Foi buscado modelos ontológicos nas bases conhecidas como no site do Protégé do SWOOGLE, OBO, bem como outras bases de ontologia conhecida para realizar a integração da ontologia construída. Porém, na busca de ontologia voltada a NM e ao câncer de mama, não foi encontrado nenhum modelo ontológico parecido ou que se adequasse ao modelo proposto;

6) Implementação: A implementação da ontologia foi realizada utilizando o aplicativo Protégé 5.1, que gera o arquivo OWL, de forma a ser lido por um computador;

7) Avaliação: Foram avaliados os dados da planilha eletrônica disponibilizado pela especialista e, posteriormente, criado instâncias de classes utilizando o modelo da ontologia;

8) Documentação: A partir das informações coletadas foram geradas as seguintes documentações: modelo OWL, planilha com vocabulário, diagramas de bloco e fluxogramas;

9) Manutenção: O modelo ontológico será disponibilizado para que outros pesquisadores e estudantes contribuam com mais informações nos sites como do Protégé e do SWOOGLE. 


\section{RESULTADO}

\subsection{ESTRUTURA GERAL DO MODELO}

O estudo foi realizado no período de 7 meses (Junho/2016 à Dezembro/2016) e gerou como resultado um modelo ONTO-MAMA - NM, focado no tratamento do câncer de mama, ilustrado na Figura 17. No ONTO-MAMA - NM tem-se 3 classes: diagnóstico, paciente e tratamento. A classe tratamento com duas subclasses: padrão e paliativo. A subclasse padrão com a subclasse chamada cirurgia. E na subclasse cirurgia com cinco subclasses que são os tipos mais comuns de cirurgias para o tratamento do câncer de mama. Na Figura 17 é observado o modelo ontológico do ONTO-MAMA - NM OWL que gerou um artigo publicado no XXV Congresso Brasileiro de Engenharia Biomédica (CBEB, 2016), conforme certificado no Anexo 2.

- MELO, BRAGA, SANCHES, GOMIDE e BRASIL ONTO-MAMA: Ontologia Para Ensino e Aprendizagem de Estudantes no Estudo do Câncer de Mama no XXV Congresso Brasileiro de Engenharia Biomédica (CBEB 2016), número do ISSN 2359-3164, página de 2141 à 2144 publicado em novembro de 2016. 


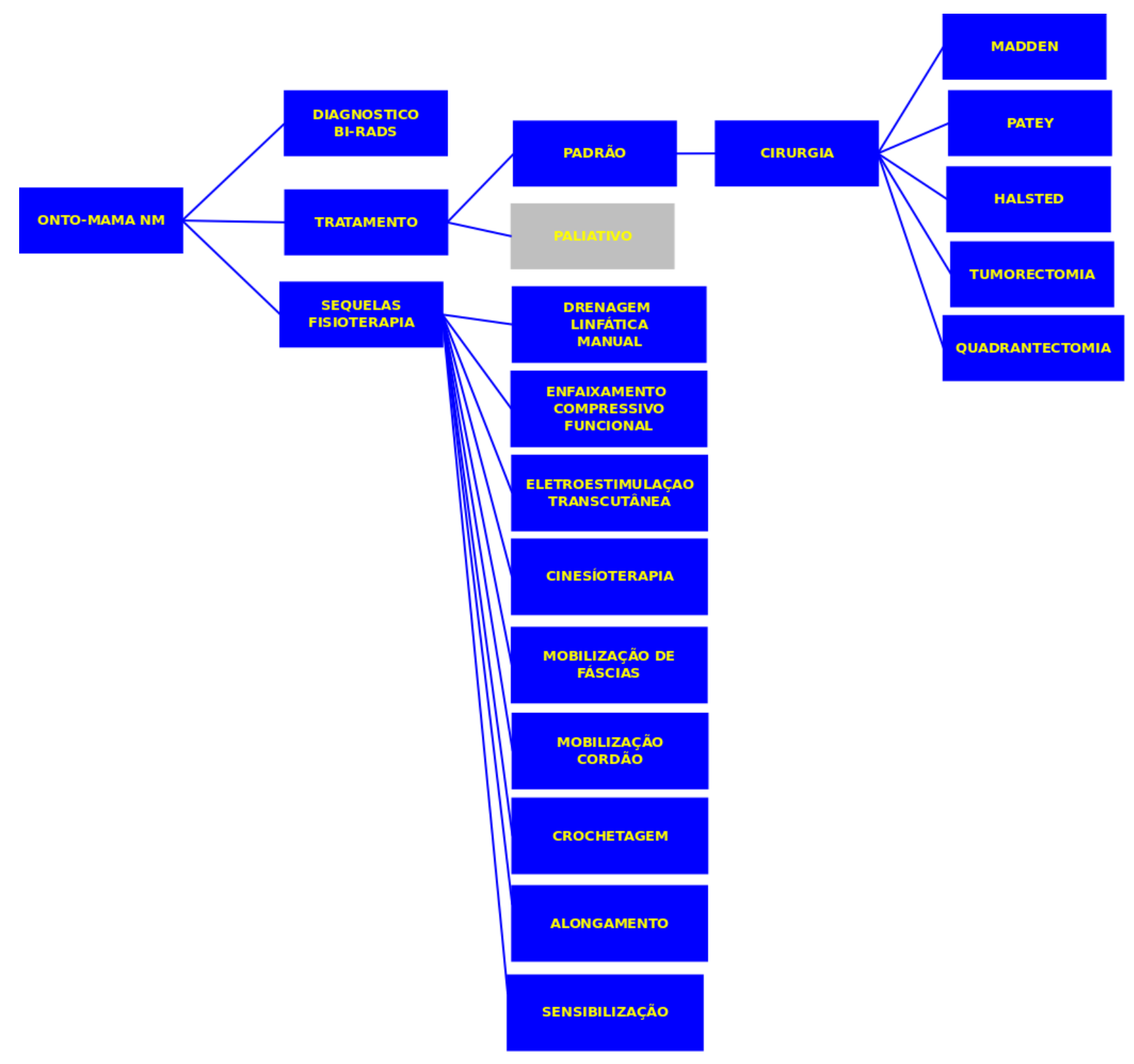

Figura 17: Modelo ONTO-MAMA - NM.

Na Figura 18 tem-se a estrutura do ONTO-MAMA - NM em que se pode observar em tom de cinza o que está implementado, em rosa a versão atual e de roxo o que deve ser implementado. 


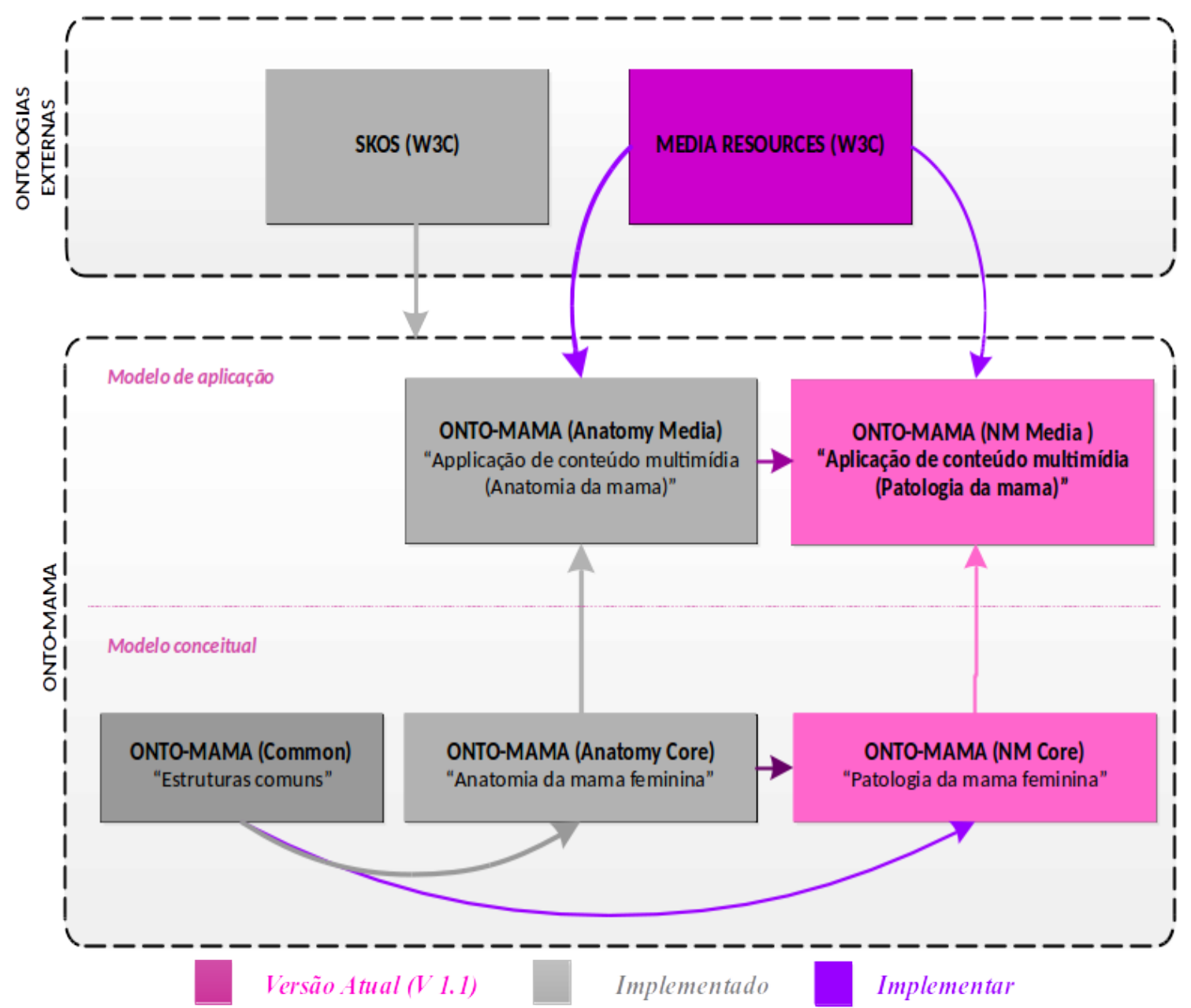

Figura 18: Estrutura ONTO-MAMA - NM OWL. 


\subsection{PERFIL DAS PACIENTES COM CÂNCER DE MAMA}

As características de idade e lado da mama acometido na planilha eletrônica estão apresentadas na Tabela 7 e na Tabela 8 são mostrados os tipos de cirurgia para o tratamento da NM. Para o cálculo das porcentagens foi utilizado a regra de três simples.

Tabela 7: Perfil das pacientes com Câncer de Mama.

\begin{tabular}{|c|c|c|}
\hline Variável & Frequência & $\%$ \\
\hline \multicolumn{3}{|l|}{ Idade } \\
\hline 26 à 30 & 3 & 1,61 \\
\hline 31 à 40 & 20 & 10,75 \\
\hline 41 à 50 & 46 & 24,73 \\
\hline 51 à 60 & 82 & 44,08 \\
\hline 61 à 70 & 28 & 15,05 \\
\hline 71 a 80 & 5 & 2,68 \\
\hline 81 à 84 & 2 & 1,07 \\
\hline \multicolumn{3}{|c|}{ Lado Acometido } \\
\hline Esquerda e Direita & 8 & 4,30 \\
\hline Direita & 78 & 41,93 \\
\hline Esquerda & 100 & 53,76 \\
\hline
\end{tabular}


Tabela 8: Tipos de Cirurgias da Mama.

\section{TIPOS DE CIRURGIAS}

$\begin{array}{ll}\text { Tumorectomia } & \text { Retirada do tumor } \\ \text { Quadrantectomia } & \text { Retirada do tumor e de um quadrante da mama } \\ \text { Madden } & \text { Retirada do tumor e da mama } \\ \text { Patey } & \text { Retirada do tumor, da mama e músculo peitoral menor } \\ \text { Halsted } & \begin{array}{l}\text { Retirada do tumor, da mama e músculos peitoral maior e } \\ \text { menor }\end{array}\end{array}$

Os nomes citados na Tabela 8, são os nomes utilizados atualmente na planilha. No entanto, as cirurgias de Madden, Patey e Halsted podem também ser denominadas Mastectomia simples, Mastectomia radical modificada e Mastectomia radical, respectivamente.

- Mastectomia simples (extirpação da mama com preservação dos músculos peitorais maior e menor).

- Mastectomia radical modificada (extirpação da mama e do músculo peitoral menor.

- Mastectomia radical (extirpação da mama, do músculo peitoral maior e menor e linfonodectomia axilar completa)

Na Tabela 9 é apresentado o significado de cada sigla do tratamento fisoterápeutico da neoplasia mamária.

Tabela 9: Significado de Siglas.

\section{SIGNIFICADO DE SIGLAS}

DLM

ECF

TENS
Drenagem Linfática Manual

Enfaixamento Compressivo Funcional

Estimulação Elétrica Nervosa Transcutânea 
A Tabela 10 apresenta o número de pacientes que realizou o tratamento fisioterapêutico após a cirurgia.

Tabela 10: Tratamentos Fisioterapêuticos.

\begin{tabular}{ccc}
\hline Tratamentos & Frequência & $\%$ \\
\hline DLM & 154 & 82,79 \\
ECF & 16 & 8,60 \\
TENS & 45 & 24,19 \\
CINESIOTERAPIA & 146 & 78,49 \\
MOBILIZAÇÃO DE & 54 & 29,03 \\
FÁSCIAS & & \\
MOBILIZAÇÃO DE & 127 & 68,27 \\
CORDÃO & & \\
CROCHETAGEM & 10 & 5,37 \\
SENSIBILIZAÇÃO & 51 & 27,41
\end{tabular}

Na Figura 19 é apresentada a hierarquia completa do tratamento da NM da cirurgia e da fisioterapia criado no Protégé 5.1, em que é observado a ligação de cada classe e subclasse. 


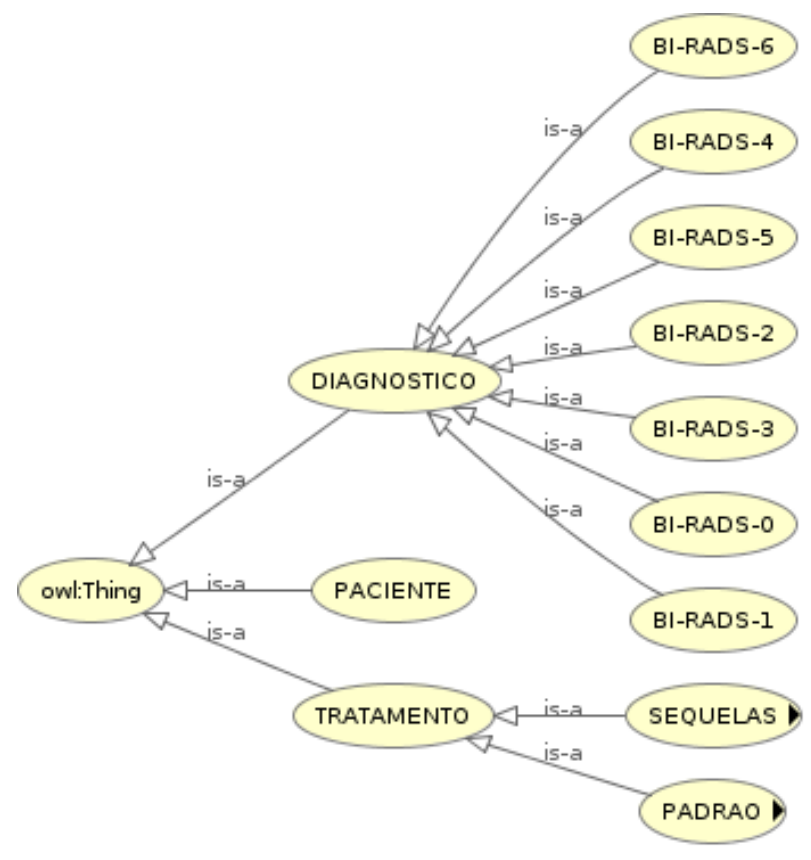

Figura 19: Hierarquia do Tratamento da NM.

A Figura 20 apresenta a hierarquia do tratamento cirúrgico da NM criado no Protégé 5.1, em que é observado a ligação de cada classe e sub-classe.

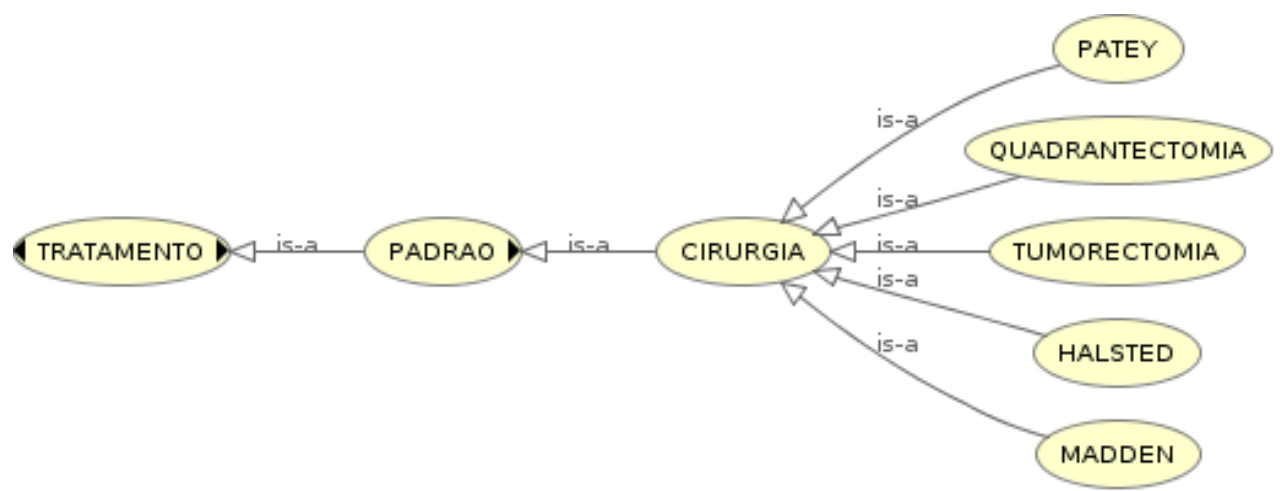

Figura 20: Hierarquia da NM da Cirurgia.

Na Figura 21, apresenta-se a hierarquia do tratamento fisioterapêutico da NM criado no Protégé 5.1. 


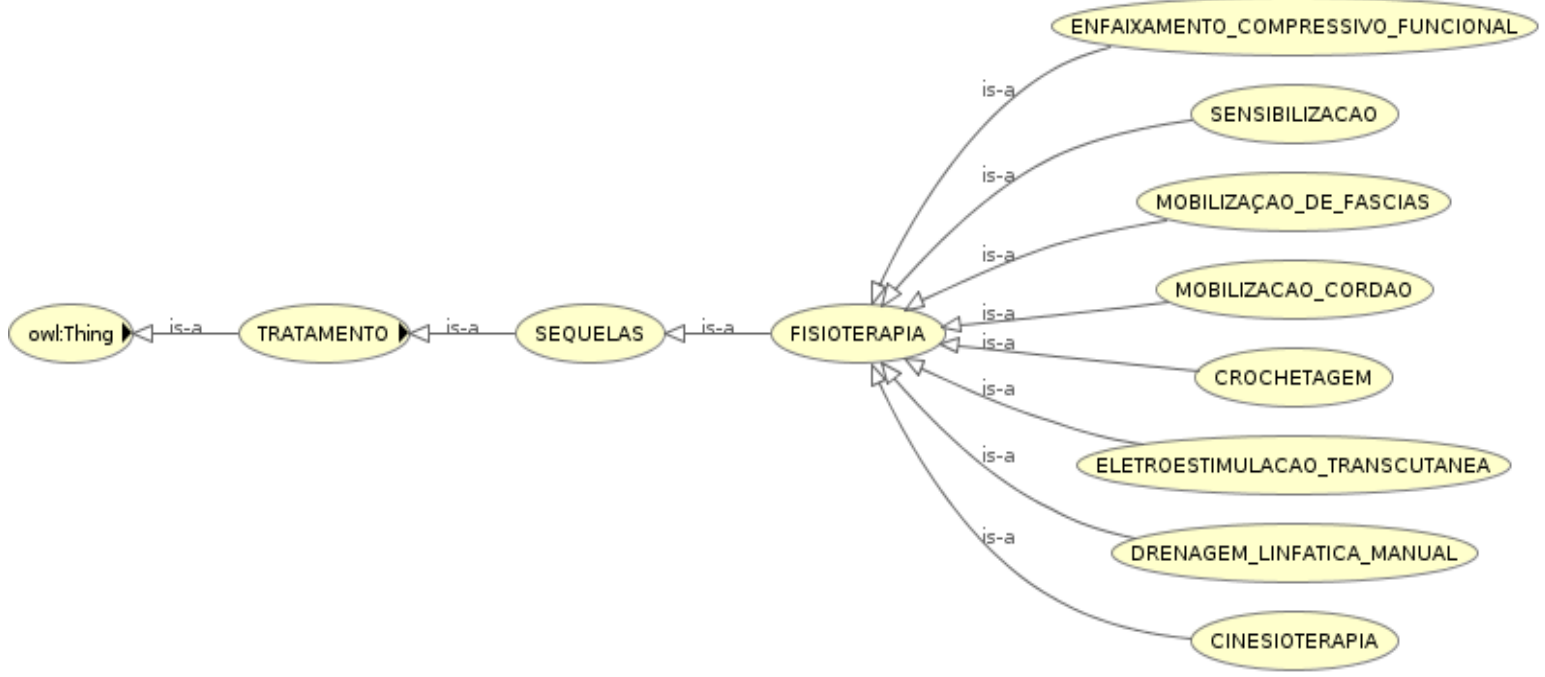

Figura 21: Hierarquia da NM na Fisioterapia.

Ao abrir o Protégé foi criado a classe na subclasse owl:thing. Na Figura 22 é apresentada a ontologia da NM dentro do Protégé com suas classes (diagnóstico, paciente e tratamento) e subclasses (padrão, sequelas e fisioterapia). Ainda, pode ser vista as informações referentes ao BI-RADS.

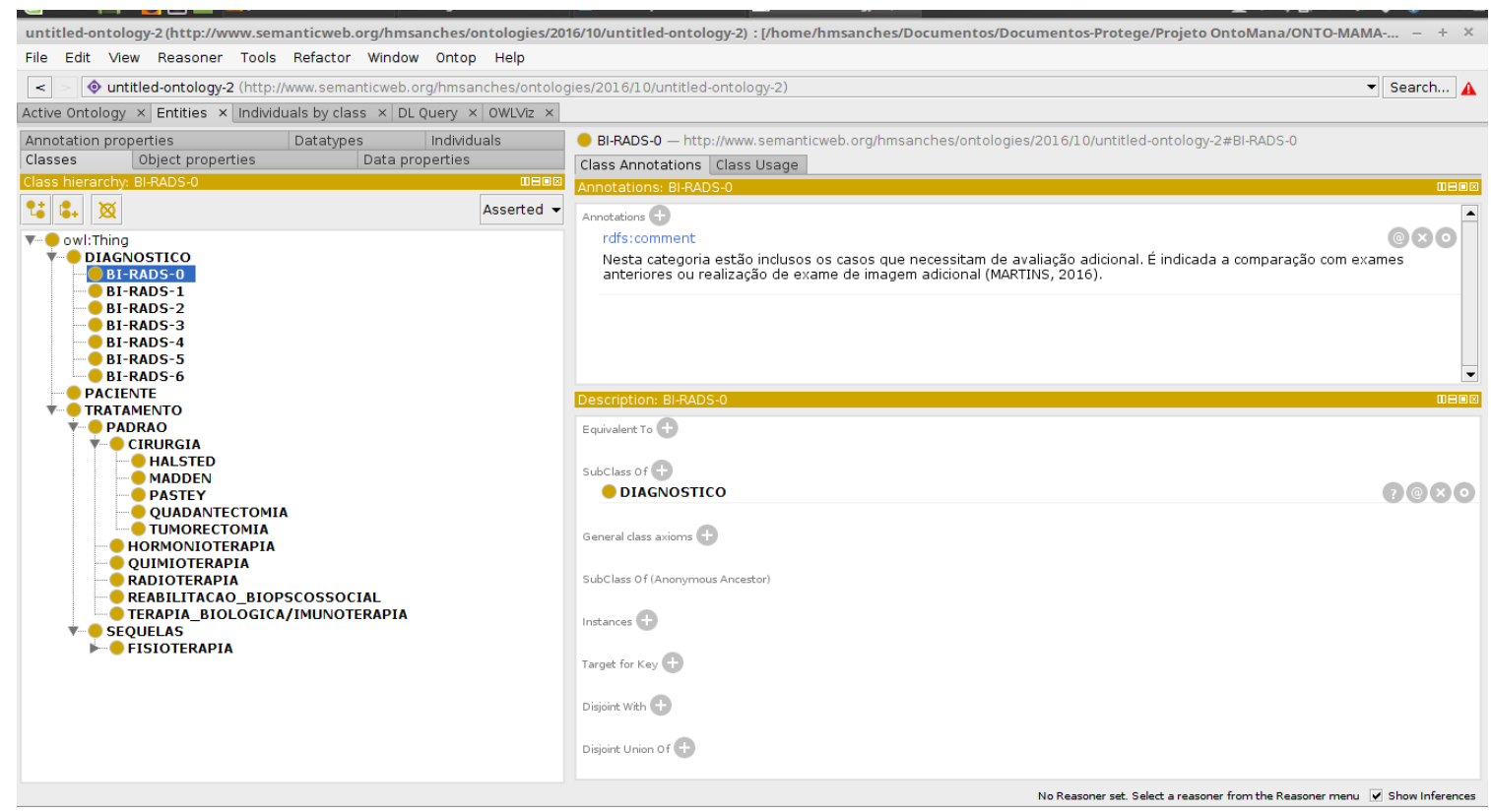

Figura 22: Ontologia da NM no Protégé 5.1.

Os object properties (propriedades do objeto) descrevem relações entre duas instâncias (Indivíduos). Eles vinculam indivíduos de um domínio a indivíduos de um 
intervalo. OWL usa domínio e alcance como axiomas no raciocínio, como apresentado na Figura 23.

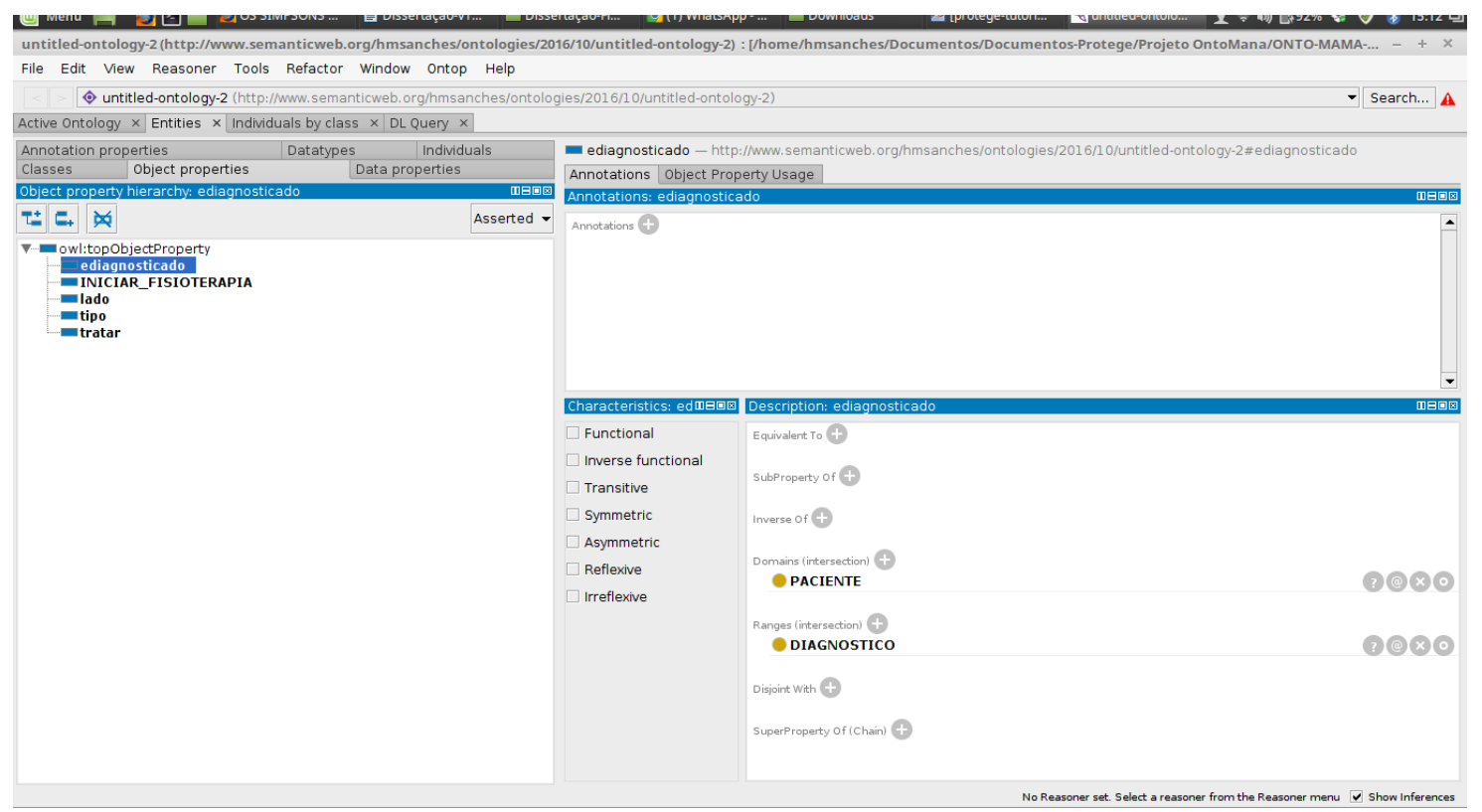

Figura 23: Object Properties da NM no Protégé 5.1.

Os data properties (propriedades de dados), descrevem relações entre instâncias (Indivíduos) e valores de dados. Na Figura 24 é apresentada as propriedades de dados da ontologia de NM.

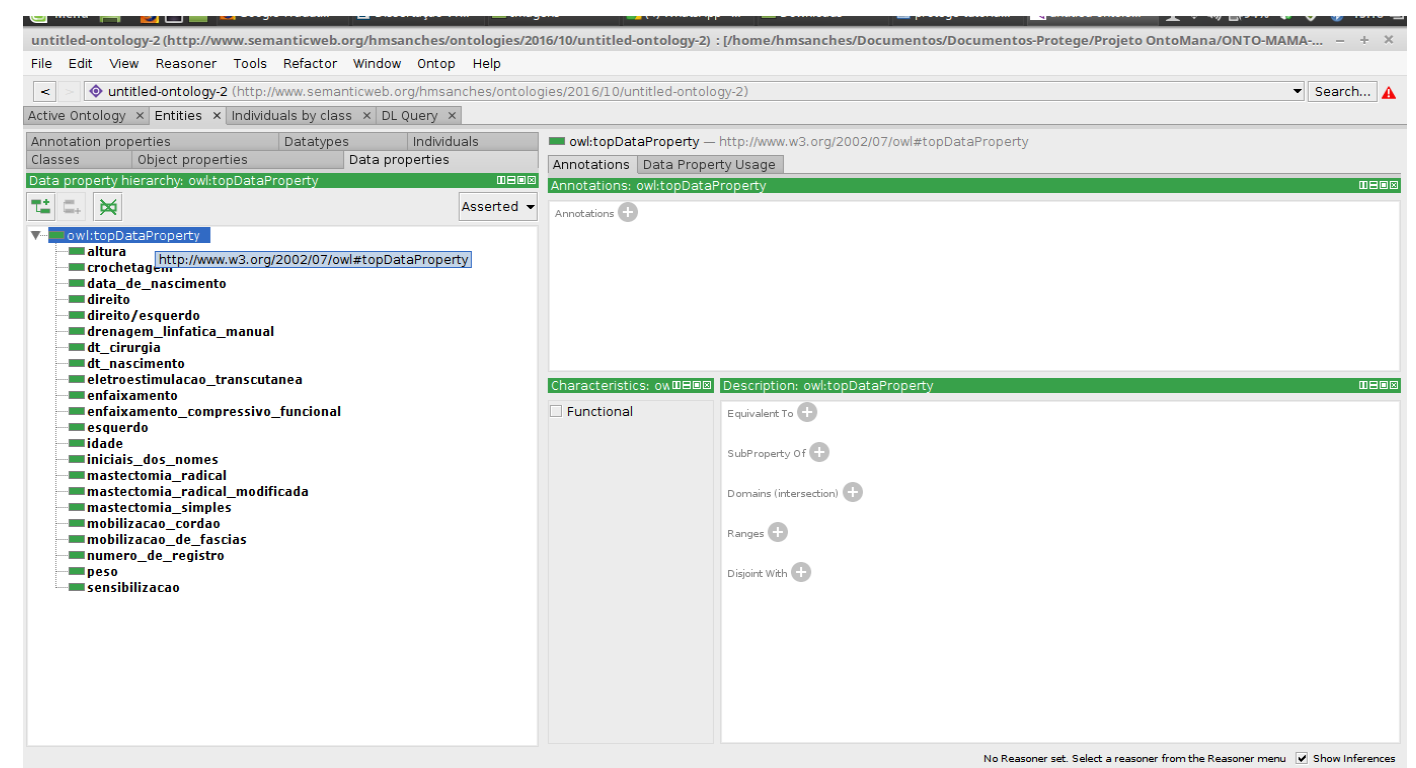

Figura 24: Data Properties da NM no Protégé 5.1. 


\subsection{SOBRE O USO E REUSO DE INFORMAÇÕES DO MODELO}

Com a ontologia criada junto a especialista na linguagem $O W L$, todo pesquisador, aluno e professor que queiram estudar, melhorar e implementar algo na ONTO-MAMA - NM, será disponibilizado todos os dados, bem como os metadados para que possam ter um entendimento do modelo criado.

\subsection{SOBRE O USO E REUSO DE INFORMAÇÕES DO MODELO}

O modelo ontológico realizado foi avaliado pela fisioterapeuta especialista Luísa Costa e pela professora $\operatorname{Dr}^{\mathrm{a}}$ Liana B. Gomide Matheus. Além disso, foi apresentado, apreciado e discutido no evento da XVI Jornada Cientifica do HUB ocorrida nos dias 16 à 18 de novembro, com a presença de médicos, alunos e especialistas no tratamento de NM do HUB com aproximadamente 200 pessoas, sendo bem aceito pela comunidade. Todos os presentes viram o modelo ONTO-MAMA-NM sendo executado com todas as funcionalidades deste aplicativo. Desde o paciente realizando o diagnóstico, a cirurgia e o encaminhamento para o tratamento fisioterapêutico com comentários dos presentes. Questionaram quando seria implementado no HUB, tendo em vista que todos comentaram que desconheciam a ontologia e não tinham visto nada parecido referente ao tratamento da NM.

Na Figura 25 é mostrada a validação realizada dento do Protégé, sendo observadas as classes mãe owl:Thing (sendo a primeira classe ao abrir o Protégé) e as três subclasses, sendo elas: diagnóstico, paciente e tratamento. Todas estas subclasses indicam em que o paciente foi diagnosticado, foi tratado por meio do tratamento padrão e depois tratada as sequelas pela fisioterapia.

Todavia, é ainda ilustrada na Figura 25, as linhas azuis como sendo as ligações das classes com suas subclasses, a linha vermelha é a ligação para diagnóstico de NM, conforme o BI-RADS, a linha cinza liga o paciente à cirurgia, a linha vermelha liga da cirurgia à fisioterapia e, por último, a linha amarela que conecta do tratamento para a fisioterapia. 


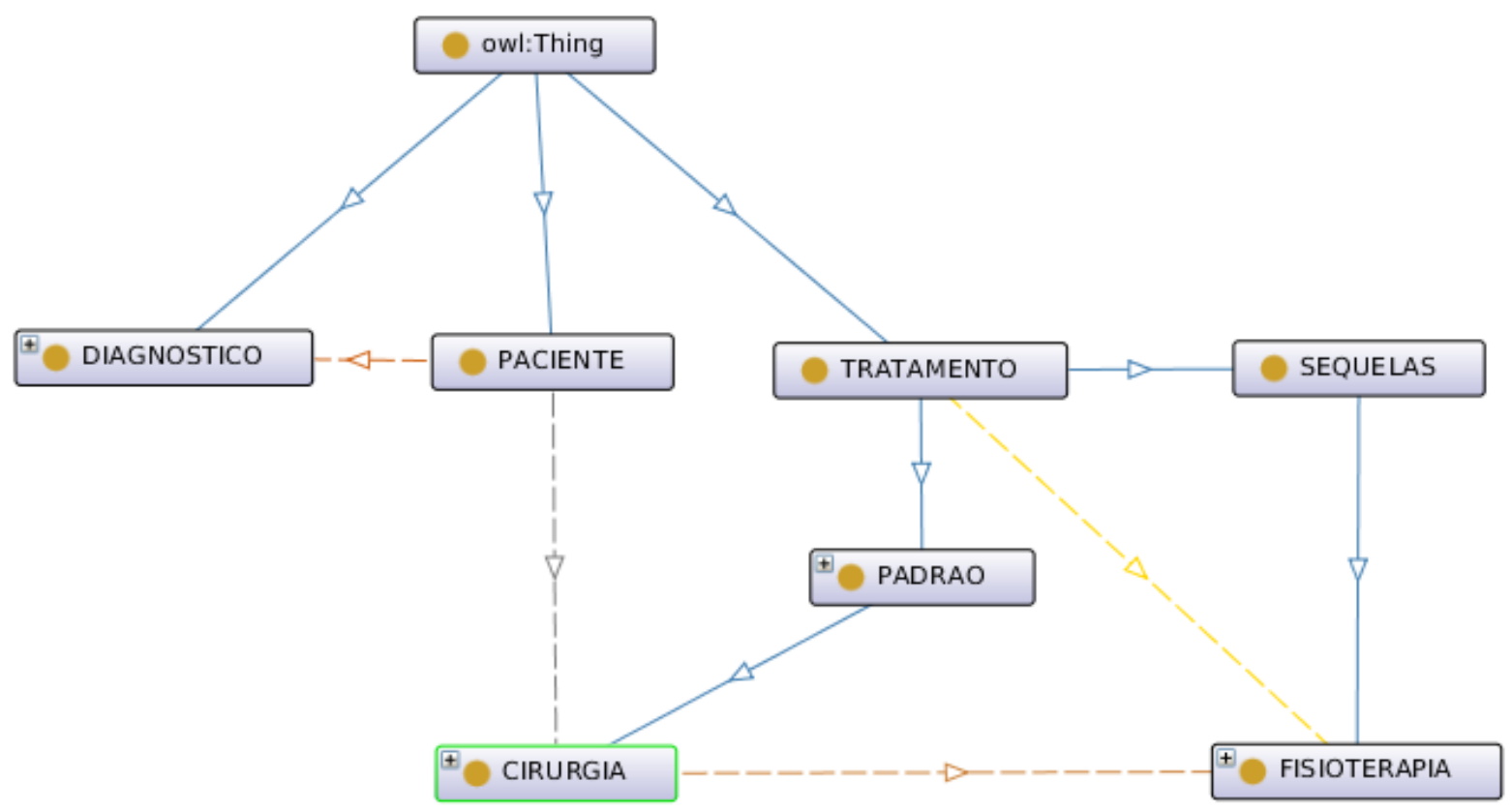

Figura 25: Validação do Tratamento da NM no Protégé 5.1. 


\section{DISCUSSÃo}

\subsection{DISCUSSÃO FINAL}

Nesse estudo foi desenvolvido um modelo semântico de dados que, ao mesmo tempo em que se mantém compatível com os padrões médicos existentes (DICOM e HL7), propõe uma nova forma de se armazenar a informação dos pacientes submetidos ao tratamento do câncer de mama. $\mathrm{O}$ modelo proposto não tem como objetivo a substituição dos padrões existentes, mas sim a complementação dos mesmos de modo a facilitar o armazenamento de informações não incluídas nestes protocolos e permitindo futuras customizações por parte dos especialistas.

Diferentemente do DICOM e HL7, o modelo proposto é totalmente aderente aos padrões utilizados na Web Semântica, o que garante uma interoperabilidade em nível mais abrangente, podendo atingir não somente as entidades associadas diretamente com a instituição de saúde que detém a informação, mas também outras entidades que prestam serviços de saúde pública. Por exemplo, aquelas que aplicam dados reais em pesquisas ou levantamentos estatísticas para controle e acompanhamento de doenças.

Clínicas de saúde e hospitais podem se beneficiar com a utilização do modelo proposto que traz um dicionário de dados padronizado para armazenar informações envolvendo a NM e construído por meio de regras semânticas bem definidas. Em visita técnica no HUB, foi observado o procedimento de tratamento da NM e das complicações advindas desse tratamento. Atualmente, os dados dos pacientes são armazenados no prontuário eletrônico do Aplicativo de Gestão de Hospitais Universitários (AGHU) e, na existência de pesquisa em andamento, após autorização do Comitê de Ética em Pesquisa, os dados são customizados e organizados pela especialista da área da saúde, numa planilha eletrônica no formato Microsoft Excel (“.xls”). Esta planilha é alimentada manualmente e armazenada localmente no computador disponível no departamento. Além disso, o processo de análise das informações da planilha é demorado, pois as informações são alimentadas de forma repetitiva e muitas vezes sem seguir um padrão definido. Por exemplo, a referência de um dos lados da mama pode estar escrito como esquerdo ou esquerdo ponto (ESQ ou ESQ.). O armazenamento de informações especializadas da área médica é bastante difícil com o uso dos padrões de dados atuais. Atualmente, um especialista da área de câncer de mama que deseje armazenar informações para pesquisas 
futuras acerca de análise clínica ou tratamento da NM, isto é, não o faz, em sua maioria, por meio do DICOM e nem do HL7. A solução que tem sido adotada, na maioria dos casos, é o desenvolvimento de Sistemas Especialistas ou o uso de planilhas eletrônicas que não se interligam com nenhum dos demais sistemas dentro do hospital ou das clínicas. Logo, as informações são replicadas e dificilmente reutilizadas. Nesse sentido, o modelo proposto neste trabalho pode ser aplicado na construção de Sistemas Especialistas ou de ferramentas inteligentes para processamento e análise de dados na área de câncer de mama. Além disso, uma outra aplicação é a área educacional em que pode-se utilizar os dados do modelo para melhorar o conhecimento dos jovens estudantes que desejam atuar na área de NM. O acesso aos casos médicos reais beneficiam enormemente os estudantes, pois os guiam diretamente da teoria para a prática médica. Logo, a proposta de criar um modelo ontológico de tratamento da NM de modo a dar mais flexibilidade para os profissionais e estudantes que atuam na saúde foi de enorme aplicabilidade.

Uma particularidade e diferencial deste trabalho foi a escolha da ontologia como forma de representação da informação médica. A ontologia é um mecanismo de representação do conhecimento que possibilita a descrição de conceitos e regras de inferência. Pode-se dizer que enquanto os bancos de dados encontram-se na esfera de estruturação da informação, as ontologias se colocam acima disto, provendo não só estruturação dos dados, mas também padronização de nomes, significados e acesso ao esquema ou regras de formação e conexão de uma informação para com as demais. A escolha pela ontologia e não pela criação de um banco de dados se deve pelo fato de que ao criar uma ontologia no formato OWL, qualquer pesquisador ou estudante terá acesso a todas as informações referentes a ontologia da NM, diferentemente do banco de dados. Neste contexto, as ontologias são expressas por meio de linguagens lógicas ou lógica descritiva. Diferentes linguagens ontológicas poderiam ser utilizadas, mas este trabalho faz uso da OWL que traz mais facilidades para expressar significados e semânticas do que outras linguagens existentes.

Por meio deste estudo foram realizadas investigações envolvendo o uso de tecnologias e padrões para a implantação de um modelo ontológico direcionado para o tratamento da NM. Essas investigações geraram como resultado um modelo ontológico para a condução do projeto do ONTO-MAMA, bem como a integração de ontologias 
existentes voltados a NM. Da idealização dessa proposta, por sua vez, considera-se os seguintes pontos de discussão:

I. A participação do especialista na criação da ontologia e no tratamento do câncer de mama e dos engenheiros biomédicos nos projetos de criação e integração;

A participação do Engenheiro Biomédico e das fisioterapeutas especialistas foi de grande importância. Devido à complexidade da NM, este profissional tem que abstrair as informações do especialista para melhorar o trabalho do profissional da saúde quanto do paciente, pois ambos devem trabalhar em conjunto.

II. A complexidade da ontologia proposta;

A complexidade do trabalho está no fato que não existe nenhum trabalho de ontologia da NM como o que foi desenvolvido nesta pesquisa. Sendo assim, este é o primeiro modelo ontológico de tratamento da NM.

Segundo Porn (2014), os erros são definidos como antipadões devido a maioria dos erros serem causados por padrões adotados pelos especialistas na área, que resultam em inconsistência das informações como a criação de elementos; criação de classes; definição incorreta de propriedades; anotações incompletas; etc.

III. A consolidação do padrão DICOM e HL7 no Brasil;

Ambos os padrões estão consolidados no Brasil tendo em vista que o DICOM é utilizado para padronização de imagens e o HL7 é utilizado mais para a interoperabilidade. Além disso, o Ministério da Saúde (MS), desde 2008 vem implementando o padrão HL7 na rede pública e no trabalho de Siqueira et al. (2016) apresenta um quadro com vários trabalhos que usam Web Services com o padrão DICOM e o HL7, assim como a linguagem XML, conforme Tabela 11. 
Tabela 11: Web Services DICOM, o HL7 e XML (Adaptado de SIQUEIRA et al., 2016).

\begin{tabular}{|l|l|}
\hline \multicolumn{1}{|c|}{ TRABALHO } & \multicolumn{1}{|c|}{ LINGUAGEM } \\
\hline (Baptista et al., 2013) & $\begin{array}{l}\text { Web Services, REST, XML, Android, } \\
\text { ASP.net }\end{array}$ \\
\hline (Petrova et al., 2012) & $\begin{array}{l}\text { Web Services, Web Services Adapters, XML, } \\
\text { DICOM }\end{array}$ \\
\hline (Alam et al., 2011) & Web Services, HL7, HSSP, BPEL, WSDL, \\
Java
\end{tabular}

IV. A necessidade de evolução da ontologia no Brasil;

Observando o ONTOBRAS ocorrido em 2016 e em 2015, foi possível observar um aumento de trabalhos apresentados em 2016 sendo 10 full paper e 12 short paper dentro dos temas: ciência da informação; banco de dados; inteligência artificial; engenharia de software; informática na educação e linguística e filosofia, assim como os temas de interesse em: Ontology and Conceptual Modeling; Ontology Engineering; Semantic Web; Ontology and Natural Language Processing; Ontology applications e Ontology Visualization.

O Brasil tem um grande potencial para crescer em pesquisas voltadas a ontologia dentro da área da saúde tendo como exemplo que na ONTOBRAS 2016 teve a apresentação de uma ontologia relacionada à área da saúde voltado ao Zika Vírus tendo como tema: "Ontology-based Zika Virus news authoring environment for the Semantic Web", que descreve a experiência de pesquisar e ensinar o conceito e a prática para a especificação, modelagem e concepção de um ambiente de autoria de notícias baseadas em ontologia para a Web Semântica, que descreve a construção e o uso de uma ontologia da doença de Zika, desenvolvido pela UnB e pela FGA em 
conjunto com o Prof. Dr ${ }^{\circ}$. Edgard Costa Oliveira. Outra situação, pode-se destacar o tema "Ferramentas de Apoio a Criação e Edição de Ontologias: Tainacan Ontology e uma Análise Comparativa", que apresenta uma análise comparativa dessas ferramentas, como foco na disponibilização de funcionalidades baseadas em OWL realizado pela Universidade Federal do Goiás (UFG).

Pode-se, ainda, observar que a cada ano a ontologia vem sendo consolidada no Brasil e crescendo. Atualmente, pode-se destacar algumas Universidades que vem trabalhando com ontologia, sendo elas: UnB, FGA, UFES, UFG.

V. Os cuidados na execução de projetos de integração entre as ontologias existentes com as que estão sendo desenvolvidas.

O maior cuidado que pode ser destacado é a integração dos modelos ontológico com os padrões DICOM e HL7 com as tecnologias existentes, ou seja, salvando os modelos ontológicos nos formatos OWL/XML ou RDF/XML. Ainda, pode-se observar esta situação no trabalho de Siqueira et al. (2016), que mostra um quadro com inúmeras linguagens utilizadas onde o XML tem interoperabilidade com os padrões DICOM e HL7.

\subsection{CONTRIBUIÇÕES RELEVANTES}

A principal contribuição desse estudo foi a criação da primeira versão do modelo ontológico do tratamento da NM, tendo em vista que nas pesquisas não foi encontrado nenhum modelo existente ou parecido nos bancos de dados científicos. Outra contribuição é a disponibilização do arquivo OWL nas bases de ontologia para que outros pesquisadores, alunos e professores tenham a oportunidade de melhorar o modelo ontológico da ONTO-MAMA - NM. Assim, os pesquisadores podem reutilizar o modelo ontológico desenvolvido e aprimorarem. 


\section{CONCLUSÃO E TRABALHOS FUTUROS}

\subsection{Conclusão}

Foi desenvolvido uma ontologia do tratamento da NM por meio da Methontology padrões DICOM e HL7, sendo salvos em formato OWL/XML. A escolha da ferramenta foi o Protégé, sendo considerado de fácil interação, de arquitetura expansível e facilmente disponível na área da saúde. O modelo foi apresentado em evento científico, CBEB 2016 (Anexo 2), validado por especialistas: fisioterapeutas, médicos, residentes, alunos da fisioterapia e alunos da medicina do HUB. Obteve-se assim, o primeiro modelo ontológico da NM, o ONTO-MAMA-NM.

\subsection{Trabalhos Futuros}

Foram realizadas diversas modificações e ajustes na plataforma ONTO-MAMA durante o estudo e implementação do tema em estudo. Uma delas foi a utilização da plataforma no modelo ontológico da NM. Entretanto, existem pontos que podem ser melhorados e expandidos a partir desse trabalho. Alguns desses são sugeridos como trabalhos futuros:

I. Integrar o ONTO-MAMA - NM no sistema de Anatomia da Mama Feminina (ANAMAMA), criado por Braga (2015), com a criação de uma API para a leitura do OWL;

II. Implementar no ONTO-MAMA - NM a ontologia dos demais tratamentos da NM como a quimioterapia, a radioterapia, a hormonioterapia, entre outros tratamentos;

III. Implementar a função MEDIA RESOURCES (W3C) no ONTO-MAMA tanto na anatomia da mama feminina quanto no tratamento da NM;

IV. Aplicar o ONTO-MAMA - NM a professores, alunos e pesquisadores da área da saúde, por exemplo, no curso de Fisioterapia, Enfermagem, entre outros da UnB e HUB. 


\section{REFERÊNCIAS BIBLIOGRÁFICAS}

ABRÃO, F. S. Tratado de Oncologia Genital e Mamaria 1ª Edição, Editora: Roca, 1995.

ANDERSON, R.; OLIVEIRA, N. DE; SERGIPE, U. F. DE. Integração de sistemas de informação em saúde com a utilização de service oriented architecture (soa) healthcare information systems integration using soa. v. 13, n. 2, p. 255-274, 2016.

BRAGA, D. S. Tutoria da Anatomia Mamária Feminina Utilizando uma Rede Neural Artificial Interactive Activation and COMPETITION Orientada a Serviço. 2015. Tese (Mestrado) - Faculdade Gama, Universidade de Brasília, Brasília, 2015.

BERNERS -LEE, T. The World Wide Web - Past Present and Future. In: Japan Prize Commemorative Lecture, 2002.

DICOM - Digital Imaging and Communications in Medicine 2016 $<$ http://dicom.nema.org/> acessado em Setembro de 2016.

ELISA, M.; PICKLER, V.; FERNEDA, E. Um Método para a Utilização de Ontologias na Indexação Automática. Informação \& Tecnologia (ITEC), v. 1, n. 2, p. 13-33, 2014.

FERREIRA, C. H. J. Fisioterapia na Saúde da Mulher: Teoria e Pratica, Editora Gen, 2011. FREITAS, F.; SCHULZ, S.; MORAES, E. Pesquisa de terminologias e ontologias atuais em biologia e medicina. Reciis, v. 3, n. 1, p. 8-20, 2009.

G1 - Globo Disponível em $\quad<$ http://g1.globo.com/pe/caruaruregiao/noticia/2016/04/biomedica-de-pe-desenvolve-chip-que-detecta-18-tipos-decancer.html> acessado em Abril de 2016.

GUIMARÃES, J. R. Q. Manual de Oncologia, Editora: LBBS, 2004.

GOMIDE, L. B.; MATHEUS, J. P. C.; CANDIDO DOS REIS, F. J. Morbidity after breast cancer treatment and physiotherapeutic performance. International Journal of Clinical Practice, v. 61, n. 6, p. 972-982, 2007.

GUIZZARDI, G. et al. Ontologias de Fundamentação e Modelagem Conceitual. II Seminário de pesquisa em Ontologia do Brasil, n. i, p. 1-6, 2009. 
HENDLER, J; BERNERS-LEE, T; LASSILA, O. The SemanticWeb. Issue of Scientific American, Maio 2001

HINZ, V. T. Proposta de Criação de uma Ontologia de Ontologias. 2006.

HL7 - Health Level Seven International 2016. Disponível em <http://www.hl7.org/> acessado em Setembro de 2016.

HL7 Brasil - Instituto HL7 Brasil Afiliado ao HL7 Internacional 2016. Disponível em $<$ http://www.hl7.com.br/> acessado em Setembro de 2016.

INCA - Instituto Nacional do Câncer estimativa 2016. Disponível em $<$ http://www.inca.gov.br/estimativa/2016/index.asp> acessado em Março de 2016.

ISAC, C.; CONCI, A. Uso de ontologias para a manipulação de imagens relacionadas ao câncer de mama. v. 2, n. 2011, p. 178-187, [s.d.].

ISAC, C.; CONCI, A. A Survey on Ontology-Based Systems to Support the Prospection, Diagnosis and Treatment of Breast Cancer. p. 271-277, 2016.

KLAVDIANOS, P. B. L. et al. Onto-mama: An ontology of the female breast anatomy applicable to a virtual learning environment. 2011 Pan American Health Care Exchanges, n. 1999, p. 315-315, 2011.

LICHTENSTEIN, F. E.; SIGULEM, D. MD, P. Criando uma Ontologia em Saúde com a ferramenta Protégé no padrão OWL. UNIFESP - Departamento de Informática em Saúde - DIS, p. 1-6, 2008.

LIMA, J. C. D.; CARVALHO, C. L. D. Ontologias - OWL (Web Ontology Language). Technical Report-RT-INF_004-05, p. 22, 2005.

MARTINS, J. P. V. M. EIR - Sistema Inteligente Para Detecção e Classificação de Calcificações em Mamografias. 2016. Tese (Mestrado) - Faculdade Gama, Universidade de Brasília, Brasília, 2016.

MEDIA RESOURCES - Disponível em $<$ https://www.w3.org/TR/mediaont10/\#example5> acessadas em Agosto de 2016.

MORAIS, E. A. M.; AMBRÓSIO, A. P. L. Ontologias: conceitos, usos, tipos, metodologias, ferramentas e linguagens. p. 21, 2007. 
MUNDO

$<$ http://mundoeducacao.bol.uol.com.br/geografia/era-informacao.htm $>$ acessadas em agosto de 2016.

PROTÉGÉ - Disponível em <http://protege.stanford.edu/> acessadas em Junho de 2016.

PORN M. A. Teste de Mutação para Ontologias OWL. 2014. Tese (Mestrado) Universidade Federal do Paraná, Curitiba, 2014.

OLHAR DIGITA - Disponível em $<$ http://olhardigital.uol.com.br/noticia/chip-criado-porpernambucana-consegue-detectar-18-tipos-de-cancer-em-15-minutos/56952> acessadas em Abril de 2016.

SABINO, A. R.; HEINZLE, R. Ferramenta para Construção de Ontologia a Partir de Dados Não Estruturados. 2015.

SOUZA, F. DE; FALBO, R. A.; VIJAYKUMAR, N. L. Uso de Ontologias na Garantia da Qualidade e Melhoria de Processos '. 2012.

SIMPLE KNOWLEDGE ORGANIZATION SYSTEM (SKOS) - Disponível em $<$ https://www.w3.org/2004/02/skos/> acessadas em Agosto de 2016.

$\begin{array}{lllll}\text { TECMUNDO } & - & \text { Tecmundo } & \text { Disponível } & \text { em }\end{array}$ $<$ http://www.tecmundo.com.br/medicina/103332-brasileira-cria-chip-detecta-varios-tiposcancer-15-minutos.htm> acessadas em Abril de 2016.

SWOOGLE Swoogle Semantic Web Search Engine. Disponível em $<$ http://swoogle.umbc.edu/> acessado em Março de 2016.

WebODE - Disponível em <http://mayor2.dia.fi.upm.es/oeg-upm/index.php/en/oldtechnologies/60-webode/> acessado em Setembro de 2016.

W3C - World Wide Web. Disponível em < http://www.w3.org > acessado em Março de 2016. 
APÊNDICES 


\section{APÊNDICE I: TABELAS DESENVOLVIDAS}

Tabela 12: Sintaxe de Componente de consulta URI.

\begin{tabular}{|l|l|}
\hline \multicolumn{2}{|c|}{ Sintaxe de Componentes DICOM } \\
\hline Imagem & JPEG \\
\hline Web & HTTP, HTML \\
\hline
\end{tabular}

Tabela 13: Detalhes da Versão HL7.

\section{HL7}

\section{Versão 2.x}

\section{Versão 3}

Exemplo de mensagem de identificação do Modelo RIM HL7 Versão 3 - Clinical paciente (versão 2.3): PID PATID Document Architecture (CDA) Silva`Jose M B M B Rua Ficticia $46^{\wedge}$ São $\mathrm{Paulo}^{\wedge} \mathrm{SP}^{\wedge}$

Problemas do HL7: Não determina que HL7 - Na versão 3 os documentos são partes do protocolo devem ser estruturados de acordo com o CDA, o qual implementadas. Assim, não é possível haver propõe uma estrutura para troca de teste de compatibilidade entre vendedores, o documentos clínicos; utiliza XML, RIM, que leva a problemas de interoperabilidade. HL7 Data Types e vocabulários controlados Versão 3.0 promete resolver problemas do para garantir interoperabilidade HL7 
Tabela 14: Formatos Salvos pelo Protégé 5.1.

\begin{tabular}{|c|}
\hline Formatos Salvos no Protégé $\mathbf{5 . 1}$ \\
\hline RDF/XML Syntax \\
\hline Turtle Syntax \\
\hline OWL/XML Syntax \\
\hline OWL Funcional Syntax \\
\hline Manchester OWL Syntax \\
\hline OBO Format \\
\hline Latex Format \\
\hline JSON-LD \\
\hline
\end{tabular}

$\mathrm{Na}$ Tabela 15 tem-se os formatos com interoperabilidade, desenvolvido conforme o arquivo OWL - NM neste estudo.

Tabela 15: Formatos com Interoperabilidade OWL - NM.

\begin{tabular}{|c|c|c|}
\hline \multicolumn{3}{|c|}{ Interoperabilidade entre os Padrões } \\
\hline DICOM & HL7 & OWL - NM \\
\hline XML, JSON, HTTP, & XML, RIM & RDF/XML, OWL/XML, \\
HTML & & JSON - LD \\
\hline
\end{tabular}




\section{APÊNDICE 2: FIGURAS E FLUXOGRAMAS NÃO UTILIZADOS}

Seguem algumas figuras, diagramas de bloco e fluxogramas desenvolvidos neste estudo. A indicação em cor amarela são as utilizadas nesse estudo, as na coloração cinza são as não implementadas, por não ser o foco do estudo, e as na coloração roxo são as que serão futuramente implementadas.

A Figura 26 apresenta o tratamento da NM para o paciente que pode iniciar pela quimioterapia, passar pela cirurgia e retornar para a quimioterapia. Neste diagrama é considerado que o paciente pode realizar a cirurgia primeiro e ser encaminhado para o tratamento da quimioterapia, posteriormente.

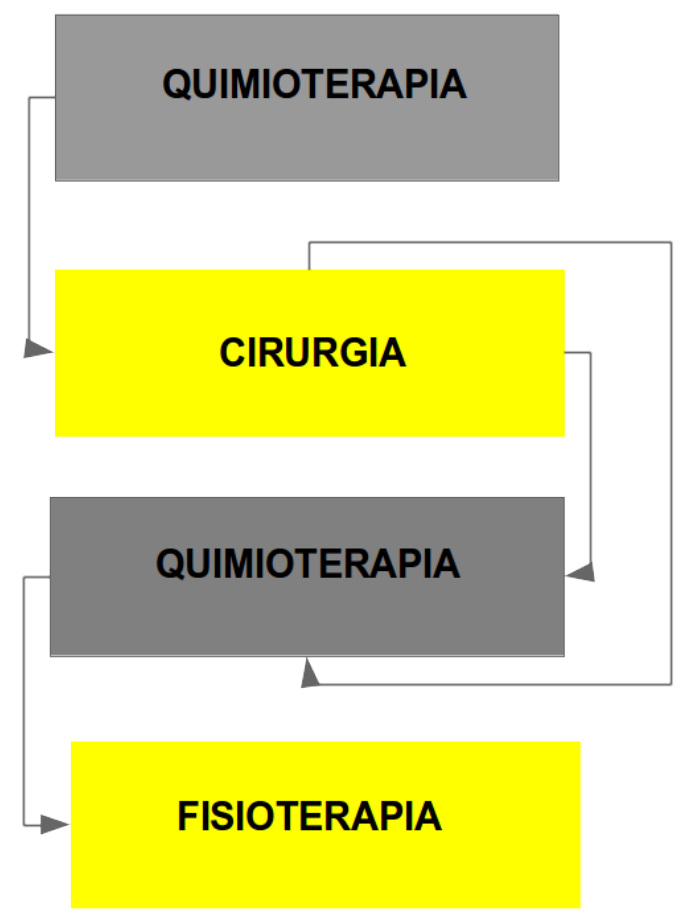

Figura 26: Diagrama de Bloco de Tratamento da Quimioterapia para a Cirurgia.

Na Figura 27 é apresentado o fluxograma do tratamento da quimioterapia, em que o especialista toma a decisão com a escolha de realizar a quimioterapia antes ou após a cirurgia, sendo encaminhado, posteriormente, para a fisioterapia. 


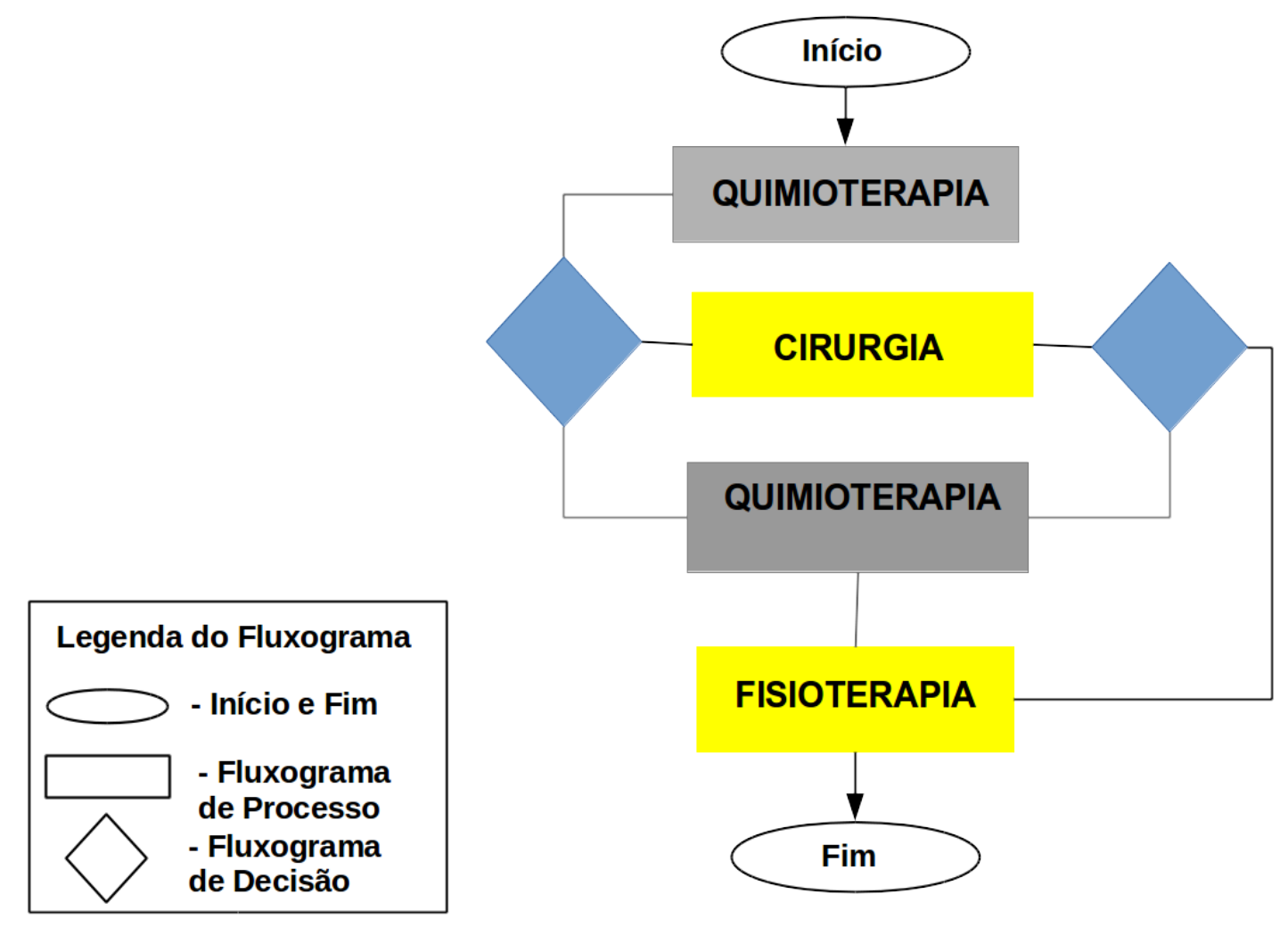

Figura 27: Fluxograma de Tratamento da Quimioterapia da Cirurgia.

Na Figura 28 apresenta-se o diagrama de bloco dos procedimentos para a cirurgia.

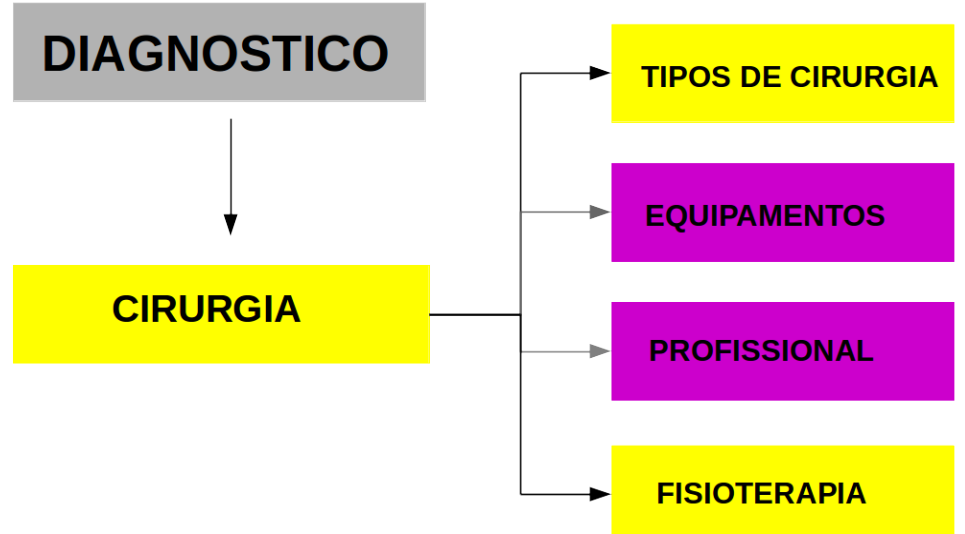

Figura 28: Diagrama de Bloco dos Procedimentos da Cirurgia. 
Na Figura 29 é mostrada a validação do diagnóstico em que as linhas azuis indicam as ligações das classes com suas subclasses, a linha amarela a ligação do paciente para diagnóstico de NM, com a classificação do BI-RADS, e, por último, a linha vermelha o paciente ao tratamento.

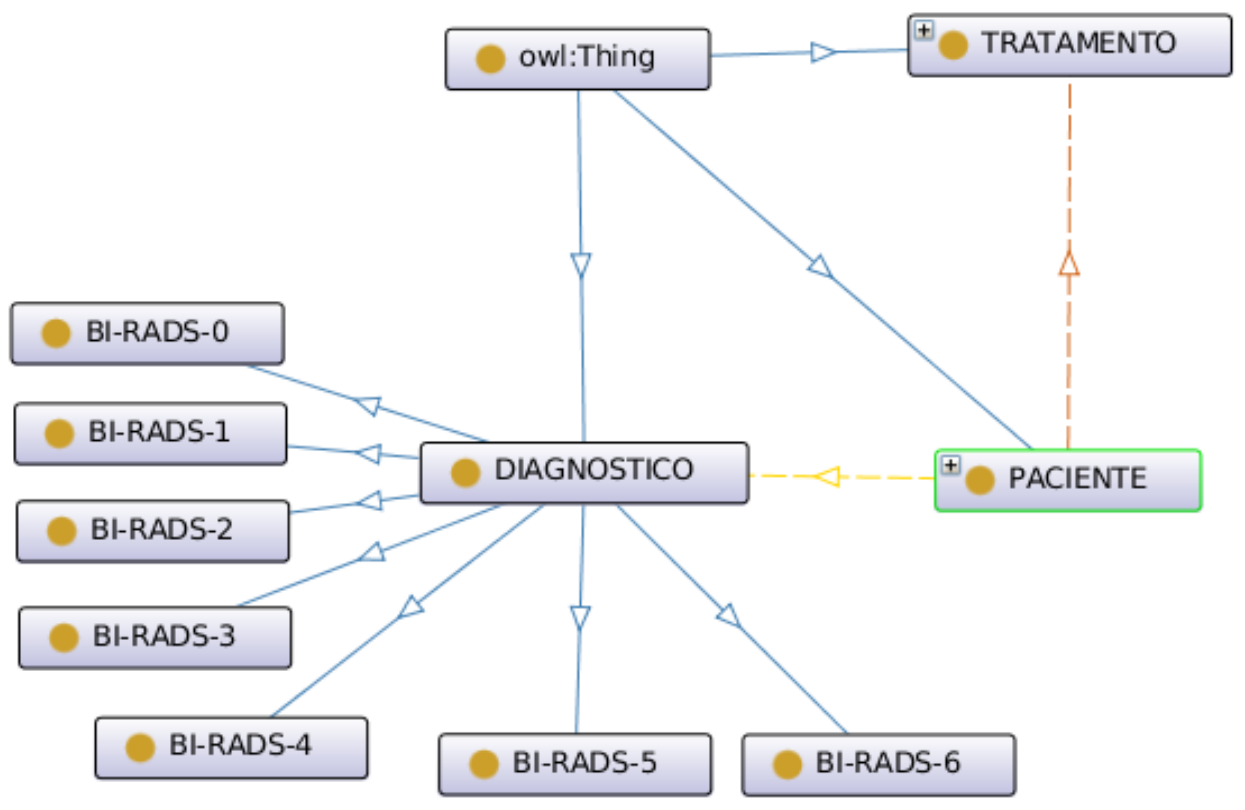

Figura 29: Validação do Diagnostico da NM no Protégé 5.1. 
ANEXOS 


\title{
ANEXO 1: TERMO DO PROJETO
}

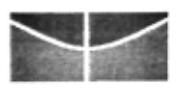 \\ Universidade de Brasília \\ Faculdade de Ciências da Saúde \\ Comitê de Ética em Pesquisa - CEP/FS

\section{PROCESSO DE ANÁLISE DE PROJETO DE PESQUISA} \\ Registro do Projeto no CEP: 031/12 \\ Título do Projeto: "Abordagem fisioterapêutica em mulheres com câncer de mama.". \\ Pesquisadora Responsável: Liana Barbaresco Gomide \\ Data de Entrada: 09/04/12 \\ 6
}

Com base na Resolução 196/96, do CNS/MS, que regulamenta a ética em pesquisa com seres humanos, o Comitê de Ética em Pesquisa com Seres Humanos da Faculdade de Ciências da Saúde da Universidade de Brasília, após análise dos aspectos éticos e do contexto técnico-científico, resolveu APROVAR o projeto 031/12 com o titulo: "Abordagem fisioterapêutica em mulheres com câncer de mama.", analisado na $4^{a}$ Reunião Ordinária, realizada no dia 08 de maio de 2012.

A pesquisadora responsável fica, desde já, notificada da obrigatoriedade da apresentação de um relatório semestral e relatório final sucinto e objetivo sobre o desenvolvimento do Projeto, no prazo de 1 (um) ano a contar da presente data (item VII.13 da Resolução 196/96).

Brasilia, 27 de junho de 2012.

Prof. Nat n Plonsores Coordenador do CEP-FS/UnB

Comite de Ética em Pesquisa com Seres Humanos - Faculdade de Ciências da Saúde Universidade de Brasilia - Campus Universitário Darcy Ribeiro - CEP: 70.910-900 Telefone: (61)-3107-1947 Email: cepfs@unb.br 


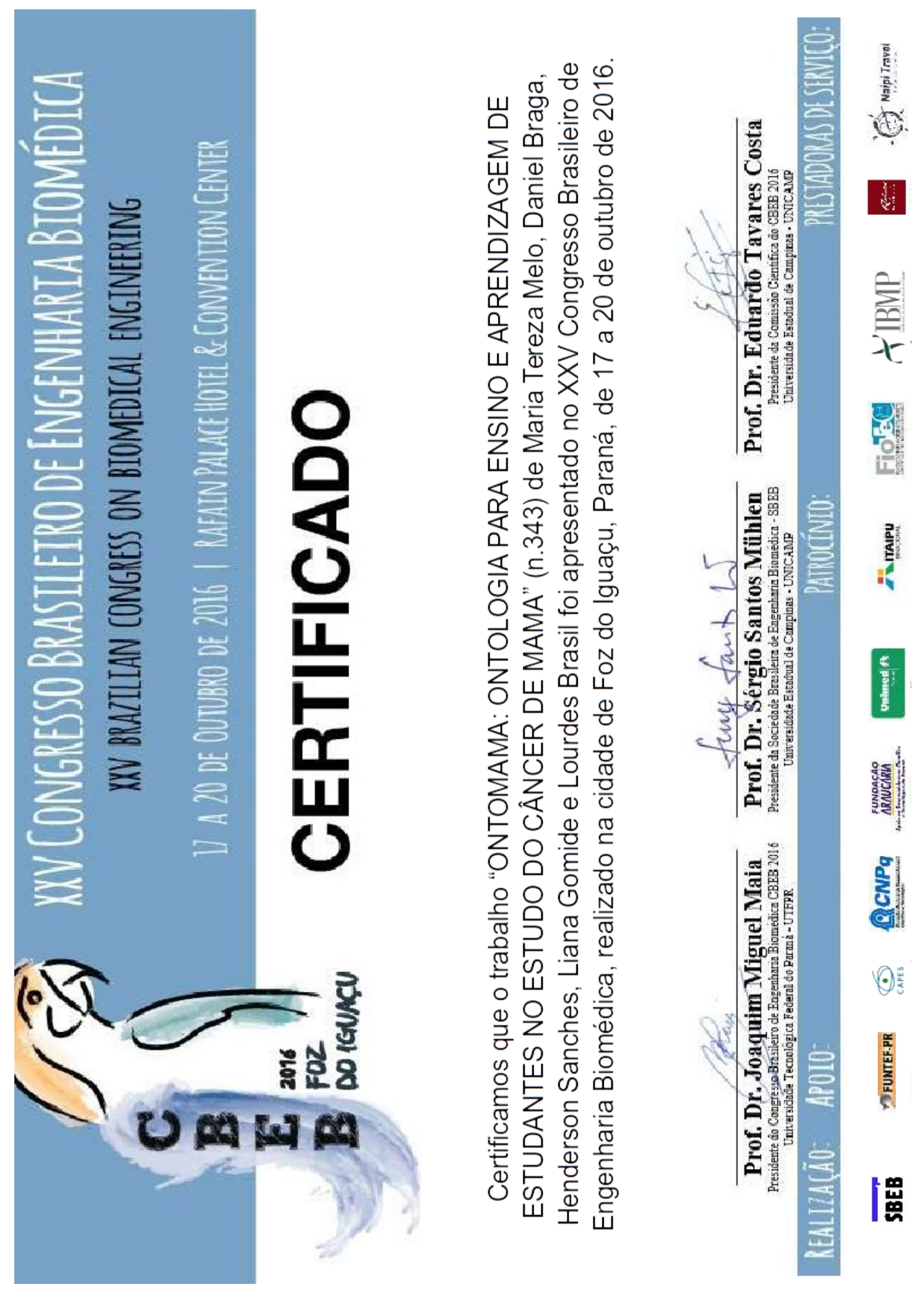




\section{ANEXO 3: FICHA DE AVALIAÇÃO FISIOTERAPÊUTICA - CÂNCER} DE MAMA

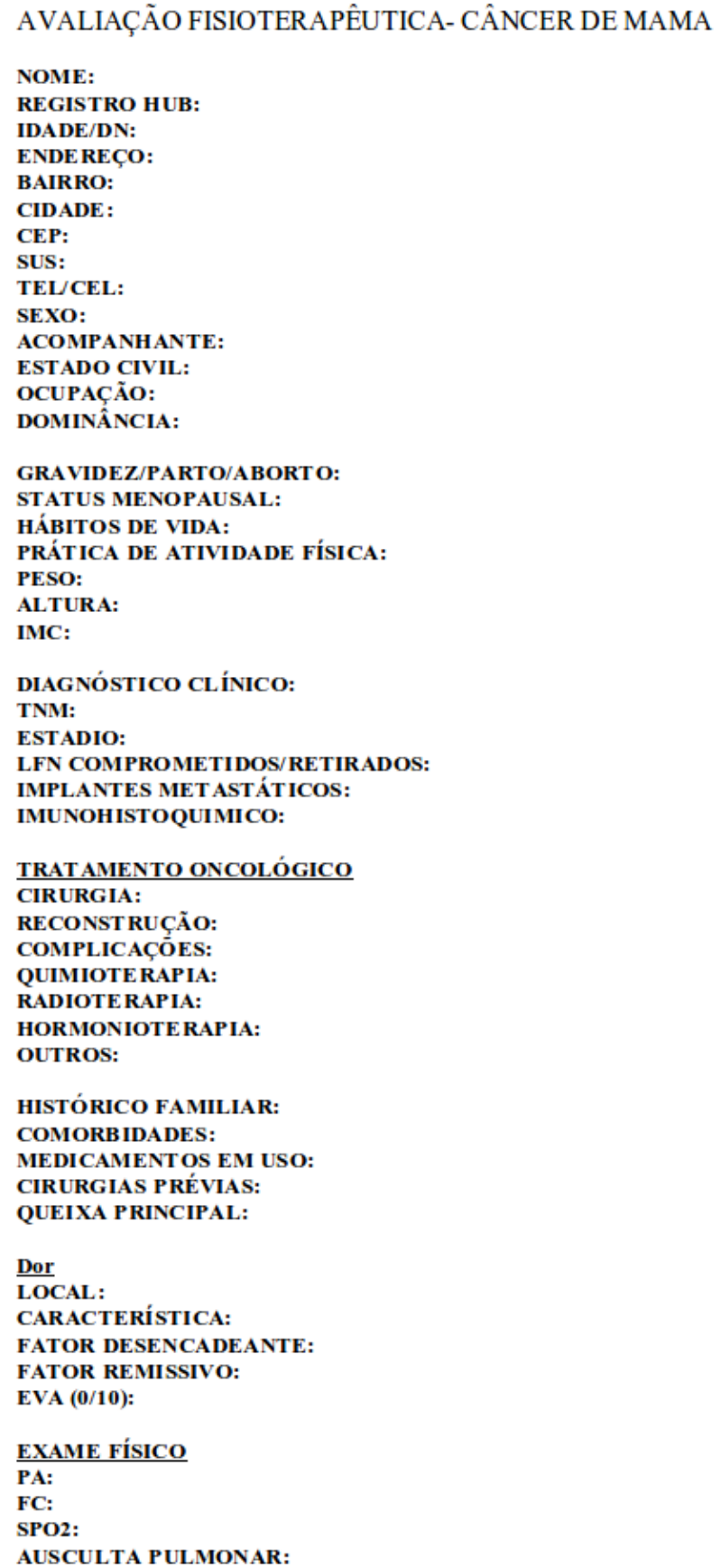


CONDIÇŌES PELE/FERIDA OPERAT ÓRIA:

EDEMA:

CORDÃO FIB ROSO/SÍNDROME DA REDE AXILAR:

CICATRIZ:

LINFONODOME GALIAS:

LESÃO N.INTE RCOSTOBRAQUIAL:

AVALIAÇÃo POSTURAL:

ESCÁPULA

POSTURA ESTÁTICA:

RITMO ESCAPULOUME RAL:

AMPLITUDE DE MOVIMENTO - GONIOMETRIA

FLEX̃̃o

MSD MSE

ABDUÇÃo

EXTENSÃO

ROT. INTERNA

ROT. EXTE RNA

FUNÇÃO MUSCULAR:

LINFEDEMA

CARACTERISTICAS/CONSISTENNCIA PELE:

HIDRAT AÇÃO:

TEMPERATURA:

COLORAÇÃO:

ERISIPELA:

QUEIXAS ASSOCIADAS:

TRAT AMENTOS PRÉVIOS:

FATOR DESENCADEANTE:

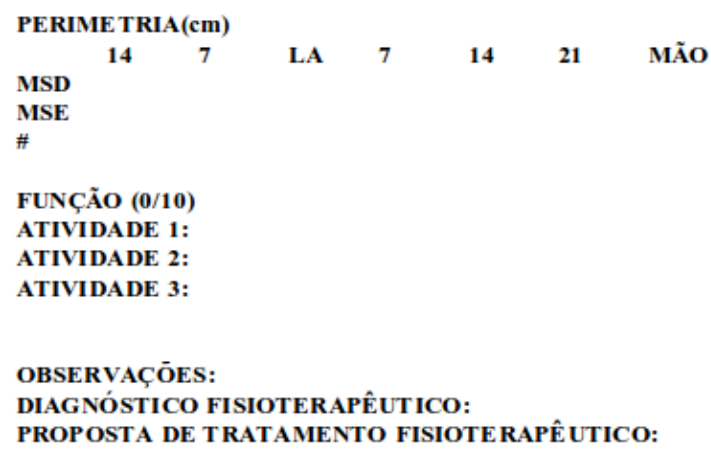

Orientaçōes: 